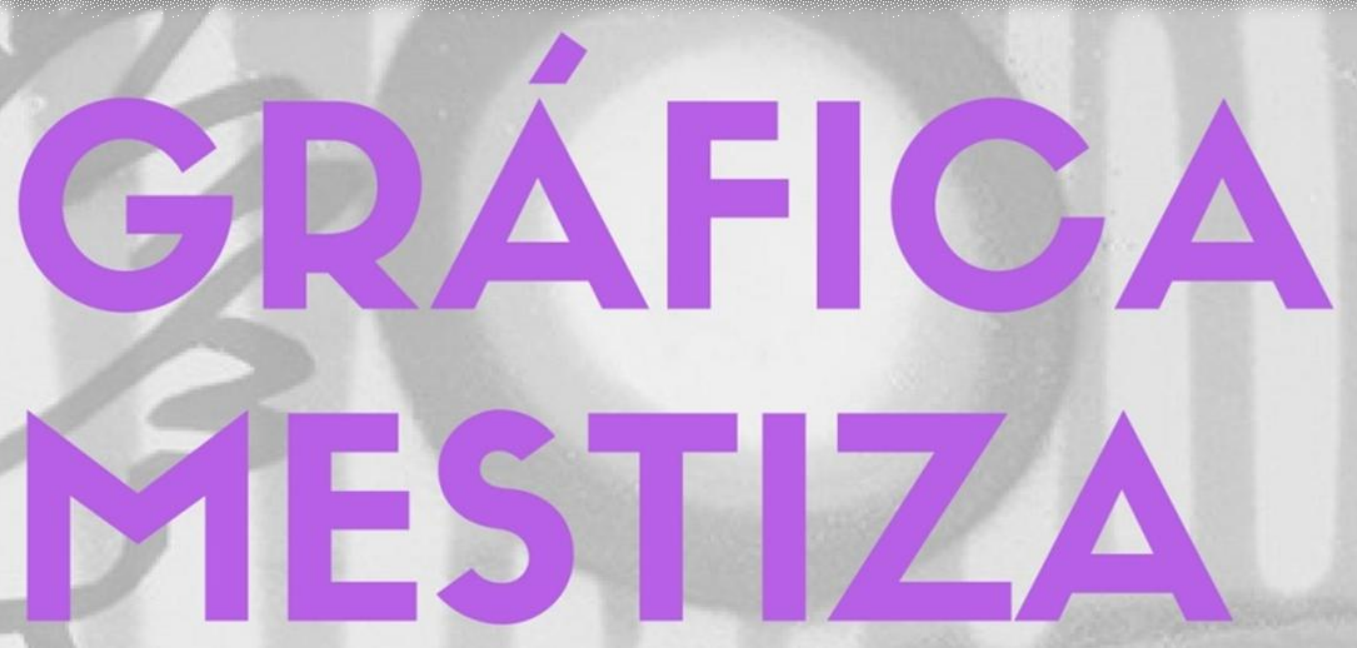

Experiencias y herramientas de gestión y comunicación a través de la gráfica urbana sudamericana.

Casos: Colombia y Argentina

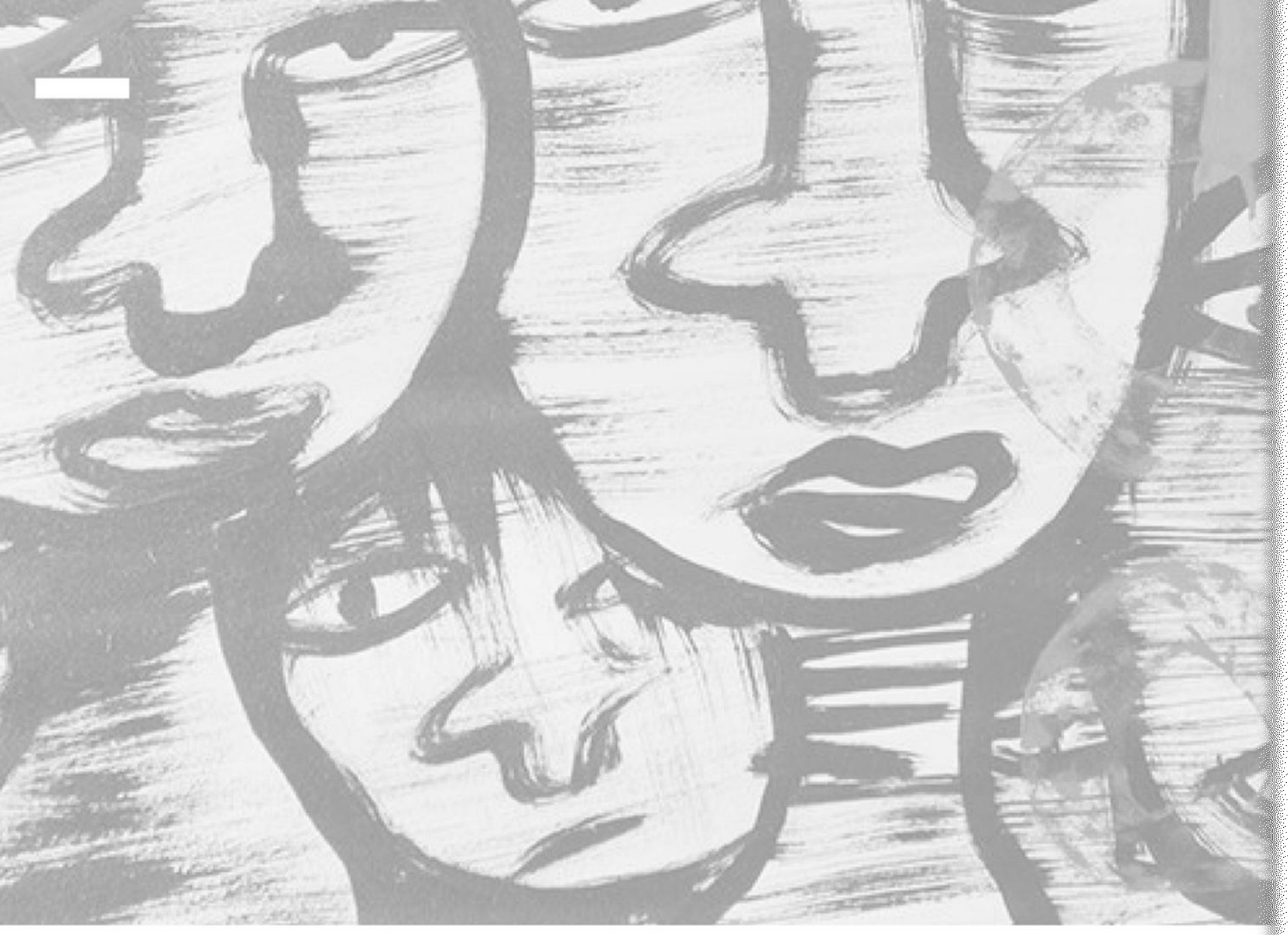




\title{
GRÁFICA MES'TIZA:
}

\author{
Experiencias y herramientas de gestión y \\ comunicación a través de la gráfica urbana \\ sudamericana. Casos: Colombia y Argentina
}

Tesista

Katherine Muñoz Osorio

Directora

Vanesa Arrúa

Maestría en Planificación y Gestión de Procesos Comunicacionales PLANGESCO

Facultad de Periodismo y Comunicación Social

Universidad Nacional de La Plata

La Plata, Bs.As. - Argentina - 2017

llustración de portada

Luxor

https://www.facebook.com/soyluxor/ 


\section{Agradecimientos}

A mi familia que sigue creyendo en mí, a mi compañero de ruta que me alienta a ser cada día mejor y a los amigos que me hicieron partícipe de sus experiencias y aprendizajes. 
INDICE

1. Presentación .................................................. 9

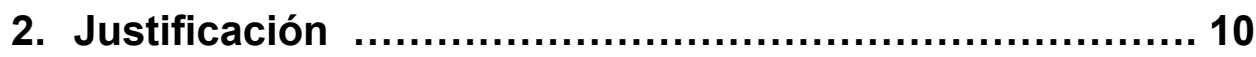

3. Marco teórico ................................................... 19

3.1. Cultura .................................................. 20

3.2. Desarrollo .................................................. 24

3.3. Comunicación transformadora ........................... 30

3.4. Rol del comunicador .......................................... 34

3.5. Gráfica urbana ............................................... 35

3.6. La ciudad .................................................... 37

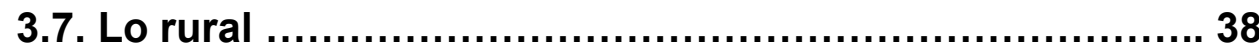

4. Políticas culturales ............................................ 39

4.1. Colombia .................................................. 39

4.2. Argentina ...................................................... 46

5. Presentación de experiencias .............................. 48

5.1. Sistematización ............................................. 49

5.2. Metodología ............................................ 51

5.3. Gráfica Mestiza ............................................... 51

5.4. Minga artística de Muralistas de los Pueblos ............. 53

5.5. Volver a Habitar ................................................ 54

6. Estrategias y aprendizajes .................................... 56

6.1. Estrategias ............................................... 57

6.2. ¿Qué se puede replicar? .................................... 61

6.3. Amigarse con la tecnología .................................66 66

6.3.1. Herramientas digitales .................................. 75

6.3.2. Plataformas ................................................ 76

6.3.3. Estrategias de comunicación ........................ 77

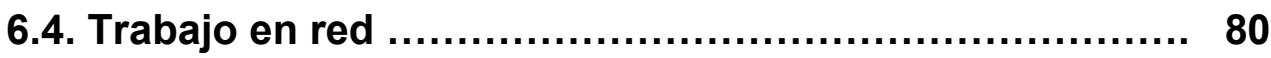

6.5. Convocatorias ................................................ 80

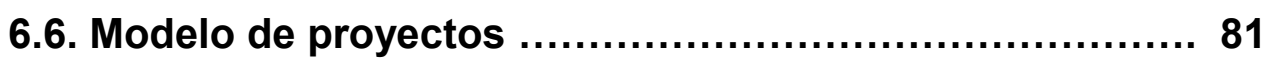

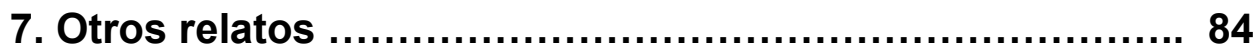

8. Conclusiones ............................................... 86

9. Bibliografía .................................................. 89

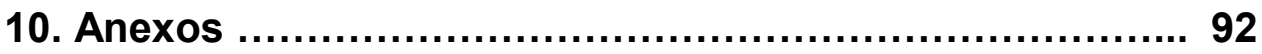




\section{PRESENTACIÓN}

En esta tesis de posgrado PLANGESCO presento la sistematización de algunas experiencias, que considero significativas, de gestión de la gráfica urbana, a través del trabajo realizado por el colectivo Gráfica Mestiza ${ }^{1}$, del que hago parte desde el 2009 , dedicado a la difusión y articulación de propuestas artísticas latinoamericanas, específicamente, las que tienen que ver con el graffiti, el street art y la cultura que se genera en torno a éstas expresiones.

En este trabajo en particular, mi interés se centra en cómo estas expresiones artísticas y culturales logran comunicarse con la comunidad y vincularla a un proceso de transformación social de su propio entorno, más allá de lo estético y del interés particular de cada artista, destacando el valor performativo y movilizador que puede llegar a tener el arte urbano. Por esto, las experiencias seleccionadas para esta tesis provienen de los dos extremos del continente, con el fin de mostrar un panorama y destacar el trabajo realizado en función del desarrollo social. Éstas son: la Minga de Muralistas de los Pueblos ${ }^{2}$, de Colombia, que trabaja en una población rural afectada por la guerrilla; y el proyecto Volver a Habitar ${ }^{3}$, del artista Luxor de La Plata, que movilizó a los vecinos de distintos barrios con motivo de la inundación de la ciudad, sufrida en abril del 2013. Éstas fueron desarrollándose de forma paralela con el trabajo de Gráfica Mestiza, que sirvió de comunicador, facilitador y gestor, pero que también aprendió mucho de los procesos llevados a cabo por éstas dos experiencias.

Este recorrido se dará a través de diversos capítulos, en los que se contextualiza histórica y teóricamente, para finalizar con la presentación de una guía de procesos y herramientas digitales, producto de la sistematización de experiencias, que pueden ser útiles para el desarrollo de nuevos proyectos.

\footnotetext{
${ }^{1}$ Página web: http://www.graficamestiza.com/

${ }^{2}$ https://www.facebook.com/MingaMuralistas? ref=ts\&fref=ts

Evento: http://www.colombia.co/cultura/arte/primera-minga-de-muralistas-en-toribio-cauca.html

${ }^{3}$ https://www.facebook.com/volverahabitar

Trailer: https://www.youtube.com/watch?v=R2f2rMFywsw
} 


\section{JUSTIFICACIÓN (De dónde surge esta tesis y qué objetivos tiene)}

Gráfica Mestiza surgió en Cali, Colombia, luego de varias asesorías del Programa de Emprendimiento de la Universidad del Valle y gracias al apoyo de Industrias Culturales de Cali ${ }^{4}$, encargada de la implementación de las políticas culturales de la ciudad. Hasta la fecha contamos con una página web y varios canales de redes sociales, además de cuatro ediciones de nuestra revista digital (e impresa) y un libro titulado Mala Fama ${ }^{5}$, productos con los cuales hemos logrado fortalecer nuestros propósitos de gestión y formación de públicos en torno al tema de la gráfica urbana.

La Minga fue una iniciativa presentada al gobierno local, por parte de un gestor (Alberto Velasco) muy interesado en el trabajo con comunidades indígenas y con alguna trayectoria en la gestión del arte urbano. Éste vive desde hace algún tiempo en la zona de Toribío, Cauca y conoce de cerca el flagelo que vive ese territorio a manos de la violencia de los distintos grupos armados (incluido el ejército) $^{6}$. En Toribío ha habido muchos ataques de la guerrilla en contra del puesto de mando militar que vigila la zona, viéndose afectadas directamente las familias de campesinos e indígenas que allí habitan ${ }^{7}$. Por tal motivo, fue necesario unir esfuerzos y gestionar la realización de La Minga, convocando artistas externos, actores sociales, entidades gubernamentales, guardia indígena y a los mismos habitantes para hacer una creativa denuncia pública, porque como lo expresa el mismo Alberto: "pintar es un acto político que significa apropiarse". Con esta movida se logró hacer un llamado al cese al fuego que trascendió las fronteras del territorio para tener visibilidad en los medios nacionales e internacionales ${ }^{8}$.

\footnotetext{
${ }^{4} \mathrm{http}: / /$ industriasculturalescali.com/

${ }^{5}$ http://www.graficamestiza.com/index.php/actualidad/noticias/364-lanzamiento-del-libromalafama

${ }^{6}$ http://www.soho.com.co/zona-cronica/articulo/el-pueblo-mas-atacado-por-la-guerrilla-por-jose$\underline{\text { navia/27724 }}$

${ }^{7}$ http://www.semana.com/especiales/proyectovictimas/crimenes-de-la-guerra/destruccion-depueblos/index.html

${ }^{8}$ http://es.globalvoicesonline.org/2013/10/27/minga-de-muralistas-de-los-pueblos-pintando-resistenciaen-colombia/
} 
En el caso de Volver a Habitar, surgió por la iniciativa del artista Luxor (Lucas), quien junto con un grupo de amigos (periodistas, músico, fotógrafa, entre otros) se propuso hacer ocho murales en ocho barrios de La Plata, afectados por la inundación del 2 de abril del 2013 y contar las historias de vida de sus habitantes. "Usamos el mural como una herramienta para que la gente se junte. (...) no estamos haciendo sólo los murales, se está haciendo una página web donde se van a subir las historias por cada barrio, y la idea es que eso pueda funcionar como un archivo histórico de lo que pasó, pero contado por los que lo vivieron." " Este proyecto se autofinancia gracias a la ayuda colectiva recaudada a través de una plataforma web (Ideame ${ }^{10}$ ), que logró juntar nueve mil pesos (900 USD aprox.) para costear los insumos de los murales y las filmaciones de micro relatos que luego fueron subidos a la página web de Volver a Habitar. Más allá del aspecto artístico que esta acción generó, este proyecto motivó la acción colectiva de los afectados y demás vecinos, visibilizó la magnitud de la tragedia (89 muertos y más de 300 mil afectados) ${ }^{11}$ y dio una nueva cara y esperanza a la ciudad con los ocho grandes "protectores" pintados por Luxor, para que la gente pudiera "volver a habitar" sus hogares.

Cada uno de éstos proyectos recorrió caminos, vivencias y estrategias distintas para llevar a cabo sus metas, en un intercambio de recursos simbólicos y materiales a través de sus propuestas artísticas (murales) y los soportes o herramientas ideadas (murales, web, etc.), aportando y resaltando el capital cultural (Bourdieu, 1997) de cada comunidad en la que trabajaron, su historia, sus vivencias y sus necesidades, para la construcción colectiva, la expresión artística, la comunicación y la transformación social, que son el tema central del presente trabajo.

\footnotetext{
${ }^{9}$ http://www.anred.org/spip.php?article6314

${ }^{10}$ http://idea.me/projetos/5523/volver-a-habitar

${ }^{11}$ http://www.anred.org/spip.php?article6314 y http://www.lanacion.com.ar/tragica-inundacion-en-laplata-t49190
} 
Contexto:

Cali, Colombia es una ciudad de casi 2 millones y medio de habitantes donde convergen personas migrantes de diferentes regiones y que por su geografía de valle, montaña y mar, alberga distintas razas, en su mayoría la negra. Históricamente ha sido una ciudad multicultural y hoy en día esto se hace evidente a través de las distintas expresiones que emergen de lugares como el teatro, la biblioteca, el centro cultural, la escuela y el barrio. Es por esto que surge la necesidad de crear espacios para la divulgación y el intercambio de la cultura, entendida como el conjunto de manifestaciones "el modo de vida" y relaciones que se ponen en juego dentro de una comunidad y no sólo como simples productos de museo (Williams, 1981).

En este caso, son el street art y el graffiti los protagonistas artísticos de ciudades como Cali, de la que provengo, y que ahora, gracias a distintos actores sociales e instituciones, ha dejado de ser una expresión marginal para ser tenida en cuenta como parte de la cultura. Tal es el caso de la apertura del portafolio de Industrias Culturales ${ }^{12}$ de la ciudad, que agrupa más de 70 proyectos artísticos de todo tipo como: festivales, medios alternativos, diseño, artesanos, bailarines, compañías de teatro, músicos, gastronomía, entre otros, como garante de la implementación de las políticas de cultura nacionales ${ }^{13}$.

Desde mi experiencia personal, los inicios más significativos de esta expresión surgen en la Universidad del Valle, universidad pública que suple la demanda educativa de las ciudades y el conurbano del suroccidente del país (cuatro provincias). En ésta, desde hace varias décadas se viven las movilizaciones estudiantiles, sociales y políticas a través de la protesta y el graffiti, por lo que los muros del campus en sus distintas facultades narra la historia de todas las luchas.

\footnotetext{
${ }^{12}$ http://industriasculturalescali.com/

${ }^{13}$ Compendio de Políticas Culturales, Política para el emprendimiento y las industrias culturales: http://culturaparaeldesarrollo.files.wordpress.com/2011/06/mincultura-colombiacompendio-polc3adticas-culturales.pdf
} 
Luego se fue haciendo evidente una creciente aparición de manifestaciones en las calles, provenientes de los barrios y de colectivos artísticos de estudiantes de diseño y artes plásticas, que llenaron los muros y los puentes de grandes paisajes, personajes fantásticos, parodias políticas, firmas y afiches.

En ese contexto nace Gráfica Mestiza como un espacio de comunicación para difundir las nuevas propuestas artísticas urbanas que se están gestando en la ciudad y en Latinoamérica. Es también un medio de socialización, discusión e intercambio de conocimientos técnicos, artísticos, sociales y culturales, donde tienen cabida los expertos, nuevos artistas y todos aquellos interesados en conocer las manifestaciones culturales que se están produciendo a su alrededor. Todo esto a través de un espacio virtual en el que se puede dar a conocer el trabajo de todos, con productos como una página web, una revista digital, participación en eventos, conferencias, distintos boletines y diversos productos gráficos y multimediales.

Gracias al trabajo de gestión y conformación de redes de Gráfica Mestiza he podido conocer experiencias dedicadas a la gestión y difusión como: Cartel Urbano $^{14}$, Centro Cultural Gaffito ${ }^{15}$; colectivos artísticos como: Guácala ${ }^{16}$, en Colombia. En Argentina conocí el trabajo del Proyecto Fauna ${ }^{17}$ (Mar del Plata); Buenos Aires Street $\mathrm{Art}^{18}$, Graffitimundo ${ }^{19}$, Alfredo Segatori "Pelado"20 (Un Cacho de Harte), Georgina Ciotti ${ }^{21}$, Muchachos Pintores de Coglhan $\left(\mathrm{eMePeCe}{ }^{22}\right.$ ) y Luxor (La Plata). En Brasil, tengo contacto con Os Gemeos ${ }^{23}$, Bruno Smoky ${ }^{24}$; en Venezuela con Flix ${ }^{25}$; y en Perú con Mónica Mirós ${ }^{26}$ y el

\footnotetext{
${ }^{14} \mathrm{http}: / /$ cartelurbano.com/

${ }^{15}$ https://www.facebook.com/provectograffito/

16 https://www.facebook.com/guacala

17 https://www.facebook.com/Proyecto-Fauna-281897358584/

18 http://buenosairesstreetart.com/

19 https://graffitimundo.com/es/

${ }^{20}$ https://www.facebook.com/alfredo.segatori/

${ }^{21}$ https://www.georginaciotti.com/

${ }^{22}$ https://www.facebook.com/permalink.php?story fbid=294434638960\&id=269889480754

${ }^{23} \mathrm{http}: / /$ www.osgemeos.com.br/pt

${ }^{24}$ http://www.brunosmoky.com/

${ }^{25}$ http://globalstreetart.com/flix

${ }^{26}$ https://www.facebook.com/monicamiros
} 
proyecto Afuera ${ }^{27}$, entre muchos otros, todos proyectos interesados en aportar su arte al trabajo de transformación de la comunidad.

Actualmente, y hablando de las experiencias que he seleccionado como objeto de estudio, La Minga de Muralistas de los Pueblos, planea expandir sus fronteras a otras poblaciones del Putumayo, que también sufren el flagelo de la violencia en Colombia; por su parte, Luxor ${ }^{28}$ junto con otros artistas nacionales e internacionales, intervendrá 3 escuelas, en un proyecto comunitario del que participarán los vecinos y pequeños emprendimientos. Todas estas actividades han sido apoyadas por la gestión y difusión de Gráfica Mestiza y por esta tesis PLANGESCO, con el objetivo principal de sistematizar y relatar experiencias de significativas en lo que se refiere a la comunicación y transformación social a través de la gráfica urbana, para divulgarlas y multiplicarlas, recopilando procesos, experiencias y vivencias, identificando transformaciones y aprendizajes, y replicando logros y saberes colectivos.

Además de lo anterior, fue importante para mi plantear esta tesis para dar cuenta del potencial educativo, cultural, comunicacional y movilizador que tiene el arte urbano, que en adelante nombraré como: gráfica urbana ${ }^{29}$, y cómo ésta se ha inmiscuido en distintos ámbitos de la sociedad para hacer su aporte. Al final espero poder recopilar todas las herramientas y aprendizajes en una guía que resulte útil a gestores culturales y comunitarios de distintos proyectos, que pueda ser compartida libremente y en distintos formatos, que en principio podrán ser publicados en la página web y revista de Gráfica Mestiza, como una plataforma de divulgación.

Para empezar es importante identificar el problema que dio pie a la formulación de esta tesis de posgrado y es que cada día es más creciente la

\footnotetext{
27 https://www.facebook.com/proyectoafuera/

28 https://www.facebook.com/soyluxor?fref=ts

${ }^{29}$ Según el sentido con el que hemos venido trabajando en Gráfica Mestiza, para darle cabida a todas las técnicas y manifestaciones que van surgiendo. Calle Libre - Graffiti + Street Art en Latinoamérica: http://www.youtube.com/watch?v=8NaHKw8bcrc\&fb source=message
} 
necesidad de las personas y sociedades por comunicarse, y han ido emergiendo distintas expresiones que son evidentes en las calles, motivadas por la urgencia de denuncia en algunos casos y posibilitadas por el triunfo de nuevas libertades (como la libertad de expresión) y la apelación a derechos civiles (como la protesta a la que ha estado asociada el graffiti). Además, posibles por el acceso a las nuevas tecnologías y a la información y en particular de la redes sociales, no sólo desde la posición de espectadores, sino también de productores de discursos.

En el capítulo: De las cavernas a las calles ${ }^{30}$, de la tesis de grado de diseñador gráfico de Jesús David Rodríguez (compañero de universidad y del proyecto Gráfica Mestiza), hace un recorrido histórico sobre la presencia del graffiti en distintos espacios sociales.

Siendo rigurosos, las primeras expresiones provienen del arte rupestre encontrado en las cavernas, que dan cuenta de las actividades y organización social de las comunidades de la época. De ahí en adelante siguen apareciendo intentos de llevar el lenguaje popular a los muros (MÉNDEZ y GARRIDO, 2002). En la cultura romana se destacan escrituras ocasionales en columnas, inscripciones en latín que expresan ideas políticas, insultos, mensajes de amor, entre otros, acompañados en muchos casos por dibujos.

El término graffiti fue divulgado por el arqueólogo Raffaele Garrucci a mediados del siglo XIX (GIMENO y MANDINGORRA, 1997) y hoy se habla más de arte urbano (street art) para incluir distintas técnicas y formatos que están visibles no solamente en los muros abandonados de las calles, sino también en la ropa, en locales comerciales, en libros, entre otros.

Vieja expresión, arte nuevo:

El graffiti y el street art han transitado un largo camino antes de ser tenidos en cuenta como "arte", entendiendo éste como las producciones creativas que se

\footnotetext{
${ }^{30}$ RODRIGUEZ, J. Análisis Gráfico del Post-graffiti en Cali. Tesis de Grado. Diseño Gráfico. Universidad del Valle.
} 
exhiben en los museos y que son avaladas por la mirada de expertos de élite (uso popularizado del concepto, que afortunadamente está siendo revaluado). Esta situación, a simple vista, puede explicarse, porque era poco común que una pieza de este tipo fuera creada por un artista de academia, y porque por lo general el espacio de creación es la calle y no el estudio o la galería.

Si nos remontamos a los inicios del graffiti encontramos que éste surge en las calles de Nueva York a finales de los años sesenta como una expresión de rebeldía de las clases bajas, que luego fue tomando matices entre las distintas comunidades que adoptaron su uso. Con el paso del tiempo el graffiti se fue expandiendo por los barrios y las calles como una forma de comunicación entre pandillas, que ya no sólo se batían cuerpo a cuerpo sino también demostrando su destreza en los muros. Empezó a ser también objeto de atención para las autoridades policiales, quienes además, lo rechazaron y estigmatizaron rotundamente. Es así como el graffiti sigue siendo rechazado por la gran mayoría como expresión artística.

Ya entrados los ochentas, los artistas reconocidos del momento se han vuelto más urbanos y la explosión de colores se hace evidente en las galerías (caso Andy Warhol). Además muchas expresiones giran en torno a las causas sociales, como el rechazo a la guerra o el antisemitismo, y el graffiti se convierte en una herramienta que sirve a cualquier ciudadano para expresar sus opiniones. Ya con el respaldo de los artistas de la época, el graffiti tiene un campo ganado.

Hoy en día se comprueba que el graffiti sí puede ser tenido en cuenta como arte, ya que a lo largo del tiempo ha ido evolucionado en sus técnicas, han aparecido nuevos estilos, aparece también el street art (ilustraciones de grandes formatos) y se ha convertido en una expresión que surge también desde la academia, con artistas estudiantes de diseño gráfico y artes visuales de las universidades, y es cada día más apoyado por las instituciones gubernamentales y artísticas.

Un gran exponente a nivel mundial que logra encarnar la esencia y la 
transformación del graffiti es Bansky, cuya identidad es secreta para muchos y por tanto su biografía es imprecisa. Este artista ha probado distintas técnicas y sus obras han tenido repercusión internacional por su fuerte contenido crítico. Dos ejemplos de esto son: "Sirenas de los inocentes" ${ }^{31}$ un camión lleno de animales de peluche que recorre las calles, haciendo alusión a la obra literaria El Silencio de los Inocentes y denunciando el consumo desenfrenado de carne. Otro, y más reciente, es el Hotel con la peor vista del mundo (The Walled of Hotel $)^{32}$, un particular hospedaje con vista al muro instalado por Israel en la ocupación a Cisjordania (Guerra del Medio Oriente de 1967).

Bansky es uno de los casos más paradigmáticos de la actualidad y al igual que sus obras, las de otros artistas no sólo aparecen en los muros de la calle, pues ahora los graffitis son usados para decorar habitaciones, locales comerciales, tablas de skate y surf, y aparecen expuestos en galerías de arte o museos ${ }^{33}$. El arte urbano se ha representado tanto en el graffiti como en la ilustración, con la aparición de personajes de gran formato que decoran muros de estacionamientos, edificios y puentes.

Claramente el graffiti ya es un fenómeno mundial, masificado; pero no en todos los lugares tiene el mismo impacto, ni el mismo contexto, ni las mismas percepciones por parte de la gente. Así como el arte tradicional a lo largo de la historia fue evolucionando en la práctica, y permitió establecer teorías para su estudio, hoy en día con el arte contemporáneo se logra observar no sólo la pieza sino su contexto. $Y$ en el caso del graffiti, todas las implicaciones sociales y culturales que ha tenido al integrarse a áreas transversales de las políticas públicas (como son la educación sexual, resolución de conflictos, uso del tiempo libre, el emprendimiento), o sin ir tan lejos, al hacer parte de las tribus urbanas como expresión, que busca contar una historia, hacer una crítica, rescatar un espacio y enseñar algo a través de los colores y la creatividad.

\footnotetext{
${ }^{31}$ Sirens of lambs. https://www.youtube.com/watch?v=txpzMQBfvEA

32 http://www.banksy.co.uk/index.html

33 Street art, de la calle a la galería: https://www.clarin.com/revista-n/arte/street-art-callegaleria 0 HJ1UsQs9e.html
} 
A pesar de su masividad, muchas experiencias aún son desconocidas por otros. Por un lado, existe una explosión de información y expresiones en internet y en los muros de las calles, pero a la vez, en esta marea de discursos muchas iniciativas valiosas quedan ocultas. Por esto, es importante hacer un recorrido por diferentes proyectos (no sólo La Minga y Volver a Habitar que serán expuestos en esta tesis) para exaltar sus logros e identificar estrategias útiles que pueden ser replicadas por otros grupos para el trabajo comunitario y cultural, puesto que las expresiones gráficas urbanas pueden ser consideradas como mecanismos de comunicación (presentes en ámbitos sociales, en su mayoría de reclamo o protesta) capaces de aportar a la transformación del entorno en su aspecto estético, cultural y político.

Las técnicas de interpretación ${ }^{34}$ de Marx, Nietzsche y Freud plantean que "el lenguaje rebasa la forma propiamente verbal, y que hay muchas otras cosas que hablan y que no son lenguaje", en este caso, el arte urbano tiene un gran potencial y a diferencia del arte tradicional (en su equivalente con el lenguaje "fue inventado por las clases superiores, no indica un significado, impone una interpretación"), "no dice exactamente lo que dice" y su sentido más importante está por debajo, es decir, leemos las expresiones urbanas no por lo que representan, sino que tenemos en cuenta quién las interpreta (nuestra propia realidad) y quién propone la interpretación (el artista).

Todo el material recolectado en este trabajo, será sistematizado y compilado en una especie de manual de planificación y gestión disponible en distintas plataformas de carácter gratuito, para que sirva de insumo en el desarrollo de otros proyectos, ya que en lo que se refiere al arte o gráfica urbana, es mucho lo que se publica hablando del arte, el estilo, el artista, los eventos, pero muy poco lo que se conceptualiza sobre los procesos, las técnicas desarrolladas, la comunicación, las comunidades y los proyectos colectivos, que sirven de ejemplo para otros y que marcan un gran paso por el lugar que están ocupando en la historia de las políticas públicas, los fondos de fomento, los canales de participación ciudadana, las movilizaciones, la cultura y la gente, y las formas

\footnotetext{
${ }^{34}$ Trías, Eugenio. Michel Foucault, Nietzsche, Freud, Marx. Estudio preliminar de Eugenio Trías. Ed. Anagrama, Buenos Aires, 2010.
} 
de comunicación y expresión en sí mismas.

Los manuales y la formulación de proyectos culturales como tal, son una buena excusa que ha demostrado ser muy útil para abordar diversas situaciones en la comunidad. A través de la gestión cultural en distintos momentos, se han potenciado espacios de participación y encuentro, específicamente cuando se trata de trabajar con jóvenes de sectores vulnerables, porque permite un acercamiento de mayor confianza y les brinda herramientas de expresión y desarrollo de habilidades artísticas. También ha sido una herramienta de comunicación y movilización sobre temáticas más globales, haciendo de los procesos sociales acciones más coherentes y armónicas con el desarrollo del lugar que habitamos (Morín, 2006).

\section{MARCO TEÓRICO}

El recorrido de las tres experiencias de gestión de la gráfica urbana -Gráfica Mestiza, Minga de los Muralistas de los Pueblos y Volver a Habitar- será sistematizado, analizado y narrado a la luz de distintos conceptos básicos que ayuden a dilucidar las estrategias utilizadas y el sentido del trabajo realizado por cada grupo según el contexto en el que se encuentra inserto.

Para tal fin es necesario definir qué se entiende por cultura, desarrollo y comunicación como conceptos básicos para el análisis (en el caso particular, pensando también lo gráfico y lo artístico como una pieza comunicativa), en el marco del trabajo para la transformación social, que es uno de los pilares, sino el más importante de la formación de la maestría PLANGESCO.

Además, de manera transversal, es necesario definir qué se entiende por gráfica urbana, ya que durante mucho tiempo se ha debatido sobre ésta temática, intentando hallar una definición única, pero que se hace casi imposible dadas las características del graffiti y la cantidad de expresiones emergentes que cada día van evolucionando, pasando por la discusión del 
arte, por las distintas técnicas, su origen y su vinculación con el entorno (piezas callejeras vs. piezas de exposición).

A su vez, la gráfica urbana, lleva anclada consigo el término: ciudad, que es importante para delimitar las condiciones en las que se produce una pieza artística y comunicativa de éste tipo, las sensaciones que la motivan, las estrategias y técnicas que utiliza y los objetivos que busca.

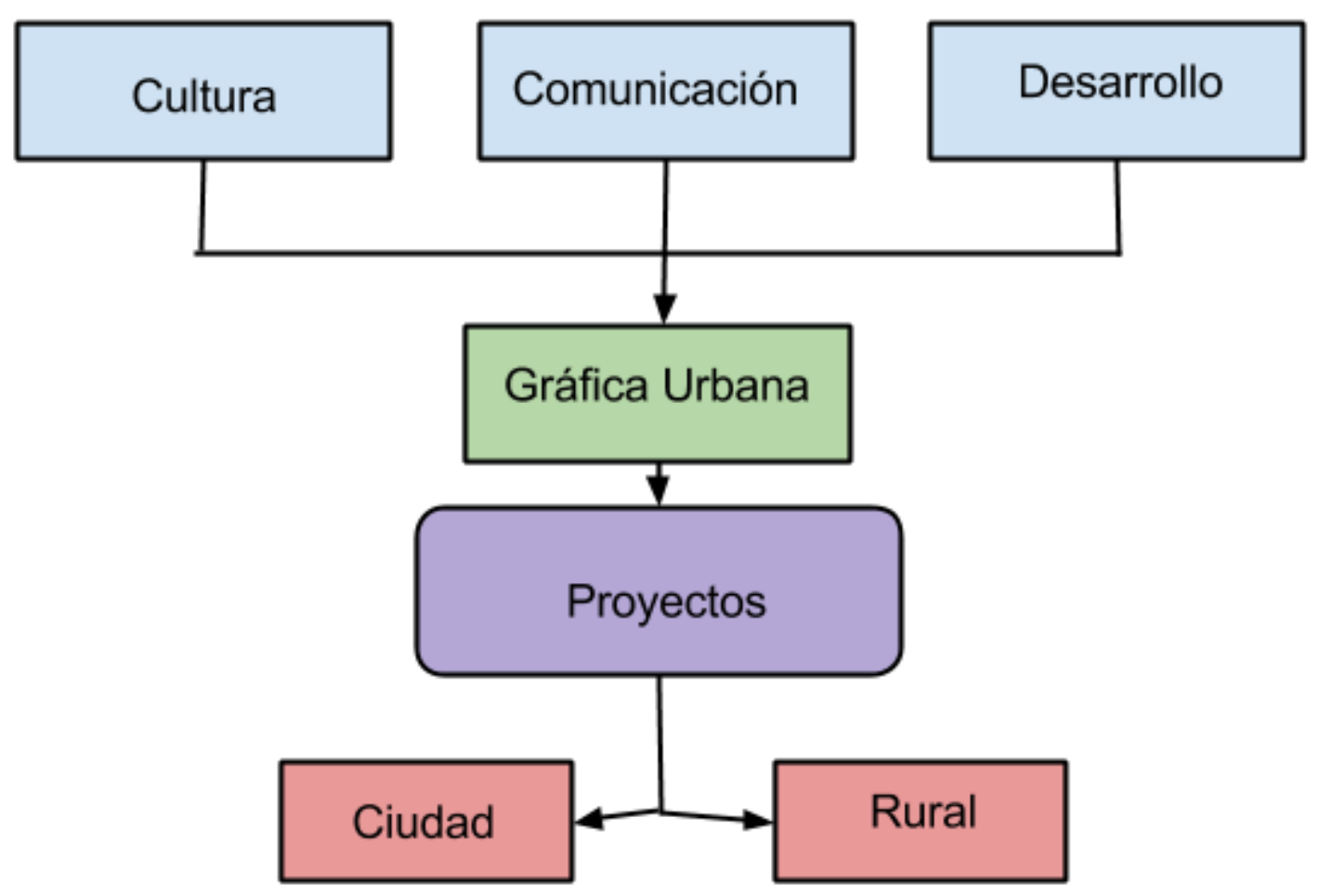

\subsection{La Cultura}

Durante el planteamiento y para la realización de este trabajo, concibo la cultura no como una idea del arte de museo ni del saber ilustrado y elitista, sino como el conjunto de manifestaciones y relaciones sociales que caracterizan una comunidad, la cultura como motor para el desarrollo y la transformación social. Es por esto, que me adhiero a definiciones de distintos autores que trabajan el concepto desde una visión más antropológica y sociológica, y para tal fin, me apoyo en el recorrido histórico y conceptual realizado por Maccari y Montiel en su texto: Gestión Cultural para el Desarrollo. 
El concepto de cultura, como muchos otros conceptos académicos, parte de una visión euro céntrica, que desde mediados del siglo XIX se fue desplegando a otras posturas y en los últimos cincuenta años, se ha observado en su relación con el desarrollo, estando aún este concepto muy ligado a una perspectiva tecnocrática y economicista.

Las corrientes interesadas en definir la cultura fueron la escuela evolucionista con las primeras formalizaciones de autores como Klemm y Tylor, a la que reaccionó Boas desde el particularismo histórico. Para Tylor en 1871 la cultura era "aquel todo complejo que incluye el conocimiento, las creencias, el arte, la moral, el derecho, las costumbres y cualesquiera otros hábitos y capacidades adquiridos por el hombre en tanto miembro de la sociedad" (Tylor, en Kahn, 1975, pp. 28). El contrapunto fue la noción de cultura en cuanto "conjunto diferenciado de costumbres, creencias e instituciones sociales que parecen caracterizar a cada sociedad aislada. En vez de que las distintas sociedades tengan diferentes grados de cultura, cada sociedad tenía una cultura propia" (Goodenough, en Kahn, 1975, pp. 29).

A partir de aquí, se fueron sucediendo distintas definiciones desde diversas corrientes como el difusionismo (Graebner, Schmidt), funcionalismo (Malinowski, Radcliffe-Brown), estructuralismo (Lévi-Strauss), simbolismo (Geertz), "personalismo" (Benedict, Mead), neoevolucionismo (White, Steward), materialismo cultural (Harris), entre otras (pp. 29).

Por su parte, para la antropología "la cultura consiste en la memoria hereditaria no genética de la sociedad". Se concibe a la cultura como un fenómeno humano, un proceso acumulativo ininterrumpido y un "hecho social" que incluye las creencias, ideales y valores, comparable con un organismo vivo (pp. 30). Y es a la luz de esta definición abarcativa, que me propongo observar y sistematizar la experiencias de gestión y sus procesos de comunicación social.

La UNESCO, en la Declaración de México de 1982 sobre "cultura y desarrollo" expresa: "La cultura definida únicamente a partir de criterios estéticos no expresa la realidad de otras formas culturales. Hay una tendencia unánime a 
favor de una definición socio antropológica de la cultura que abarque los rasgos existenciales, es decir, concretos de pueblos enteros: los modos de vida y producción, los sistemas de valores, las opiniones y creencias, etc." (MONDIACULT, 1982, pp. 31). Aunque esta tesis incluye expresiones artísticas y gráficas, no está de más reiterar que el interés principal se centra precisamente en la carga contextual y cultural que estas manifestaciones conllevan e implican en su proceso de creación.

No obstante, y a pesar de haberse abierto el panorama frente a lo que se entiende por cultura, hasta la fecha, aún se seguía (en algunos casos desafortunadamente aún se sigue) trabajando en los territorios desde una lógica restringida que respondía a las necesidades del mercado, vinculada más al desarrollismo, y negaba la posibilidad de desarrollar nuevas formas de intervención y desarrollo. Es así, tal vez, como surge la necesidad de instaurar políticas culturales que se encarguen de encauzar el trabajo conjunto del Estado, organizaciones y sociedad civil en beneficio de la cultura y la comunidad.

Según García Canclini (1987), junto al accionar del Estado, resulta central el rol de organizaciones, grupos y colectivos sociales a la hora de determinar dinámicas y rasgos principales. En la medida en que desde las políticas públicas se tenga en cuenta las aspiraciones de todos los actores involucrados (creadores y emprendedores) se podrán identificar los límites, las posibilidades y los alcances de la cultura en función incluso del sector cultural, para concebirlo en la integralidad de su oficio y para que los responsables de proyectos puedan asumirse como trabajadores de la cultura, en el ideal laboral de poder subsistir del oficio que conocen, disfrutan y saben hacer.

En este sentido, la cultura debe salir, siguiendo a Focault, de su aspecto "coercitivo", "el intelectual o artista que vigila y guía a la sociedad desde su torre de marfil, en un panóptico desde el que es posible articular su función preceptora y observar sus efectos en el comportamiento de los individuos" 
(Marcé y Bosch, 2007, pp.33), ya que hoy en día, "La cultura, comprendida más allá de una noción artística humanística, incluyendo la tecnología y la ciencia, es parte de un concepto de cultura ampliado, abarcativo y global [...] en el que la apertura de la modernidad es fundamental para avanzar" (Bonet, 2009, pp. 34).

La cultura debe ser tenida en cuenta como un recurso, pues "el papel de la cultura se ha expandido de una manera sin precedentes al ámbito político y económico, al tiempo que las nociones convencionales de cultura han sido considerablemente vaciadas" (Yúdice, 2002, pp. 35).

Maccari y Montiel proponen que "en lugar de centrarse en el contenido de la cultura -esto es, el modelo de enaltecimiento (según Schiller o Arnold) o el de distinción o jerarquización de clases (de Bourdieu) que ofrecía en sus acepciones tradicionales, o su más reciente antropologización como estilo de vida integral (Williams) conforme a la cual se reconoce que la cultura de cada uno tiene valor -, tal vez sea más conveniente abordar el tema de la cultura en nuestra época, caracterizada por la rápida globalización, considerándola como un recurso" (Yúdice, 2002, pp. 35).

Es así como la cultura se convierte en un "recurso estratégico fundamental a la hora de gestionar proyectos y organizaciones actuales, que posean no solo un nuevo impacto sobre el desarrollo de la propia actividad, sino que, además, en virtud de su capacidad "transversal", se transformen en una dimensión fundamental para la productividad de un conjunto mayor de sectores y esferas asociadas, que sus acepciones históricas no eran capaces de sostener y alimentar" (Maccari y Montiel, 2012, pp. 35).

Después de este recorrido no sobra aclarar entonces que esta tesis pretende poner en tensión la visión clásica y hegemonizante de la cultura y propone una lectura más cercana a las prácticas cotidianas y populares de una cultura que se legitima a sí misma en el contexto social. 


\subsection{EI Desarrollo}

"Desarrollo significa el enriquecimiento de la identidad de un pueblo, de sus aspiraciones, de la calidad integral de su vida tanto en el plano colectivo como en el individual", explicitando una concepción de desarrollo centrada en los problemas más acuciantes para la sociedad y en la búsqueda de un mejoramiento en la calidad de vida y las posibilidades de los seres humanos (pp. 39). Por su parte, "El concepto de desarrollo humano, por el contrario, subraya la ampliación progresiva de las oportunidades y capacidades de las personas, individual y colectivamente consideradas, como un modo de hacer posible la libertad efectiva de las personas y, por tanto, una vía para consolidar sus derechos" (Rey, 2008, pp. 39).

En el Diccionario del Desarrollo ${ }^{35}$ Gustavo Esteva expone que el Desarrollo se define por oposición al subdesarrollo, que comenzó en 1949 durante el gobierno del presidente Truman en Estados Unidos. "En realidad, desde entonces (2 mil millones de personas) dejaron de ser lo que eran, en toda su diversidad, y se convirtieron en un espejo invertido de la realidad de otros: un espejo que los desprecia y los envía al final de la cola, un espejo que reduce la definición de su identidad, la de una mayoría heterogénea y diversa, a los términos de una minoría pequeña y homogeneizante" (pp. 53).

Truman no fue el primero en emplear la palabra. Wilfred Benson, quien fuera miembro del Secretariado de la Oficina Internacional del Trabajo, fue probablemente la persona que la inventó, cuando se refirió a las 'áreas subdesarrolladas' al escribir sobre las bases económicas de la paz en 1942.

Pero la expresión no tuvo mayor eco, ni en el público ni en los expertos. Dos años más tarde, Rosenstein-Rodan siguió hablando de 'áreas económicamente atrasadas'. Arthur Lewis, también en 1944, se refirió a la brecha entre las naciones ricas y las pobres. A lo largo de la década, la expresión apareció ocasionalmente en libros técnicos o en

\footnotetext{
${ }^{35}$ SACHS, W. (Ed.). Diccionario del Desarrollo, Una guía del conocimiento como poder. PRATEC. 1996.
} 
documentos de Naciones Unidas. Sólo adquirió relevancia cuando Truman la presentó como emblema de su propia política. En este contexto, adquirió una virulencia colonizadora insospechada (pp. 53).

En conclusión para Esteves, el desarrollo se centraba más en escapar de la condición indigna llamada subdesarrollo. Es por esto que en la década de los noventa surgió el término de redesarrollo, destinada a corregir errores del pasado y dando forma al desarrollo sostenible.

Es evidente que la idea de desarrollo surge inicialmente más asociada al concepto de desarrollismo, enfatizando en aspectos economicistas como el ingreso, el crecimiento y el progreso, y relegando el conjunto de componentes culturales, puesto que éstos eran un obstáculo para la consecución de los objetivos materiales. Esta definición se tuvo en cuenta hasta entrado el último cuarto de siglo pasado, en el que surgió una idea de desarrollo más humano, ligado a políticas de ajuste económico que perseguían la inclusión de medidas sociales.

"Desde el mundo de la cultura comenzó a manifestarse una honda preocupación por "el modelo de desarrollo prevaleciente" y "el modo en que éste atenta contra la diversidad cultural y la independencia política de los pueblos", y se iniciaron una serie de cambios en innovaciones efectivas en los indicadores, las dimensiones y las valoraciones a la hora de referirse al desarrollo" (Maccari y Montiel, 2012, pp. 38). A partir de este punto, la riqueza material pasó a ser solo una parte del progreso y éste, pasó a incluir el aspecto socioeconómico determinado por lo cultural (Sen, 2000, pp. 39).

Es así como el rol de la cultura se torna un activo estratégico por sus alcances como acción colectiva y por su potencialidad para la recuperación de los lazos de asociatividad, sumando así a la definición de un tipo de desarrollo más humano, instancia en la que los individuos son tenidos en cuenta como "sujetos del desarrollo" (Rey, 2002, pp. 40). 
"El objetivo real del desarrollo humano es ampliar las opciones de las personas. $\mathrm{El}$ ingreso es solo una de esas opciones -y una extremadamente importante-, pero no es la suma total de la vida humana. La salud, la educación, el ambiente físico, la libertad -por nombrar algunas opciones- pueden ser tan importantes como el ingreso" (Haq, 1995, pp. 41).

En el Informe sobre Desarrollo Humano PNUD 2004, se define la cultura "ya no como algo que inspira, enaltece y educa, sino como un complejo campo de actividades humanas que debe estar en el centro mismo de la economía, la política y todos los servicios sociales" (Yúdice, 2005, pp. 44) y en esa misma línea surge la idea de "desarrollo humano sustentable" como "la necesidad de sostener todas las formas de capital y recursos (físicos, humanos, financieros, ambientales) como una precondición para asegurar las necesidades de futuras generaciones" (Yúdice, 2005, pp. 42).

Se hace evidente que la cultura y el desarrollo están intrínsecamente relacionados y en constante tensión, desde la perspectiva del desarrollo en cuanto al progreso material y la cultura como obstáculo al avance económico. Según Bonet: "la idea errónea de culpar a la cultura del no progreso se basa en un conjunto de tautologías falsas [...] La primera es afirmar que el desarrollo es igual a bienestar económico y viceversa". Como se ha señalado, la acepción ampliada de desarrollo implica una serie de dimensiones articuladas, dentro de las que "lo económico es solo una posibilidad. Válida, pero no única" (Bonet, 2009, pp. 45).

No obstante, al igual que la cultura, la evolución del concepto de desarrollo empieza a tener en cuenta aspectos ancestrales, contextuales y culturales de las sociedades, propiciando así el surgimiento de conceptos como "desarrollo cultural" y "dimensión cultural del desarrollo", ligados a la diversidad, la identidad, participación, libertad y legitimación de la cultura como una de las dimensiones principales del desarrollo (UNESCO, 1988). Y en esta misma línea, la Declaración de Río de 1992, postula la necesidad de plantear una noción de desarrollo que contemple las necesidades de las generaciones futuras, es decir, que tenga en cuenta el criterio de "sostenibilidad" (pp. 46). 
Tres años después (1995) la Comisión Mundial de Cultura y Desarrollo, legitima tres elementos centrales para la productividad del binomio ("creatividad", "diversidad" y la noción de "construcción compartida"...) y ubica en el centro de la reflexión al componente cultural, remarcando sus rasgos estratégicos y su finalidad por encima de su instrumentalización (pp. 47).

Así pues, la idea de cultura en términos de desarrollo no es "un instrumento del progreso material: es el fin y el objetivo del desarrollo, entendido en el sentido de realización de la existencia humana en todas sus formas y en toda su plenitud" (Unesco, 1997). Se reconoce la importancia de la economía y el crecimiento material como elementos del desarrollo, pero en esta dinámica la cultura debe ser más que un medio para alcanzar tal fin, debe ser el fin en sí mismo. El desarrollo social y económico como parte de la cultura de los pueblos, que se preocupa por el crecimiento de manera responsable y sustentable. Esta idea de desarrollo es a la que me adhiero para observar los aportes que las distintas experiencias de gráfica urbana hacen a sus comunidades y sus entornos. Es así como, "de cultura como barrera del desarrollo, se avanzó a la cultura como factor y de allí a la cultura como dimensión y finalidad del desarrollo" (Rey, 2008, pp. 49) redefiniendo su rol y lugar, que la separan cada vez más de los rasgos elitistas y sesgados de "lo ilustrado", para dar lugar a su potencialidad como recursos para la transformación social y el desarrollo humano.

No obstante, cabe aclarar que no se puede concebir a la cultura como "una fórmula redentora de todos los males" (Alberto Vives y Espinosa Espinosa, pp. 50). "El que reduce la cultura a una dimensión del desarrollo sin el menor cuestionamiento de la cultura del desarrollo (...) hace del crecimiento material la dimensión prioritaria del sistema social de vida y que convierte al mundo en un mero objeto de explotación. (...) un parche con el que encubrir la dinámica radical invasiva (en lo económico y en lo ecológico) de los modelos aún hegemónicos del desarrollo (Martín-Barbero, 1999, pp. 50). Yúdice propone, siguiendo líneas anteriores, una cultura asociada justamente a los conceptos de sustentabilidad y ecología: "ecología cultural del desarrollo" o "desarrollo culturalmente sustentable", conceptos todos enmarcados en una idea más 
global de "desarrollo cultural", donde la creatividad, la cooperación, la ética, la diversidad, el pluralismo y el trabajo colectivo son fundamentales para la "transformación de la realidad".

El desarrollo debe, no sólo ser responsable y culturalmente sustentable, sino que además debe promover estrategias de intervención y promoción de actores particulares, como del resto de esferas sociales, integrando distintos rubros y a la cultura como eje de la economía.

En este punto, el desarrollo converge con la cultura en su ámbito económico, social y político, ya que el principal déficit sigue siendo la baja formalización y profesionalización del sector cultural y es aquí donde entraron a jugar un papel importante las políticas culturales y los programas de fomento y financiación.

(...) estas concepciones sobre cultura y desarrollo deben ser incorporadas e impulsadas no sólo desde la iniciativa del sector público, sino también desde el trabajo de las organizaciones, tanto del sector privado como de la sociedad civil. En la medida en que se trata de estrategias que deben ser reformuladas, dinamizadas y puestas en marcha de un modo coherente con sus valoraciones y alcances, sus marcas de transversalidad e integración sectorial necesariamente debe conllevar al ejercicio de implicación creciente de -y entre- sus diversos actores, a fin de consolidar colectivamente políticas y permanente productividad y consenso (Maccari y Montiel, 2012, pp. 52).

El sector cultural es muy amplio, pero siempre se ha puesto la mirada y los fondos en lo concerniente al patrimonio, los museos, la preservación de cascos históricos y al turismo. Otra vertiente ha venido siendo la gestión de grandes eventos artísticos, la inversión en infraestructura y en los llamados "programas de democratización y acceso cultural" (pp. 55), que hasta el momento son los que albergan a mayor cantidad de usuarios y espectadores. "El destino de los presupuestos públicos (...) solo una parte residual se dirige a la formación artística, el apoyo a la producción de contenidos de titularidad privada, al 
desarrollo industrial, a la creación emergente o a la creación real de nuevos públicos" (Marcé y Bosch, 2007, pp. 58).

El gran problema al respecto es que la tendencia es a que estos fondos y programas se vean directamente relacionados con las campañas de gobiernos de turno que con, como lo dice Canclini, "políticas de democratización y acceso" (pp. 56) reales que vayan más allá de una buena estrategia de producción artística y consumo cultural.

El desarrollo a nivel social y económico hace su entrada con los programas de fomento y financiación de iniciativas culturales, a través de las políticas públicas, a los que distintos actores de la sociedad civil han podido acceder en los últimos años con diferentes iniciativas culturales y que ha logrado unir esfuerzos (de parte de unos más que otros) del Estado, el sector privado y cooperación internacional, con modelos "asociativos", créditos "blandos", subvenciones, entre otros.

En el caso de Colombia, se ha avanzado a este respecto con convocatorias como el programa Ventures, Fondo Emprender del SENA, Destapa Futuro y específicamente en Cali, Industrias Culturales administró y gestionó los fondos destinados a más de 70 emprendimientos culturales representados en asesorías, acompañamiento y formación.

Si bien, ha sido un gran paso, aún se piensa mucho en términos industriales y en la cosificación de la cultura como producto mercantil, lo cual implica mayor compromiso y preparación de parte de los gestores culturales y sociedad civil para salir del estado de dependencia frente al sector público, ejecutar de manera eficiente y eficaz sus planes de acción y generar nuevos y creativos esquemas de recursos.

Respecto a esto, Maccari y Montiel aseguran que el Estado tiene la

responsabilidad indelegable en el fomento de los nuevos esquemas socioeconómicos asociados a la cultura y el desarrollo (...) Más aún cuando 
los actores implicados en dicha empresa socioeconómica no están movidos estrictamente por transacciones con vistas a la utilidad, sino también por valoraciones de carácter solidario y cooperativo (pp. 61).

En resumen, podría concluirse que la cultura es un ingrediente fundamental para un desarrollo sustentable, en la medida en que logra cohesionar a la sociedad en pro de la transformación con la ayuda de iniciativas y reformas del Estado, que sólo existen y son útiles si parten del colectivo social.

\subsection{Comunicación Transformadora}

Para que la comunicación sea una herramienta que permita la interacción y potencie el desarrollo en distintos niveles sociales, se requiere de otros procesos paralelos que posibiliten las relaciones donde todos sus actores son fundamentales.

Uno de éstos es la planificación, que en el presente caso de estudio sobre la transformación social a través de la gráfica urbana, sería de tipo comunicativa, donde los ejes centrales serán la integridad, la diversidad y la construcción colectiva. Esta planificación requiere de una mirada holística de los procesos que no pretende tener dominio ni resolverlo todo, sino que da cabida a distintas miradas e intereses como riquezas del proceso de construcción colectiva, que además es flexible a los cambios del contexto y a las distintas situaciones que se vayan presentando entre los diferentes actores que intervienen: colectivos de trabajo, artistas, los barrios y sus procesos de intervención, como objetos de conocimiento. Citando a C. Ceraso, la tarea principal a la hora de planificar es: "introducir organización y racionalidad en la acción", sin que esto implique ceñirse a una estructura rígida, sino por el contrario, poder trazar un mapa de navegación que permita replantearse y construirse a medida que progresa el proyecto junto con sus actores. 
En 1980 Luis Ramiro Beltrán ${ }^{36}$, formuló un "modelo de comunicación horizontal" cifrado en el acceso, el diálogo y la participación entendidos como factores interdependientes. "La comunicación es el proceso de interacción social democrática que se basa sobre el intercambio de símbolos por los cuales los seres humanos comparten voluntariamente sus experiencias bajo condiciones de acceso libre e igualitario, diálogo y participación".

La comunicación alternativa para el desarrollo democrático es la expansión y el equilibrio en el acceso de la gente al proceso de comunicación y en su participación en el mismo empleando los medios masivos, interpersonales y mixtos - para asegurar, además del avance tecnológico y del bienestar material, la justicia social, la libertad para todos y el gobierno de la mayoría (pp. 15).

Esto es lo que se evidencia en propuestas como las mencionadas de: el Proyecto Afuera, Poetalatas, Proyecto Fauna o lo que ocurre actualmente en Colombia con la Minga Muralista de los Pueblos ${ }^{37}$, en Toribío, Cauca (pueblo azotado por la violencia y olvidado por el Estado), en la que con ayuda de artistas, la gente del pueblo se está expresando. También es el caso de una de las más recientes intervenciones de Bansky, con la que apoya la protección animal ${ }^{38}$.

En esta medida la planificación sería más conveniente en términos cualitativos que cuantitativos porque lo fundamental no es medir el impacto que pueda tener la intervención de la gráfica urbana en cifras, sino más bien caracterizar y sistematizar sus procesos en términos de avances y transformación, pues citando de nuevo a C. Ceraso, el desarrollo se mide por cuánto mejora la calidad de vida de una comunidad y no sólo por el incremento de su nivel económico.

\footnotetext{
${ }^{36}$ BELTRÁN, L. R. La comunicación para el desarrollo en Latinoamérica: un recuento de medio siglo. Texto presentado en el III Congreso Panamericano de la Comunicación. Buenos Aires. 2005.

${ }^{37}$ http://www.nasaacin.org/informativo-nasaacin/3-newsflash/6237-1\%C2\%AA-minga-demuralistas-de-los-pueblos https://www.facebook.com/MingaMuralistas?fref=ts

${ }^{38} \mathrm{http}: / /$ www.youtube.com/watch?v=WDIz7mEJOeA
} 
El gran desafío además de planificar comunicativamente, y pensando ya de manera general en cualquier tipo de proyecto, en términos de gestión es encontrar puntos convergentes con las instituciones y lograr la planificación de proyectos que garanticen la sustentabilidad para sus integrantes y su duración en el tiempo.

Todo proyecto tiene unos creadores, unos gestores y unos patrocinadores (sin que necesariamente en esto medie el dinero), pero es una realidad que de estos actores depende el feliz término del mismo, y tal vez en esta parte el dinero sí influye bastante, pues será muy diferente la ejecución de una iniciativa que surja de una empresa o que tenga patrocinio monetario internacional con el que se garantice la sostenibilidad del proyecto y el bienestar de sus participantes; que el desarrollo de un proyecto auto gestionado, con las preocupaciones laborales de los integrantes y las pocas garantías de poder lograr las metas trazadas. Porque puede ser más productivo un proyecto en el que trabajen personas de tiempo completo o con una dedicación considerable, que uno en el que participe un grupo de personas que se va diluyendo con el tiempo.

El dinero es una preocupación, pero no es garantía del éxito de un proyecto. De todas formas, tanto el proyecto rentado como el auto sustentado, podrán tener excelentes resultados de desarrollo comunitario si trabajan de manera colectiva, coherente y participativa, que permita aprovechar los recursos existentes y motivar a los participantes, con una previa planificación y proyección de las actividades. La gestión debe ser un proceso global en el que todas las decisiones y acciones cuentan, como lo plantea C. Ceraso.

Desde la experiencia personal, Gráfica Mestiza fue planificada bajo el formato de empresa cultural, a partir de diversas convocatorias de emprendimiento y capital semilla. Para tal fin, tuvo que proyectarse en términos de acciones, metas e indicadores en un tiempo estimado tal cual como se propone en un plan de negocio convencional. Sin embargo, la realidad indica que los procesos culturales difieren de los procesos de producción industrial para los que están diseñados los parámetros de éste tipo de convocatorias aún en Colombia, y 
más cuando éste proyecto no se basaba en la venta de ningún producto como tal, y por eso, Gráfica Mestiza se fue gestionando paralelamente a través del uso de herramientas digitales libres y gratuitas que permitieron avanzar en el trabajo de conformación de redes y bases de datos para lograr un trabajo colaborativo como el que se efectúa hoy en día.

En términos de sustentabilidad, aún no se ha logrado establecer un mecanismo de captación de recursos diferente a la presentación a nuevas convocatorias y el intercambio empresarial e interinstitucional con actores que comparten los mismos intereses. No obstante, y a pesar de la incertidumbre que esto pueda generar, también ha servido para darse a conocer mucho más y ampliar las redes de trabajo.

Es por esto que, "el desafío en el campo de la Comunicación / Desarrollo, es poner cauces a la comunidad, para disparar la palabra y construir nuevos sentidos que den lugar a otros valores y modos de estar en el mundo". (ARRÚA,V. pp. 79) es necesario que los actores sociales sean los constructores de su propia realidad y que la comunicación sea una herramienta para lograr esta transformación.

La comunicación pensada como hecho cultural, como proceso de producción de sentidos, nos da la oportunidad de situarnos en procesos de creación. Nos permite situarnos en instancias de re significación de la realidad. En momentos en que podemos producir nuevos sentidos que nos permiten comprender más profundamente "cómo estamos en el mundo", cómo es el mundo en el que estamos, y cómo es el mundo en el que queremos habitar. (ARRÚA,V. pp. 80)

Si bien actualmente los grupos "minoritarios" han logrado empoderarse y generar espacios de participación en distintos ámbitos sociales, el rol del facilitador o comunicador es fundamental en el acompañamiento a estos procesos, en la medida en que sirve de puente entre las necesidades de la comunidad y las estructuras del Estado, no en la calidad de asesor externo, 
sino con la intención de fortalecer las herramientas y la autonomía de la sociedad.

\subsection{Rol del Comunicador}

Tal como lo propone la maestría PLANGESCO durante el desarrollo de cada una de sus asignaturas, nuestro rol como profesionales dentro de la comunidad es diagnosticar, planificar y evaluar medios, procesos y proyectos de comunicación que se efectúan en distintos niveles de la sociedad, desde una postura de facilitadores de los mismos.

Como lo plantea C. Villamayor, los comunicadores debemos mediar pedagógicamente para que la comunicación no sea vista como un mero instrumento mediático, sino como una herramienta donde interactúan prácticas socio culturales, donde se construyen significados y sentidos para la comunidad. Es por esto que, "diagnosticar y planificar procesos desde una perspectiva comunicacional no significa planificar la comunicación, significa crear condiciones para que las personas se comuniquen y sean ellas sujetos de derecho a la comunicación".

Los comunicadores debemos adoptar el rol de gestores de estos procesos, como agentes transformadores y educadores para el cambio social, más no como interventores externos a la comunidad que aplicamos una fórmula de solución a los problemas y necesidades que se identifican. Las prácticas comunicativas, como las concibe M. Mata, deben ser espacios de interacción entre sujetos en los que se verifican procesos de producción de sentido que no circulan de manera lineal. "Un discurso genera, al ser producido en un contexto social dado, lo que podemos llamar un campo de efectos posibles" (E. Verón), es por esto que un mensaje no produce o muestra un solo camino.

En el caso de este objeto de estudio mi rol será el de aprender de las experiencias seleccionadas, cómo se comunican con la gente y cómo logran transformar su entorno, para poder replicar y generar vínculos que les permitan a otros proponer y llevar a cabo nuevas iniciativas, aportando así al desarrollo, 
en el que la comunidad puede acceder y ser parte de la comunicación como un proceso democrático, tal como lo plantea Luis R. Beltrán, pues la comunicación representa el espacio donde cada quien pone en juego su posibilidad de construirse con otros (M. Mata) y así lograr la transformación positiva del entorno y de uno mismo.

\subsection{Gráfica Urbana}

Una de las tareas primordiales será definir conceptualmente el objeto de estudio según como lo concibe el colectivo Gráfica Mestiza, pues será a través de sus actividades que se observarán los fenómenos que generan los movimientos urbanos. Es por esto que se hablará más de gráfica urbana ${ }^{39}$ que de arte urbano, puesto que el arte exige unos parámetros gráficos, estilísticos y de técnica, y en este caso la gráfica se enfoca además de esto, en su función comunicativa, política y publicitaria, expresándose mediante el mural, el graffiti, el esténcil, los tags (firmas) y los bombardeos de color.

Remontándonos al inicio de los tiempos (si es válido para hablar del tema) "las primeras apariciones de pinturas en muros remontan a la época de las cavernas con la pintura rupestre y posteriormente es posible ver en toda la historia de la humanidad destellos de graffiti, es decir, intentos por llevar el lenguaje popular a los muros de ciudades y metrópolis" (Méndez y Garrido, 2002). En la cultura romana se hallan distintas inscripciones en muros y columnas con mensajes alusivos a la política, insultos y declaraciones de amor, y recién a mediados del siglo XIX el arqueólogo Raffaele Garrucci divulgó el término graffiti en medios académicos (Gimeno, F. y Mandingorra, M. 1997).

Recién en los años sesenta tiene su aparición el graffiti como lo conocemos hoy en día, en la ciudad de Philadelphia y New York, caracterizado a nivel formal principalmente por el uso de tipografías de diferentes tipos y niveles de

\footnotetext{
${ }^{39}$ Calle Libre - Graffiti + Street Art en Latinoamérica:

http://www.youtube.com/watch?v=8NaHKw8bcrc\&fb source=message

Documental: Historia del Graffiti en Bogotá: https://www.youtube.com/watch?v=1REZmPKrINA
} 
complejidad y entendimiento, dibujadas a través del spray como herramienta básica de este estilo de gráfica callejera ${ }^{40}$.

Las categorías de análisis que hasta el momento se tendrán en cuenta serán las planteadas por C. Castoriadis, en lo que se refiere a la representación, la creación y los lenguajes (legen), puesto que en este caso los artistas urbanos crean piezas para representar sus ideas, usando como lenguaje el graffiti, el mural, la ilustración, el esténcil, entre otros.

La representación en este caso conjuga lo artístico con lo ideológico, es decir, muchos artistas optan por la gráfica urbana porque tienen un mensaje para la comunidad, y es así como desarrollan su estilo y técnicas para intervenir de manera propia diferentes espacios, en los que plasman retratos de la comunidad, seres fantásticos, elogios de la naturaleza, metáforas políticas. Esta expresión simbólica tiene valor en las prácticas sociales (teukhein) cuando se comunica el artista con la comunidad a través de su obra y genera una acción.

Así mismo, y a diferencia del arte de galería, la gráfica urbana se considera una creación única, irrepetible, efímera, que a pesar de que la técnica se comparte entre diferentes personas, ninguna pinta el mismo mural 2 veces y no existe la reproducción de una pieza a manos de otro.

Con Castoriadis también puede hablarse de las relaciones del sujeto sujetado, que indiscutiblemente dialoga con sí mismo, con lo social y con el lenguaje en el cual está inmerso, lo cual le permite construir una red simbólica que lo relaciona a través de la institución.

En la práctica, los colectivos de arte urbano se enfrentan (en acuerdo y disputa) con las instituciones establecidas de la sociedad, y es con sus reglas que el legen y el teukhein actúan o se hacen visibles en sus manifestaciones artísticas y su relación con la sociedad.

\footnotetext{
${ }^{40}$ Rodríguez, Jesús D. Análisis del postgraffiti en Cali: Una aproximación formalista y estilística a la gráfica callejera. Tesis de grado de la Carrera de Diseño Gráfico de la Universidad del Valle, Colombia.
} 
En esta línea, vuelvo a citar a P. Bourdieu con sus conceptos sobre campo, espacio social, habitus, entre otros, para hablar de la disputa por el territorio y la posición social del artista callejero dentro de una comunidad. La lucha por el territorio en términos gráficos entre sus pares y con las instituciones que legitiman o reprimen las expresiones urbanas. Todo esto, en este caso, más en términos internos de las relaciones de los colectivos de trabajo gráfico y luego de su relación con la sociedad.

Los graffiteros y muralistas poseen ciertos recursos que se convierten en capital que los distingue entre sí por sus técnicas y logros, construyendo una trayectoria, que a su vez les permite tener cierto reconocimiento y distinción dentro del campo a nivel simbólico.

Finalmente, de M. Focault adopto los conceptos cuerpo, poder, espacio y tiempo; para explorar las prácticas cotidianas de los artistas urbanos: el reconocimiento que logran, la resistencia a las instituciones del poder, la identidad como grupo, la recuperación y apropiación de espacios, sus horarios y relaciones con la comunidad.

A la luz de los conceptos de estos autores se pueden analizar las prácticas, modos de organización de los colectivos, estrategias de comunicación y acciones transformadoras dentro de la sociedad, pero también su proceso de institucionalización, que es un fenómeno que se hace evidente hoy en día.

\subsection{La Ciudad}

"La ciudad cumple un papel básico para el desarrollo, ya que tiene características que le permiten jugar de elemento de transacción de flujos materiales e inmateriales entre personas, ideas, mercancías y valores" (Bonet, 2008, pp.72).

Entre estos valores, la gráfica callejera introduce la discusión de lo público y lo privado, del rescate de los espacios en ruinas a través de murales o de 
intervenciones artísticas que se integran a las texturas de la ciudad. Así mismo, la gráfica urbana reconfigura la noción de arte puesto que evalúa las competencias de los artistas callejeros frente a los convencionales de museo hasta el punto de giro logrado por Marcel Duchamp y su introducción de objetos cotidianos en el arte. Este punto de quiebre logró la valoración de piezas callejeras, de su característica efímera y su mimetismo con la ciudad a tal punto, que hoy en día se pasó al extremo de la comercialización y aparición del graffiti en las galerías de arte.

Más allá de su valor estético, la gráfica urbana como elemento de la cultura, se ha encargado de relatar los procesos sociales, las inquietudes y necesidades de la gente, las inconformidades frente al Estado, las injusticias y ha hecho parte del desarrollo (o ha estado en contra en cierta medida) de las ciudades, en cada rincón donde un muro queda libre, antes de que éste caiga por completo o cuando uno nuevo se erige.

Pero la gráfica urbana no está solo en las ciudades ni en los muros de concreto, el campo también es lienzo de expresiones y transformaciones sociales.

\subsection{Lo Rural}

Como ya lo había mencionado antes, los grupos minoritarios han logrado espacios importantes de participación, y en el caso de este trabajo de tesis, con el proyecto: La Minga de Muralistas de los Pueblos, la comunidad rural de Toribío, Cauca, ha logrado visibilizarse frente a la comunidad internacional y estar en la agenda de los medios, para denunciar el flagelo de la guerra a través del graffiti.

En este caso, lo rural se entiende por las zonas no urbanizadas, que en la mayoría de los casos no acceden a los servicios básicos y que no cuentan con la infraestructura necesaria para suplir las necesidades de sus habitantes. Por otro lado, lo rural es la base de la cadena productiva desde el abastecimiento agrícola, y es afectado por el progreso con la intromisión de procesos invasivos 
con el entorno y la población, como es el caso de la extracción minera, por ejemplo.

A continuación, viene al caso de manera ilustrativa, la opinión de una lideresa indígena que defiende su territorio:

Nosotros no nos oponemos al desarrollo, nos oponemos a la destrucción de la vida y los territorios ancestrales, nos oponemos a la destrucción ambiental, nos oponemos a la pérdida de la soberanía alimentaria, nos oponemos a la destrucción de nuestra cultura, nos oponemos a que nuestros ríos Ovejas y Cauca, Teta y Palo se envenenen con cianuro y mercurio y que hoy los Caleños estén siendo envenenados sin saberlo. Nos oponemos a ser desplazados de nuestros territorios ancestrales, nos oponemos a la corrupción de funcionarios públicos que no realizan las acciones establecidas en la Constitución para proteger nuestros derechos como colombianos ${ }^{41}$.

Es aquí donde toman valor expresiones artísticas y comunicativas para lograr la transformación.

\section{Políticas culturales: Colombia y Argentina}

\subsection{Colombia}

La preocupación por el fortalecimiento de las Industrias Culturales, entendidas por la UNESCO como: "Aquellos sectores de actividad organizada que tienen como objeto principal la producción o la reproducción, la promoción, la difusión y/o la comercialización de bienes, servicios y actividades de contenido cultural, artístico o patrimonial"42, es un tema presente en la regulación cultural de Colombia, gracias a la aparición de la Ley General de Cultura en 1997; ésta a

\footnotetext{
${ }^{41}$ http://www.nasaacin.org/informativo-nasaacin/3-newsflash/7310-nosotros-no-nos-oponemos-aldesarrollo,-nos-oponemos-a-la-destrucci\%C3\%B3n-de-la-vida-y-los-territorios

42 UNESCO, 2009 http://www.unesco.org/new/es/culture/themes/cultural-diversity/diversity-of-culturalexpressions/tools/policy-guide/como-usar-esta-guia/sobre-definiciones-que-se-entiende-por-industrias-culturalesy-creativas/e Industrias Culturales de Cali, pag.4.
} 
la vez que desarrolla el reconocimiento de la cultura como un derecho de carácter universal, y que como tal implica un compromiso explícito del Estado en términos de financiación y gasto social, caracteriza también el sector cultural como un sector productivo capaz de aportar al desarrollo económico de la nación, generando crecimiento y empleo en condiciones de equidad, tanto para los agentes y organizaciones de la actividad cultural, como para toda la sociedad. Este doble y complementario carácter de la cultura como derecho universal y como potencial productivo, es desarrollado ampliamente por el Plan Nacional de Cultura 2001-2010: "Hacia una ciudadanía democrática y cultural", cuando se hace referencia directa a las industrias culturales como creadoras de nuevas expresiones y símbolos, y como generadoras de canales de comunicación que tejen la red de significaciones de la sociedad ${ }^{43}$.

El Plan establece, en su interés por gestionar una agenda intersectorial entre economía y cultura, estrategias de impulso a las industrias culturales. Tales estrategias hacen énfasis en la vinculación de las políticas sociales y económicas del Estado a las organizaciones del campo cultural, a través del fomento a las micro, pequeñas y medianas empresas, el diseño de líneas especiales de crédito, la implementación de programas de capacitación empresarial, el incentivo a las experiencias exitosas, la creación de incubadoras empresariales especializadas en el sector.

Por su parte, el documento CONPES 3162 de $2002^{44}$, "Lineamientos para la Sostenibilidad del Plan Nacional de Cultura 2001-2010", en concordancia con dicho Plan, caracteriza a las industrias culturales como vehículos del diálogo intercultural, del conocimiento, la creatividad, la información, los procesos educativos, el entretenimiento y la construcción de sociedades más

\footnotetext{
${ }^{43}$ Al respecto el Plan Nacional de Cultura señala: "La diversidad de medios expresivos a través de la música, las artes plásticas y escénicas, la literatura, la poesía y la producción mediática, conforman espacios de creación cultural y de formación de sensibilidades, a la apreciación crítica de las diversas producciones culturales y al goce creativo de todas las manifestaciones. En esta tarea no se debe olvidar el papel central que tienen las industrias culturales, que con sus producciones (...) crean y controlan espacios de expresión y comunicación y generan nuevos elementos simbólicos que entran a alimentar una compleja red de significaciones." Plan Nacional de Cultura: Hacia una ciudadanía democrática y cultural 2001-2010. Bogotá: Ministerio de Cultura. (2002), pag. 47.

${ }^{44}$ A este documento se suma el CONPES 3659 de 2010: Política Nacional para la Promoción de Industrias Culturales en Colombia. (CONPES se refiere a Consejo Nacional de Política Económica y Social).
} 
democráticas $^{45}$. En consecuencia centra sus recomendaciones para fomentarlas en cinco frentes, a) El desarrollo de incentivos fiscales y tributarios b) la implementación de líneas de fomento financiero c) el fortalecimiento de las asociaciones de creadores, productores y distribuidores d) la formación artística y técnica de los actores del sector e) la protección de los derechos de autor y f) la búsqueda y apertura de mercados internacionales.

De igual manera y partiendo de estos lineamientos comunes, el Plan Para las Artes "2006-2010", se ha propuesto como objetivo el reconocimiento de las prácticas artísticas como factor de desarrollo sostenible, de renovación de la diversidad cultural y principio de la ciudadanía cultural ${ }^{46}$. Como tal, la economía creativa se ha incluido como uno de los principios del enfoque sobre el cual se erigen las estrategias y acciones de la política pública para las artes, en cuanto se manifiesta que el desarrollo profesional de las vocaciones y talentos artísticos es un derecho que implica la consolidación del arte como un subsector socioeconómico con características específicas. Para ello se ha planteado articular las políticas culturales con las demás políticas económicas de fomento, haciendo mención explícita de la legislación que promueve el desarrollo integral de las micro, pequeñas y medianas empresas, atendiendo las necesidades y las particularidades del sector con el propósito de mejorar la calidad de vida de los artistas y demás agentes que conforman este campo.

Las normativas de impulso a las Industrias Culturales están estrechamente vinculadas a la regulación y a las políticas de impulso al emprendimiento, las mipymes, y la competitividad de los sectores productivos ${ }^{47}$. La ley 590 de 2000

\footnotetext{
45 Documento CONPES 3162 de 2002: Lineamientos para la Sostenibilidad del "Plan Nacional de Cultura".

${ }^{46}$ Plan Nacional para las Artes 2006-2010. Bogotá: Ministerio de Cultura. (2005), pag. 53.

${ }^{47}$ Esta ley Mipyme ha sido modificada por la ley 905 de 2004 y la ley 1151 de 2007, esta última por la cual se expidió el plan de desarrollo 2006-2010-. En esta ley se establece que: Para todos los efectos, se entiende por micro incluidas las Famiempresas pequeña y mediana empresa, toda unidad de explotación económica, realizada por persona natural o jurídica, en actividades empresariales, agropecuarias, industriales, comerciales o de servicios, rural o urbana, que responda a dos (2) de los siguientes parámetros: 1. Mediana empresa: a) Planta de personal entre cincuenta y uno (51) y doscientos (200) trabajadores, o b) Activos totales por valor entre cinco mil uno (5.001) a treinta mil (30.000) salarios mínimos mensuales legales vigentes. 2. Pequeña empresa: a) Planta de personal entre once (11) y cincuenta (50) trabajadores, o b) Activos totales por valor entre quinientos uno (501) y menos de cinco mil (5.000) salarios mínimos mensuales legales vigentes. 3. Microempresa: a) Planta de personal no superior a los diez (10) trabajadores o, b) Activos totales excluida la vivienda por valor inferior a quinientos (500) salarios mínimos mensuales legales vigentes.
} 
que tiene por objeto promover el desarrollo integral de las mipymes en consideración de sus aptitudes para generar empleo, el desarrollo regional y la integración de sectores económicos ${ }^{48}$, establece responsabilidades en torno a la promoción de la participación de las mipymes en las compras públicas, la realización de ferias y exposiciones para facilitarles el acceso a mercados y la creación del Fondo Colombiano de Modernización y Desarrollo Tecnológico (Fomipyme) con miras a financiar programas, proyectos y actividades para el desarrollo empresarial y tecnológico de las Mipymes y aplicar instrumentos no financieros dirigidos al fomento y promoción de las Mipymes, mediante cofinanciación no reembolsable de programas, proyectos y actividades.

Por su parte, la ley 1014 de Fomento a la Cultura del Emprendimiento, establece responsabilidades institucionales en torno a la promoción de los vínculos entre la formación para el emprendimiento y el sistema formal de educación en todos sus niveles, así como mecanismos para facilitar la creación de nuevas empresas articuladas con las cadenas y clusters productivos relevantes para la región y con un alto nivel de planeación y visión a largo plazo. Esta ley prescribe la obligación de asignar recursos públicos para el apoyo a redes de emprendimiento debidamente registradas en el Ministerio de Comercio, Industria y Turismo, así como la gestión de acuerdos con las entidades financieras para hacer que los planes de negocios de los nuevos empresarios sirvan como garantía para el otorgamiento de créditos y la generación de condiciones para que en las regiones surjan fondos de inversionistas, fondos de capital semilla y fondos de capital de riesgo para el apoyo a las nuevas empresas ${ }^{49}$.

El Plan Nacional de Desarrollo 2006-2010 Estado Comunitario: Desarrollo para Todos, establece una política de competitividad y productividad basada en el proceso de Agenda Interna, que inició en 2004 y ha permitido a las regiones y sectores partícipes identificar sus apuestas productivas y estrategias competitivas. El Ministerio de Cultura lideró la construcción de la agenda interna para el Sector Cultura, Medios y Publicidad, en concertación con varios

\footnotetext{
48 ley 590 de 2000. Capitulo 1, Artículo 1.Objeto de la Ley

${ }^{49}$ Ley 1014 de 2006. Capitulo 1. Articulo 4. Obligaciones del Estado
} 
de actores privados del campo cultural, recogiendo las demandas y apuestas del sector y proponiendo una respuesta institucional orientada a hacer frente a los retos que plantea en términos de política pública el desarrollo de las Industrias Culturales en el país.

El Plan Nacional de Desarrollo propone una estrategia de competitividad basada en el desarrollo empresarial y tecnológico, con miras a una creciente inserción en los mercados internacionales y una competencia eficiente en el mercado local. El desarrollo empresarial implica para el Plan, establecer programas de fomento a la innovación y estrategias específicas de productividad y competitividad para las microempresas y para las pymes ${ }^{50}$, centradas en (1) la promoción de la formalización empresarial; (2) el incremento de la productividad y la competitividad de las empresas; (3) la eliminación de barreras de acceso a mercados financieros, tecnológicos y de información; y (4) c no financieros de desarrollo empresarial, (5) el fomento de la asociatividad empresarial (6) facilitar el acceso a las compras estatales y (7) promover y apoyar la cultura del emprendimiento. Al Ministerio de Comercio, Industria y Turismo se le asigna la tarea en el Plan, de promover y apoyar el desarrollo y fortalecimiento de clusters industriales a través de la colaboración entre empresas, y entre estas y entidades de investigación. El Plan también señala la necesidad de regionalizar la política de competitividad a través de la conformación de Consejos Regionales de Competitividad vinculados al Sistema Nacional de Competitividad que está liderado por la Alta Consejería para este fin.

Todos estos instrumentos deben ser articulados hacia las organizaciones del campo artístico y cultural, lo que implica visibilizarlo como generador de empleo y motor de crecimiento, ante la sociedad y ante las instituciones encargadas de liderar la implementación de las políticas descritas, en particular, el Ministerio de Comercio, Industria y Turismo, el Servicio Nacional de Aprendizaje (SENA), el Sistema Nacional de Competitividad y las Entidades Territoriales (Municipios y Departamentos) quienes participarán de manera importante en los consejos

\footnotetext{
${ }^{50}$ Plan Nacional de Desarrollo: Estado Comunitario, Desarrollo para Todos. Capitulo 4. numeral 4.2.1.5
} 
regionales de competitividad, espacios locales que son vitales para el desarrollo de las Industrias Culturales en Colombia.

Sin duda la Agenda Interna para la productividad y la competitividad del Sector Cultura, Medios y Publicidad será la carta de navegación para la implementación de todas las acciones de fomento a las industrias culturales, incluidas las del campo artístico. La propuesta institucional que se cristalizó en este documento debe permitir el acercamiento a los demás actores de la política pública de fomento a la competitividad, el emprendimiento y el desarrollo de las Mipymes, y es la base de la construcción de las agendas intersectoriales que implica el despliegue de una política de apoyo a las industrias culturales en el país.

En el caso de Cali, se lograron, en términos de indicadores y cifras, buenos resultados, pero después de todo el proceso los diferentes emprendimientos aún no están preparados para constituirse como empresas ni competir en el mercado para aportar al "desarrollo económico de la región" y convertirse en "factor de desarrollo sostenible" (plan para las artes 206-2010), como lo plantean las leyes. Todo esto, a pesar de la existencia de un Comité Técnico de Competitividad para las Industrias Culturales, que funciona a nivel nacional y ha sido creado en el marco de éstas políticas para garantizar su implementación y desarrollo.

El Proyecto de Industrias Culturales de Cali terminó su proceso de creación de los emprendimientos de la ciudad, sin desligarse de éstos y ofreciendo aún espacios de consultoría en beneficio del fortalecimiento del sector. No obstante, se hacen evidentes distintas situaciones que están enmarcadas en la Ley y que seguramente se repiten en los distintos proyectos desarrollados en otras regiones del país.

El esfuerzo conjunto de los distintos actores y sectores sociales ha dado sus frutos, con la aparición de nuevas empresas, fondos de capital semilla, políticas que amparan a la cultura e indicadores que incluyen al sector cultural dentro de la economía nacional. Sin embargo, es obvio que este tipo de procesos se 
consolidan a largo plazo, por lo que por ahora lo que queda es seguir su ejecución, evaluación y mejoramiento de las estrategias para lograr que la cultura se posicione como motor de desarrollo para la ciudad, entendiéndolo como "proceso de desarrollo económico sustentable en un territorio delimitado dentro de un contexto histórico, que genera un bienestar para el conjunto de sus miembros, a partir de potenciar las capacidades instaladas (recursos humanos, económicos y culturales), en el marco de procesos políticos participativos y democráticos" (Boisier, Clemente, Arroyo) ${ }^{51}$.

De la mano de los resultados obtenidos, en el caso particular del proyecto de Industrias Culturales de Cali, luego de conocer su experiencia, vale la pena aportar que es necesaria una estrategia de comunicación previa y socialización de la Ley (o las leyes en general) para que los emprendedores de la cultura conozcan los beneficios y planes a los que pueden acogerse. Así, éstos podrán ser además partícipes activos y no simples receptores, tal como lo plantea Daniel Arroyo en su texto: La Planificación del Desarrollo local en el marco de la emergencia, especificando que el desarrollo local es un desarrollo "desde abajo", desde el territorio para mejorar las condiciones de vida del lugar. Lograr esto sería un claro ejemplo de descentralización en el que la productividad pueda ser un primer paso para la resolución de las necesidades y el mejoramiento de la calidad de vida de toda la población y no sólo de los integrantes de los 75 emprendimientos que se vieron beneficiados con el proyecto. Los canales de comunicación deben ser una herramienta fundamental de información y participación.

Otro aspecto que se debe mejorar en la implementación de programas y políticas públicas debe ser, en este caso, la formación de públicos consumidores de la industria cultural. Durante un diagnóstico, además de identificar que las necesidades de cada sector y emprendimiento son distintas, se hace evidente que la aplicación de soluciones depende de las características de la población, de su estructura y niveles de pobreza. Es por esto, que no sólo los productores deben ser capacitados, sino también los

\footnotetext{
${ }^{51}$ Módulo 3: Desarrollo Local. Seminario de Estado y Procesos Sociales. PLANGESCO 2011.
} 
consumidores para lograr cerrar la cadena productiva y hacer realmente que la política de gobierno municipal (refiriéndome al proyecto de Industrias Culturales de Cali) aporte al desarrollo productivo y local, que los artistas puedan vender lo que saben hacer y que los ciudadanos puedan consumir productos que los satisfagan según sus necesidades e intereses.

Finalmente, y teniendo en cuenta que Cali es un municipio que se ha identificado con un perfil turístico y cultural, vale la pena pensar la aplicación de la Ley de Cultura y la implementación de programas de emprendimiento en otras ciudades como alternativas económicas a la actualidad de Colombia, donde aún el sector de la industria pesada es débil, cada día es menor la inversión real para hacer el campo productivo y donde, gracias o por culpa del TLC (Tratado de Libre Comercio) con Estados Unidos, compraremos más de lo que vendemos. Así las cosas, el turismo y la cultura pueden fortalecerse para ser el servicio que se venda a nivel global, aportando al desarrollo de nuestro territorio.

\subsection{Argentina}

En el caso de Argentina, el país y en particular la Capital Federal, cuenta con una nutrida oferta cultural de carácter gubernamental y de iniciativas sociales más espontáneas, que vinculan a distintos públicos con distintas expresiones y formatos.

Buenos Aires y La Plata tienen gran variedad de centros culturales subsidiados y auto gestionados, con programación cultural y artística de gran calidad que compite con la oferta de los grandes shows y espacios de alta cultura como son los teatros, galerías y museos, y sin embargo, no dejan de aparecer expresiones urbanas de distinta índole (gráfica urbana, performances e intervenciones), que se apropian y recuperan espacios para comunicar sus inquietudes con creatividad a la comunidad.

En los últimos años, con cambio de gobierno incluido, el país ha atravesado transformaciones positivas en el campo de las leyes y el acceso a la cultura, 
como es el caso de la Ley de Habilitación de Espacios Culturales ${ }^{52}$, que permitió a muchos colectivos acceder a un lugar físico para el desarrollo de sus actividades y seguir potenciando el escenario alternativo y más cercano a los públicos barriales. "En dichos establecimientos pueden realizarse, además, ensayos, seminarios, talleres, clases y/o cualquier actividad de carácter educativa y formativa relacionada con todas las manifestaciones tangibles e intangibles del arte y la cultura" ${ }^{23}$.

También cabe mencionar el caso de la Ley de Medios ${ }^{54}$ que licenció canales de radio y televisión para que pudieran ejercer su oficio de manera legal e integral, accediendo a recursos para mejorar su infraestructura y configurarse como proyectos sostenibles y sustentables. "El objeto primordial de la actividad brindada por los servicios regulados en la presente es la promoción de la diversidad y la universalidad en el acceso y la participación, implicando ello igualdad de oportunidades de todos los habitantes de la Nación para acceder a los beneficios de su prestación. En particular, importa la satisfacción de las necesidades de información y comunicación social de las comunidades en que los medios estén instalados y alcanzan en su área de cobertura o prestación" 55 .

Por último, el proceso de asociativismo y cooperativización ${ }^{56}$, ejecutado por el Ministerio de Desarrollo Social, alentó a la recuperación de muchas fábricas y en lo que compete a la presente tesis, a la organización de muchos emprendimientos comunicacionales y culturales, que actualmente conformados como cooperativas de trabajo, asociaciones civiles u organizaciones sociales, pueden acceder a subsidios del Estado y a convocatorias de carácter privado para el desarrollo de proyectos.

\footnotetext{
52 http://leymeca.com.ar/docs/ley centros culturales.pdf (MECA- Movimiento de espacios culturales y artísticos). Ley aprobada en 2015.

53 Idem

${ }^{54}$ http://www1.hcdn.gov.ar/dependencias/dip/L\%2026522.pdf Ley 26.522 de Servicios de Comunicación Audiovisual.

55 Idem

${ }^{56}$ http://www.cnct.org.ar/nueva-resolucion-del-inaes-sobre-cooperativas-de-trabajo Resolución 4664/13 INAES - Instituto Nacional de Asociativismo y Economía Social
} 
En Argentina, como en otros países, se ha venido potenciando el campo de las industrias culturales y el emprendimiento, y es por esto que existen distintos mecanismos como los subsidios, el mecenazgo y la responsabilidad social empresaria, que destinan recursos económicos para impulsar el trabajo de un sinnúmero de organizaciones y proyectos e intentan dejar capacidades instaladas para que sigan trabajando de manera autónoma. Si bien no existe una Ley de cultura ni de industrias culturales como tal, en Argentina, durante el período histórico en el que se inscribe esta tesis, se presentó una coyuntura óptima para el desarrollo de nuevas iniciativas a pesar del cambio político y de gobierno; coyuntura que dejó a muchas organizaciones fortalecidas y empoderadas para continuar con su trabajo, ideales y luchas.

En un apartado posterior se presentará una lista que sirve de guía para el acceso a recursos económicos y técnicos.

\section{PRESENTACIÓN DE EXPERIENCIAS}

El desarrollo de este trabajo consiste en la revisión de los recorridos de la Minga de Muralistas de los Pueblos y Volver a Habitar, a través de internet y específicamente de las redes sociales, partiendo de mi experiencia personal en Gráfica Mestiza, como plataforma de gestión y medio de divulgación.

Además de la participación en eventos relacionados con intervenciones urbanas, talleres y demás actividades en las que se vinculen los artistas con la comunidad.

Las experiencias más lejanas serán documentadas mediante la revisión de páginas web y entrevistas virtuales, potenciando el aprovechamiento y uso de las redes sociales y demás aplicaciones digitales gratuitas, como herramientas de producción y gestión.

Al final, espero producir un documento tipo manual que cumpla con la estética del tema desarrollado y que pueda estar disponible en distintos soportes para 
su efectiva difusión.

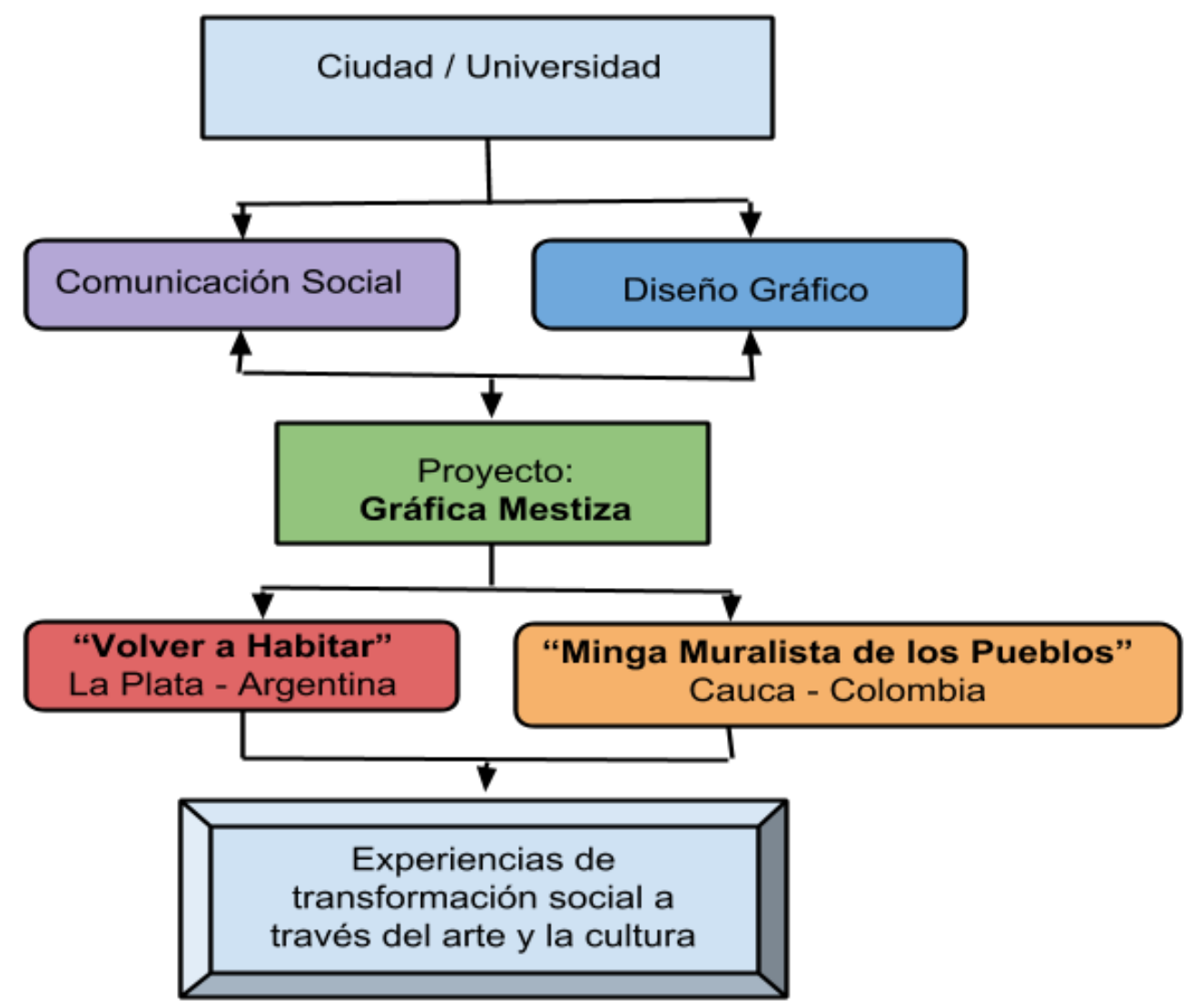

\subsection{Sistematización}

Existen varios conceptos que intentan definir la sistematización, pero tal vez todos se centran en reconocer que desde la práctica se genera conocimiento. En mi proyecto aplicaré la sistematización como un proceso de reconstrucción y reflexión analítica sobre una experiencia (varias), sus actores, las acciones que se realizaron y los contextos en que se dieron. Mediante diferentes mecanismos en los que se interprete lo sucedido para comprenderlo e identificar aprendizajes. Esto permitirá obtener conocimientos consistentes y sustentados que pueden ser confrontados con otras experiencias similares y con el conocimiento teórico existente, y así contribuir a una acumulación de conocimientos generados desde y para la práctica ${ }^{57}$.

\footnotetext{
${ }^{57}$ Guía de sistematización de Experiencias: Haciendo memoria de las Redes Sociales de Apoyo (RSA). Ministerio de Protección Social. Colombia, 2009.
} 
Por el momento los pasos a seguir se basan en la experiencia de R. M Alfaro y están enfocados a reconocer que el trabajo práctico de investigación nos pone frente a sujetos de la comunicación y por tanto, se deben observar las relaciones que se tejen entre sí. También es fundamental concebir la comunicación como un ejercicio de participación y democracia, que a su vez es la herramienta para identificar problemas, conflictos e inconformidades en el plano de la injusticia social.

En este sentido, la comunicación dentro de la práctica es el objeto de estudio, la herramienta y debe ser el resultado o propósito en términos de educación y formación para la comunidad, que les ayude en el "proceso de encuentro del sujeto consigo mismo y con su realidad" (P. Freire).

Durante todo el proceso que irá desde el contacto con los artistas y colectivos de trabajo a través de redes sociales, hasta la realización de entrevistas, encuentros e intervenciones, se aplicará el método de observación participante descrito por R. Guber, que me permitirá seguramente conocer a fondo el desarrollo de las actividades, las perspectivas de sus actores, su organización, sus relaciones de comunicación, y a su vez construir y aportar al proceso. Sin embargo, también será necesaria la reflexividad como método de análisis, que implica la separación de la "experiencia para iluminarla, comprenderla y poder transformarla" (M. Mata).

El producto del trabajo de campo será la sistematización de la información en una especie de manual con relatos de experiencias y estrategias útiles para el desarrollo de otras iniciativas culturales y comunicativas, comunitarias y barriales, acompañado de productos que surjan del proceso y con una estética coherente con el tema y las actividades.

Todo este material hará parte de los contenidos de Gráfica Mestiza para ser compartidos con la comunidad interesada en el tema a través de la web de forma gratuita. 


\subsection{Metodología:}

Se trata de la revisión de los proyectos Volver a Habitar, Minga de Muralistas de los Pueblos y Gráfica Mestiza; entrevistas semi estructuradas realizadas a los responsables de los proyectos, a través de internet y de manera personal.

Adicionalmente, se han contemplado para la preparación de los casos herramientas de desk research (análisis de fuentes secundarias, estudios, informes, etc.), instancias de observación estructurada, relevamiento en medios de comunicación y, en algunos casos, el análisis documental y de espacios, todo ello con la finalidad de sistematizar la información para extraer estrategias significativas que puedan ser socializadas y replicadas en otros proyectos.

\subsection{Gráfica Mestiza}

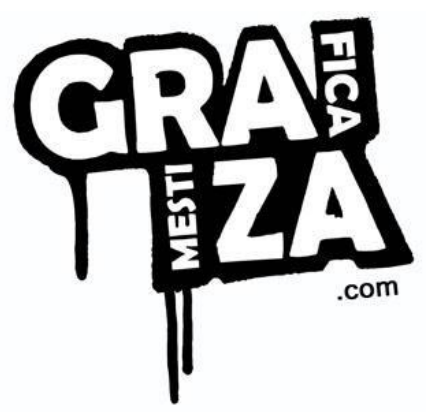

En el 2009 surge la necesidad de plantear un proyecto de emprendimiento para aprovechar el potencial de las expresiones gráficas emergentes en la ciudad de Cali, Colombia. Una necesidad que surge del ámbito universitario, lleno graffitis, murales, publicaciones, entre otras, que relatan la lucha estudiantil en defensa de la educación pública.

Por esa fecha, se estaba implementando la ley de industrias culturales y la oficina de emprendimiento de la Universidad del Valle ofrecía asesorías en planes de negocio para acceder a fondos y capital semilla a través de convocatorias como Ventures, Destapa Futuro y Fondo Emprender, las cuales abrían el espectro empresarial para dar espacio a la cultura.

Es así como, aprovechando la coyuntura, se propuso Gráfica Mestiza como una publicación para hablar sobre la aparición de distintas expresiones en la ciudad. En la página web se presenta este proyecto como: 
Gráfica Mestiza es un espacio alternativo de comunicación para difundir las nuevas propuestas artísticas urbanas que se están gestando en Latinoamérica.

Un medio de socialización, discusión e intercambio de conocimientos técnicos, artísticos, sociales y culturales, donde tienen cabida los expertos, nuevos artistas y todos aquellos interesados en conocer las manifestaciones culturales que se están produciendo en la patria grande.

Intentando reconocer la identidad gráfica y cultural de nuestra ciudad, de Colombia y Latinoamérica llegamos al término "mestizaje gráfico", similar al de la música mestiza, en donde se pueden encontrar y disfrutar las mezclas y simbiosis que representan los diferentes artistas latinoamericanos, sea graffiti, street art, arte urbano o arte callejero ${ }^{58}$.

Agregaría que hoy en día este mestizaje de gráficas urbanas cada vez más trasciende los formatos y técnicas, pero sobre todo, los espacios para llegar también a lugares más rurales.

Actualmente, Gráfica Mestiza se encuentra en la edición No. 4 de su revista impresa y logró la publicación de un libro titulado Mala Fama, que compila a distintos artistas gráficos y populares, además de proyectos de la ciudad de Cali.

Como proyecto académico-cultural ha accedido a distintos fondos de fomento de parte del gobierno y la empresa privada, que buscan incentivar el desarrollo social dando cumplimiento a las leyes de cultura actuales.

Hoy en día Gráfica Mestiza se ha logrado consolidar como un medio de comunicación de carácter artístico, cultural e investigativo enfocado al arte

\footnotetext{
${ }^{58}$ http://www.graficamestiza.com/index.php/quienes-somos
} 
urbano latinoamericano, ilustración, diseño y cultura alternativa a través de su sitio web, revistas, foros y eventos.

\subsection{Minga Artística de Muralistas de los Pueblos ${ }^{59}$}

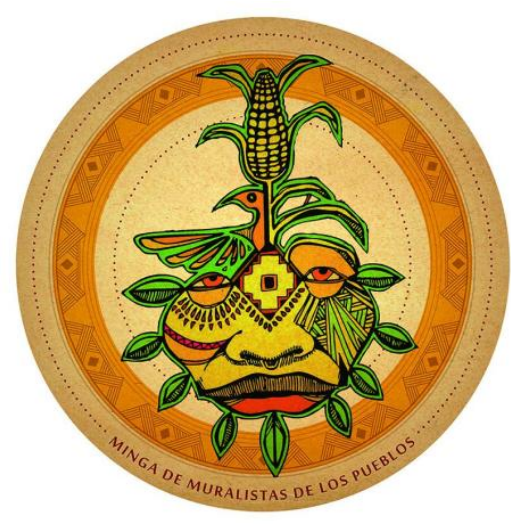

Qué mejor estrategia que una minga para convocar a la comunidad al trabajo colectivo, que en este caso, busca cambiar la cara de un municipio rural, integrar a sus habitantes $y$ promover el turismo.

Alberto Velasco ${ }^{60}$ fue el responsable de haber reunido cerca de 200 personas para cambiarle la cara a Toribío, el pueblo más azotado por las Farc en toda su historia. Desde 1979, este municipio enclavado en las montañas del norte del Cauca ha sufrido más de 600 hostigamientos y esta guerrilla se lo ha tomado un centenar de veces. Como resultado, en el casco urbano de Toribío se encuentran varias casas destruidas que se han convertido en trincheras desde las que la Policía responde a los continuos ataques.

Este paisaje de desolación cambió radicalmente en octubre de 2013. Durante una semana, 40 artistas de Italia, México, Ecuador y varias ciudades de Colombia pintaron más de 130 murales alusivos a los mitos de los indígenas Nasa y a su lucha por resistir a una guerra que se ha ensañado contra ellos. Velasco cuenta que los policías querían impedirles que pintaran sus trincheras, pero cuando vieron a los niños del pueblo decididos a intervenir esos espacios empezaron a retroceder.

\footnotetext{
59 PRIMERA MINGA ARTÍSTICA DE MURALISTAS DE LOS PUEBLOS, MUNICIPIO DE TORIBIO CAUCA, EN EL MARCO DEL IV ENCUENTRO CULTURAL ALVARO ULCUE CHOCUE 2013. KWE'SX KIWE BITE'JN Génesis de la Minga: https://www.youtube.com/watch?v=18QYYel-K80

${ }^{60}$ El hombre de los murales: http://pacifista.co/el-hombre-de-los-murales/
} 
"Lo que no habían logrado los guerrilleros con las balas lo hicimos nosotros con nuestras herramientas", dice Velasco emocionado ${ }^{61}$.

La minga inició con un ritual de "abrir camino" y luego se recibieron las orientaciones de los mayores y las autoridades tradicionales, esto con el fin de que todo lo que se plasme en los murales sea participativo. A partir de estas orientaciones los artistas hicieron los respectivos bocetos de las obras a realizar para luego socializarlos hasta lograr el consenso.

En las noches de la minga se desarrollaron actividades culturales, deportivas y video foros, con la intención de hacer lúdica la jornada durante la semana y de integrar a otras personas de la población.

Al terminar los murales se hizo una entrega formal a la comunidad del casco urbano, haciendo un recorrido por las locaciones intervenidas, y para cerrar, se convocó a un acto cultural en la plaza pública, con la participación de las autoridades tradicionales y espirituales.

Esta minga se pronunció contra todos los frentes armados presentes en la zona (ejército, guerrilla y paramilitares) y logró poner en la agenda de los medios nacionales e internacionales este territorio tan olvidado por el Estado colombiano.

\subsection{Volver a Habitar}

Luxor comenzó a intervenir paredes de la ciudad de La Plata en el 2010. Tal como sostienen Di María et al. (2011), el artista concibe sus pinturas en el espacio público como graffiti y como mural al mismo tiempo, esto por las características del soporte y por

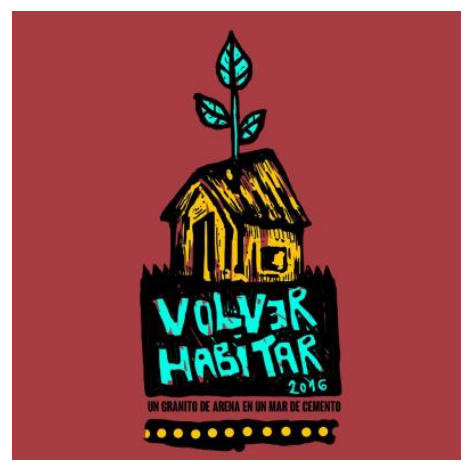
la narratividad. Así mismo, ve en el uso de este tipo de dispositivo, la resistencia y la canalización de una disputa simbólica y la posibilidad de

\footnotetext{
${ }^{61} \mathrm{El}$ hombre de los murales: http://pacifista.co/el-hombre-de-los-murales/
} 
interpelar, no sólo al transeúnte, sino también a otros a intervenir ese mismo espacio generando un diálogo con otras obras y graffitis ${ }^{62}$.

$Y$ es que al transitar por los barrios platenses se siente la legitimidad que tiene el artista entre su comunidad, porque además de pintar, Luxor ha gestado el encuentro entre vecinos, la apropiación de los espacios públicos como punto de encuentro y la autogestión a través del apoyo de los emprendimientos barriales.

Volver a Habitar es un proyecto que nace de la necesidad de recuperar los barrios afectados por la inundación ocurrida en abril del 2013 y del que hicieron parte un periodista, un fotógrafo, un músico y Luxor, para recorrer los barrios generando una pieza artística de gran formato y una serie de micro documentales que relatan la situación de cada barrio y sus habitantes.

Luxor creó una serie gráfica de "cuidadores" con poderes mágicos para cada barrio, que luego de la charla con vecinos, fueron pintados en la fachada de alguna casa donde hubiese fallecido un familiar. El proceso de intervención no solo dio como resultado bellos murales, sino que también sirvió para que los vecinos se unieran para ayudarse mutuamente y para apropiarse de la restauración de sus propias fachadas. Además, sirvió para descubrir las cifras reales de muertos y desastres causados por la inundación.

El proyecto resalta la idea de "restaurar comunidad" a partir de la realización de un mural, el cual aparece como excusa y como un "ejercicio de memoria". Es decir, el proyecto intenta generar lazos con los vecinos, construir espacios de encuentro, dar a conocer historias de vida, además de registrar las consecuencias de la inundación. A partir de la labor realizada desde "Volver a Habitar" se visualiza una fuerte idea de volver a tejer y rearmar lazos colectivos ${ }^{63}$

\footnotetext{
${ }^{62}$ VII Jornadas de Jóvenes Investigadores: Después de la inundación. Una propuesta para volver a habitar el espacio. Verónica Capasso. Facultad de Bellas Artes (FBA), Universidad Nacional de La Plata (UNLP)

${ }^{63}$ Idem.
} 
Actualmente, Luxor sigue llevando arte a los barrios, haciendo de La Plata un museo a cielo abierto del que hacen parte los vecinos, defendiendo día a día en su quehacer la idea de "democratizar el arte"64.

\section{ESTRATEGIAS Y APRENDIZAJES (Sistematización)}

El recorrido de estas tres experiencias ha sido diverso y las estrategias utilizadas dejan aprendizajes dignos de replicar en nuevos proyectos de distinta índole. A grandes rasgos se mencionan el acceso a convocatorias culturales y de fomento; el trabajo en red; la vinculación con la comunidad y la optimización de las redes sociales como medio de comunicación.

En este apartado se detallarán las estrategias utilizadas y se hará un listado de algunos recursos disponibles que pueden ser utilizados y aplicados en nuevos proyectos, y que han ayudado a potenciar iniciativas.

Los resultados de esta sistematización son el insumo para la confección de un manual o guía para la gestión de proyectos, documento anexo que responde a los objetivos de esta tesis y que será accesible y compartido libremente en formato digital.

\footnotetext{
${ }^{64}$ Democratizar el Arte - Charla TED: https://www.youtube.com/watch?v=R8TdfqXA7zc
} 


\subsection{Estrategias (ejes transversales entre proyectos)}

\begin{tabular}{|c|c|c|c|}
\hline ESTRATEGIAS & Gráfica Mestiza & Minga Muralista & Volver a Habitar \\
\hline Lugar & $\begin{array}{l}\text { Cali - Colombia (con } \\
\text { campo de acción } \\
\text { internacional) }\end{array}$ & $\begin{array}{l}\text { Toribío, Cauca - } \\
\text { Colombia (rural) }\end{array}$ & $\begin{array}{l}\text { La Plata - Argentina } \\
\text { (urbano) }\end{array}$ \\
\hline $\begin{array}{l}\text { ¿De dónde surge la } \\
\text { idea? }\end{array}$ & $\begin{array}{l}\text { - Comunicar, } \\
\text { explorar y } \\
\text { estudiar las } \\
\text { estéticas } \\
\text { emergentes } \\
\text { en la ciudad } \\
\text { - } \\
\text { formar } \\
\text { públicos }\end{array}$ & $\begin{array}{l}\text { - Comunicar y } \\
\text { visibilizar } \\
\text { pacíficamente } \\
\text { la violencia en } \\
\text { el territorio } \\
\text { - } \quad \text { Organizar a } \\
\text { la comunidad }\end{array}$ & $\begin{array}{l}\text { - Comunicar y } \\
\text { visibilizar la } \\
\text { magnitud de } \\
\text { la inundación } \\
\text { de la ciudad } \\
\text { - Unir a los } \\
\text { vecinos }\end{array}$ \\
\hline $\begin{array}{l}\text { ¿Cómo se hizo el } \\
\text { diagnóstico? }\end{array}$ & $\begin{array}{ll}\text { - } & \text { Observación } \\
& \text { participante } \\
\text { - } & \text { Revisión de } \\
& \text { redes sociales } \\
\text { de artistas } \\
\text { - } & \text { Búsqueda de } \\
\text { publicaciones } \\
\text { y proyectos } \\
\text { similares }\end{array}$ & $\begin{array}{l}\text { - } \text { Observación } \\
\text { participante } \\
\text { en el territorio } \\
\text { afectado }\end{array}$ & $\begin{array}{ll}\text { - Observación } \\
\text { participante } \\
\text { - } \quad \text { Visita y } \\
\text { entrevistas en } \\
\text { los barrios } \\
\text { afectados }\end{array}$ \\
\hline Agentes vinculados & $\begin{array}{ll}\text { - } & \text { Proponentes } \\
& \text { del proyecto } \\
\text { - } & \text { Artistas } \\
\text { - } & \text { Secretaría de } \\
& \text { Cultura y } \\
& \text { turismo }\end{array}$ & $\begin{array}{ll}\text { - } & \text { Proponentes } \\
\text { - } & \text { Artistas } \\
& \text { invitados } \\
\text { - } & \text { Comunidad } \\
\text { - } & \text { Municipalidad } \\
\text { - } & \text { Guardia } \\
& \text { Indígena } \\
\text { - } & \text { Ejército }\end{array}$ & $\begin{array}{ll}\text { - } & \text { Artistas } \\
& \text { proponentes } \\
\text { - } & \text { Vecinos }\end{array}$ \\
\hline $\begin{array}{l}\text { ¿Cómo comunicaron } \\
\text { el proyecto? }\end{array}$ & $\begin{array}{ll}\text { - } & \text { Redes } \\
& \text { Sociales: } \\
& \text { Facebook } \\
\text { - } & \text { Correo } \\
& \text { electrónico }\end{array}$ & $\begin{array}{ll}\text { - } & \text { Redes } \\
& \text { Sociales: } \\
& \text { Facebook } \\
\text { - } & \text { Escritura de } \\
\text { proyecto }\end{array}$ & $\begin{array}{ll}\text { - } & \text { Redes } \\
\text { sociales: } \\
\text { Facebook, } \\
\text { Youtube } \\
\text { - } & \text { Plataformas }\end{array}$ \\
\hline
\end{tabular}




\begin{tabular}{|c|c|c|c|}
\hline & $\begin{array}{ll}\text { (boletines y } \\
\text { mailin) } \\
-\quad \text { Página web } \\
-\quad \text { Revista } \\
\text { impresa y } \\
\text { digital } \\
- & \text { Participación } \\
& \text { en eventos }\end{array}$ & $\begin{array}{ll}\text { - } & \text { Medios } \\
& \text { digitales } \\
\text { - } & \text { Reuniones } \\
\text { con la } \\
\text { comunidad }\end{array}$ & $\begin{array}{l}\text { de } \\
\text { recaudación: } \\
\text { Ideame } \\
\text { - Escritura de } \\
\text { proyecto }\end{array}$ \\
\hline $\begin{array}{l}\text { ¿Cómo consiguieron } \\
\text { los fondos? }\end{array}$ & $\begin{array}{ll}\text { - } & \begin{array}{l}\text { Convocatorias } \\
\text { de } \\
\text { emprendimient } \\
\text { o } \\
\text { - }\end{array} \\
\text { Convocatorias } \\
\text { culturales } \\
\text { - } & \text { Venta de } \\
\text { revistas } \\
\text { - Venta de } \\
\text { merchandising } \\
\text { de artistas } \\
\text { Plataformas } \\
\text { de } \\
\text { recaudación: } \\
\text { Ideame }\end{array}$ & $\begin{array}{ll}\text { - } & \text { Entidades } \\
\text { gubernamenta } \\
\text { les } \\
\text { - } \quad \text { Autogestión } \\
\text { - } \quad \text { Comunidad }\end{array}$ & $\begin{array}{ll}\text { - } & \text { Plataformas } \\
& \text { de } \\
& \text { recaudación: } \\
& \text { Ideame } \\
\text { - } & \text { Vecinos } \\
\text { - } & \text { Autogestión } \\
\text { - } & \text { Canje }\end{array}$ \\
\hline $\begin{array}{l}\text { Vinculación con la } \\
\text { comunidad }\end{array}$ & $\begin{array}{ll}\text { - } & \text { Intervencione } \\
\text { s urbanas } \\
\text { - } \quad \text { Conferencias } \\
\text { - } \quad \text { Talleres }\end{array}$ & $\begin{array}{l}\text { - } \quad \text { Minga de } \\
\text { murales }\end{array}$ & $\begin{array}{ll}\text { - } & \text { Murales } \\
\text { - } & \text { Mateada } \\
\text { - } & \text { Cena popular }\end{array}$ \\
\hline $\begin{array}{l}\text { Ejecución y } \\
\text { desarrollo }\end{array}$ & $\begin{array}{l}\text { Trabajo } \\
\text { colectivo y } \\
\text { voluntario de } \\
\text { gestores, } \\
\text { fotógrafos y } \\
\text { escritores }\end{array}$ & $\begin{array}{l}\text { - } \\
\text { colectivo entre } \\
\text { gestores, } \\
\text { artistas y la } \\
\text { comunidad }\end{array}$ & $\begin{array}{l}\text { Trabajo } \\
\text { colectivo de } \\
\text { artista, } \\
\text { periodista, } \\
\text { músico, entre } \\
\text { otros }\end{array}$ \\
\hline Productos & $\begin{array}{ll}\text { - } & \text { Página web } \\
\text { - } & \text { Revistas } \\
& \text { digital e } \\
& \text { impresa } \\
\text { - } & \text { Libros }\end{array}$ & $\begin{array}{ll}\text { - } & \text { Murales } \\
\text { - } & \text { Publicación } \\
\text { en medios } \\
\text { alternativos }\end{array}$ & $\begin{array}{ll}\text { - } & \text { Murales } \\
\text { - } & \text { Clips } \\
\text { documentales } \\
\text { publicados en } \\
\text { Youtube }\end{array}$ \\
\hline
\end{tabular}




\begin{tabular}{|c|c|c|c|}
\hline & $\begin{array}{ll}\text { - } & \text { Stickers } \\
\text { - } & \text { Tienda virtual }\end{array}$ & & \\
\hline Evaluación & $\begin{array}{ll}\text { - } & \text { Cantidad de } \\
\text { visitas a la } & \text { página web } \\
\text { - } & \text { Cantidad de } \\
\text { contactos en } \\
\text { redes sociales } \\
\text { - } \quad \text { Venta de } \\
\text { revistas } \\
\text { - Eventos } \\
\text { gestionados } \\
\text { (como } \\
\text { proponentes e } \\
\text { invitados) } \\
\text { intervencione } \\
\text { s urbanas } \\
\text { gestionadas } \\
\text { Cantidad de } \\
\text { asistentes a } \\
\text { eventos }\end{array}$ & $\begin{array}{ll}\text { - } & \text { Visibilidad en } \\
\text { medios de } & \text { comunicación } \\
\text { - } & \text { Participación } \\
\text { de actores } & \text { armados } \\
\text { - } & \text { Participación } \\
\text { de la } & \text { comunidad } \\
\text { - Cantidad de } \\
\text { murales } \\
\text { alusivos al } \\
\text { conflicto }\end{array}$ & $\begin{array}{ll}\text { - } & \text { Fondos } \\
\text { recaudados } \\
\text { - } & \text { Cantidad de } \\
\text { murales/ } & \text { barrios } \\
\text { - } & \text { Participación } \\
\text { de la } & \text { comunidad } \\
\text { - Visibilidad en } \\
\text { medios de } \\
\text { comunicación } \\
\text { sobre la } \\
\text { situación } \\
\text { Empoderamie } \\
\text { nto de vecinos } \\
\text { y } \\
\text { recuperación } \\
\text { de los barrios }\end{array}$ \\
\hline Logros & $\begin{array}{ll}\text { - } & \text { Página web } \\
\text { - } & 5 \\
& \text { publicaciones } \\
& \text { impresas } \\
- & \text { Red de } \\
& \text { artistas } \\
- & \text { Red de } \\
& \text { colaboradores } \\
\text { (fotógrafos y } \\
\text { escritores) }\end{array}$ & 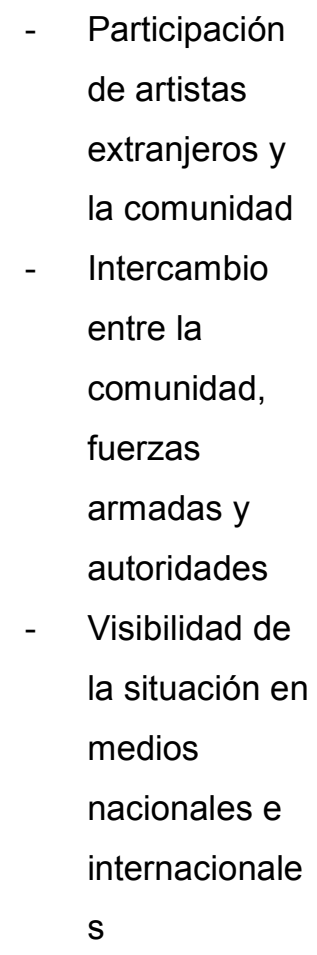 & $\begin{array}{ll}\text { - } & \text { Participación } \\
\text { - } & \text { de los vecinos } \\
& \text { mediosilidad en } \\
\text { - } & \text { Legitimación } \\
& \text { del arte } \\
\text { urbano en la } \\
\text { comunidad }\end{array}$ \\
\hline
\end{tabular}




\begin{tabular}{|c|c|c|c|c|c|c|}
\hline Continuidad & & $\begin{array}{l}\text { Actualización } \\
\text { de página } \\
\text { web } \\
\text { Diseño de } \\
\text { nuevas } \\
\text { publicaciones } \\
\text { Gestión de } \\
\text { agencia de } \\
\text { artistas } \\
\text { Desarrollo de } \\
\text { tienda virtual } \\
\text { con productos } \\
\text { de artistas } \\
\text { Participación } \\
\text { en nuevas } \\
\text { convocatorias } \\
\text { culturales } \\
\text { Gestión de } \\
\text { eventos } \\
\text { Participación } \\
\text { en eventos } \\
\text { internacionale } \\
\text { s } \\
\text { Ampliación de } \\
\text { contactos y } \\
\text { participantes } \\
\text { Grafitería: } \\
\text { apertura de } \\
\text { tienda }\end{array}$ & $\begin{array}{l}- \\
-\end{array}$ & $\begin{array}{l}\text { Nuevas } \\
\text { intervenciones } \\
\text { Actividades } \\
\text { educativas y } \\
\text { culturales con } \\
\text { la comunidad } \\
\text { Expansión a } \\
\text { otros } \\
\text { territorios: } \\
\text { Proyecto } \\
\text { Pinta } \\
\text { Putumayo }\end{array}$ & & $\begin{array}{l}\text { Revisión y } \\
\text { restauración } \\
\text { de murales } \\
\text { Proyecto } \\
\text { Concreto: } \\
\text { intervenciones } \\
\text { en escuelas } \\
\text { Intervencione } \\
\text { s } \\
\text { independiente } \\
\text { s y venta de } \\
\text { arte } \\
\text { Emprendimien } \\
\text { to: Galería de } \\
\text { arte }\end{array}$ \\
\hline
\end{tabular}

${ }^{65}$ Pinta Putumayo: https://www.facebook.com/profile.php?id=100012507278777\&fref=ts Ubicado en la ciudad de Sibundoy, Putumayo - Colombia. 


\section{2. ¿Qué se puede replicar? (experiencias significativas)}

En términos generales las tres experiencias presentadas siguieron un camino similar de vinculación con la comunidad. Todas tuvieron como objetivo principal comunicarse con el entorno y hacer partícipes a los distintos actores sociales de sus propias realidades, propiciando la construcción colectiva y el empoderamiento de sus propios procesos de transformación.

Para lograrlo, se pusieron en marcha distintas estrategias que son dignas de ser replicadas en otros proyectos:

- Trabajo colectivo:

Para que un proyecto logre tener impacto y sea coherente, cualquiera que sea su propósito, debe ser desarrollado colectivamente. Aunque la idea surja de una sola persona, para su ejecución es necesaria la intervención y participación de colegas que aporten sus puntos de vista, su experiencia, habilidades y creatividad.

En el trabajo colectivo logran ponerse en juego distintos saberes que nutren los proyectos y que permiten tener un panorama más amplio de las necesidades y potencialidades en el campo de trabajo.

Esta forma de trabajo permitió a Gráfica Mestiza expandirse a otros países. A pesar de que en su mayoría funciona virtualmente, gracias a la página web, se vincularon escritores, fotógrafos y gestores en Colombia, Ecuador y Argentina principalmente, para dar a conocer el trabajo de artistas, participar en eventos, generar espacios de exposición, intercambio e intervenciones en distintas ciudades de Latinoamérica.

- Red de colaboración e intercambio / emprendimientos:

Para legitimar un proyecto dentro de la comunidad es muy importante hacerla partícipe en distintos niveles. Algunos participantes harán parte orgánica del proyecto y otros colaborarán o harán sus aportes específicos para cierta actividad. 
En el caso de Volver a Habitar, los fondos recaudados por crowfunding ${ }^{66}$ a través de la plataforma Ideame, eran provenientes en su mayoría de los mismos habitantes de La Plata. Así mismo, los vecinos afectados lavaron y pintaron las fachadas de sus casas, aportando a la recuperación del barrio y haciendo parte de su propio proceso ${ }^{67}$.

Por otro lado, emprendimientos locales apoyaron la iniciativa haciendo donaciones en productos tangibles como la pintura para los murales elaborados por Luxor.

Cada actor social desde su posición y posibilidades se vinculó al proyecto y a su propio proceso de construcción colectiva, colaborando y generando una red que se fortalece cada día y que ha permitido el desarrollo de nuevas iniciativas.

- Vinculación de la comunidad:

Los proyectos nunca deben estar aislados de las realidades de su contexto. Es mucho más valioso cuando un proyecto surge de una necesidad o inquietud y busca resolverla. "Cuando los actores involucrados no tienen el protagonismo adecuado o nivel de liderazgo y empoderamiento en el proyecto, se pone en peligro la sostenibilidad de las intervenciones. Dependiendo del tipo de proyecto, la sociedad civil puede ser uno de los interesados más importantes que deben permanecer activos durante toda la vida del proyecto" ${ }^{\circ}$.

En esa medida, será legitimado y contará con mayor apoyo y vinculación de parte de la comunidad, como fue el caso de Volver a Habitar, que logró recaudar en ese entonces 9 mil pesos, provenientes en su mayoría de ciudadanos de la Plata. Así mismo, los moradores de Toribío se apropiaron del muralismo como una herramienta de expresión importante para denunciar los atropellos y crímenes sufridos durante años a manos de los distintos grupos

\footnotetext{
${ }^{66}$ Financiamiento colectivo. Recaudación de dinero a través de plataformas online y redes sociales para el desarrollo de proyectos de distintas índoles. Idea.me es actualmente una de las plataformas más conocidas y utilizadas en Latinoamérica: https://www.idea.me/

${ }^{67}$ http://www.idea.me/projetos/5523/volver-a-habitar

${ }^{68}$ Curso de Gestión de Proyectos de Desarrollo - BID, Módulo de Introducción a la gestión del proyecto, pag.36.
} 
armados. "Nuestros ancestros marcaban en las rocas los sitios sagrados y los límites del territorio. Nosotros hacemos lo mismo con los murales. Es un acto de resistencia y de ejercicio ancestral de gobierno sobre esta tierra". ${ }^{69}$

La Playa es una vereda de casas de ladrillo y bahareque construidas a lado y lado de la carretera. Sus habitantes cultivan hortalizas y crían vacas, cerdos y gallinas. Sobre la fachada del colegio, junto a la vía sin pavimentar, resalta el mural de Óscar Arango, un artista de Cali. El rostro de un niño, una anciana y un hombre de ceño adusto dominan la parte superior de la pared. La mujer se llama Salvadora Silva. Es la más anciana de La Playa. Tiene 103 años y aún les da de comer a las gallinas y camina por el pueblo apoyada en un bastón rústico de madera. El hombre es Honorio Chate, un líder indígena y actual presidente de la junta comunal. Las mujeres de la vereda ayudaron a pintar el maíz capio, el colibrí, la flauta y las palabras Wet Wet Fxizenxi, que completan el cuadro. "Esta pintura es un homenaje a nuestros mayores, que son quienes guían a la comunidad y les enseñan las tradiciones a los niños", explica un líder indígena a través de un megáfono $^{70}$.

La Minga dejó alrededor de 200 pinturas realizadas por 60 artistas, entre los que se encuentra la misma comunidad.

- Participación en concursos y convocatorias:

Esta opción toma gran importancia actualmente, dada la apertura de los países frente a las industrias culturales y al emprendimiento, como parte de su proyecto de crecimiento económico.

En Colombia existen fondos privados como Ventures ${ }^{71}$ y Destapa Futuro ${ }^{72}$, que ofrecen capital semilla a emprendimientos de toda índole, con un

\footnotetext{
${ }^{69}$ Memoria y Resistencia: En el pueblo que sufrió más de 700 ataques guerrilleros http://www.revistaarcadia.com/periodismo-cultural---revista-arcadia/articulo/toribio-vivio-mas-de-700ataques-guerrilleros/57231

70 ídem

${ }^{71}$ Iniciativa de Revista Dinero y Mckinsey \& Company
} 
acompañamiento profesional y con requisitos formales que debe cumplir toda empresa (constitución legal y comercial, plan de negocios, entre otros). No obstante, y a pesar de ser una gran oportunidad económica y de aprendizaje, estos espacios siguen estando muy enfocados a procesos más industriales, quedando así la cultura en desventaja en términos de producción y ganancias económicas.

Por el lado estatal para la cultura, están El Fondo de Desarrollo Cinematográfico $^{73}$, los Fondos Mixtos de Cultura $^{74}$ y las convocatorias de Estímulos de cada provincia.

Mediante estas convocatorias privadas y públicas, Gráfica Mestiza ha podido acceder a mayores recursos para financiar la impresión de publicaciones y viajes de intercambio que posibilitan el desarrollo de eventos y el fortalecimiento del proyecto. Este fue el caso de la gira realizada en Argentina, en la cual se pudieron generar nuevos vínculos a través de la visita a espacios culturales, universidades, tiendas editoriales y proyectos gráficos y sociales ${ }^{75}$.

En Argentina existen fondos específicos para este sector como Puntos de Cultura $^{76}$, Mecenazgo Cultural ${ }^{77}$ y una interesante iniciativa materializada en los Distritos de las artes, diseño, tecnológico, deportivo y audiovisual ${ }^{78}$, que concentran y asesoran el desarrollo de proyectos, generando espacios de intercambio y producción.

- Optimización de redes sociales para comunicar:

Las redes sociales actualmente son la manera más eficiente y económica de comunicar, si se las usa correctamente. Si se entiende la dinámica de los likes,

\footnotetext{
72 http://redemprendedoresbavaria.net/

${ }^{73} \mathrm{http}: / /$ www.proimagenescolombia.com/secciones/fdc/convocatorias/convocatorias.php

${ }^{74} \mathrm{http}: / /$ www.mincultura.gov.co/areas/fomento-regional/sistema-nacional-decultura/Paginas/default.aspx

${ }^{75}$ Gira Argentina: https://www.youtube.com/watch?v=NmshbkgsLOY

${ }^{76}$ http://convocatorias.cultura.gob.ar/pdc

${ }^{77}$ http://www.buenosaires.gob.ar/cultura/mecenazgo

${ }^{78}$ http://www.buenosaires.gob.ar/distritoseconomicos
} 
seguidores, etiquetas, las tendencias, entre otros, se pueden cruzar nuevas fronteras y los límites territoriales ya no serán un obstáculo.

Plataformas como Facebook implican un riesgo a nivel personal en cuanto al uso de la información y a la circulación de datos personales como ubicación, fotografías, parentescos y gustos. Pero si se aprovecha de manera institucional, tiene un gran potencial como herramienta de comunicación masiva. Lo mismo ocurre con las demás redes y plataformas que conectan intereses, actividades y gustos en todo el mundo.

Por ejemplo, Gráfica Mestiza en sus inicios contaba solamente con una cuenta de Flickr ${ }^{79}$ y de Facebook, a través de las cuales comenzaron a seguir artistas y publicaciones similares, respectivamente. Estas dos plataformas le sirvieron para hacer un diagnóstico de personas y lugares en donde la gráfica urbana contaba con visibilidad, además de conocer otras revistas (con similares enfoques o no) que podrían convertirse en sus próximas aliadas. A través de redes sociales empezaron a contactar artistas, a presentar el proyecto, a enterarse de eventos y actividades en otros lugares y cuando se presentó la oportunidad de asistir presencialmente, ya Gráfica Mestiza era conocida por unos cuantos ${ }^{80}$. Ahora Gráfica Mestiza cuenta con 48.784 seguidores en Facebook y continuas visitas a su página web y tienda virtual, lo que genera un flujo constante de contenidos e intercambios y les proporcionó más visibilidad en los motores de búsqueda y la posibilidad de vender pauta publicitaria en sus medios para poder costear sus actividades.

\footnotetext{
${ }^{79}$ Preferida inicialmente por artistas y fotógrafos, que publicaban sus trabajos en la red a manera de portafolio virtual.

${ }^{80}$ La primera participación como colectivo fue en el MOS Quito (Meeting of Styles) junto con 16 artistas colombianos que previamente habían contactado por facebook. El viaje fue autofinanciado y el hospedaje fue un intercambio con una universidad en la cual se hicieron dos murales alusivos a la facultad de comunicación y a la de robótica. En el evento ya varios artistas de otros países hablaban de Gráfica Mestiza y al conocerlos cara a cara y compartir experiencias, fueron otros los contactos que se sumaron a las redes.
} 


\subsection{Amigarse con la tecnología (recursos gratuitos)}

La escritura de proyectos es muy importante porque ordena las ideas, ayuda a planificar, a sistematizar y a acceder a recursos mediante la presentación a convocatorias y concursos. Para esto es necesario que los agentes, líderes o participantes de los proyectos pierdan el temor a la tecnología, conozcan las herramientas gratuitas que existen y le saquen todo el provecho a los dispositivos que tienen disponibles, ya sea una computadora, celular u otros. Digitalizar ciertos procesos les puede ayudar a agilizar el trabajo y a darle visibilidad en otros contextos, atravesando virtualmente límites geográficos.

Existen herramientas gratuitas de gran difusión y mucha masividad, que se han vuelto cada vez más "amigables" con los usuarios, proporcionando entornos de fácil compresión y poniendo a disposición un abanico de opciones.

Unas de las más completas hoy en día pueden ser Google y Facebook. En el caso de Google, cuenta con aplicaciones como el correo electrónico, el calendario, el canal de Youtube y el Drive, asociados todos a una cuenta de mail y muy útiles para centralizar el trabajo de gestión de un proyecto $u$ organización. Puede parecer obvio, pero el correo electrónico es fundamental como herramienta de contacto y comunicación con otras organizaciones, el calendario es muy útil para agendar y planificar actividades, el canal de Youtube permite publicar videos publicitarios, contenido y demás producciones de la organización y el Drive hace las veces de disco duro para guardar diversidad de archivos que están disponibles desde cualquier lugar y dispositivo a través de internet. Lo bueno de este servicio es que es colaborativo y cada integrante de la organización puede ingresar a las aplicaciones con su cuenta, ver el material y hacer sus aportes. Google también cuenta con la herramienta Blogger para crear blogs con plantillas prediseñadas. Ninguna de estas herramientas requiere de un conocimiento experto, pues son muy gráficas e incluso intuitivas y ofrecen un paso a paso que se puede ir siguiendo hasta su comprensión. 


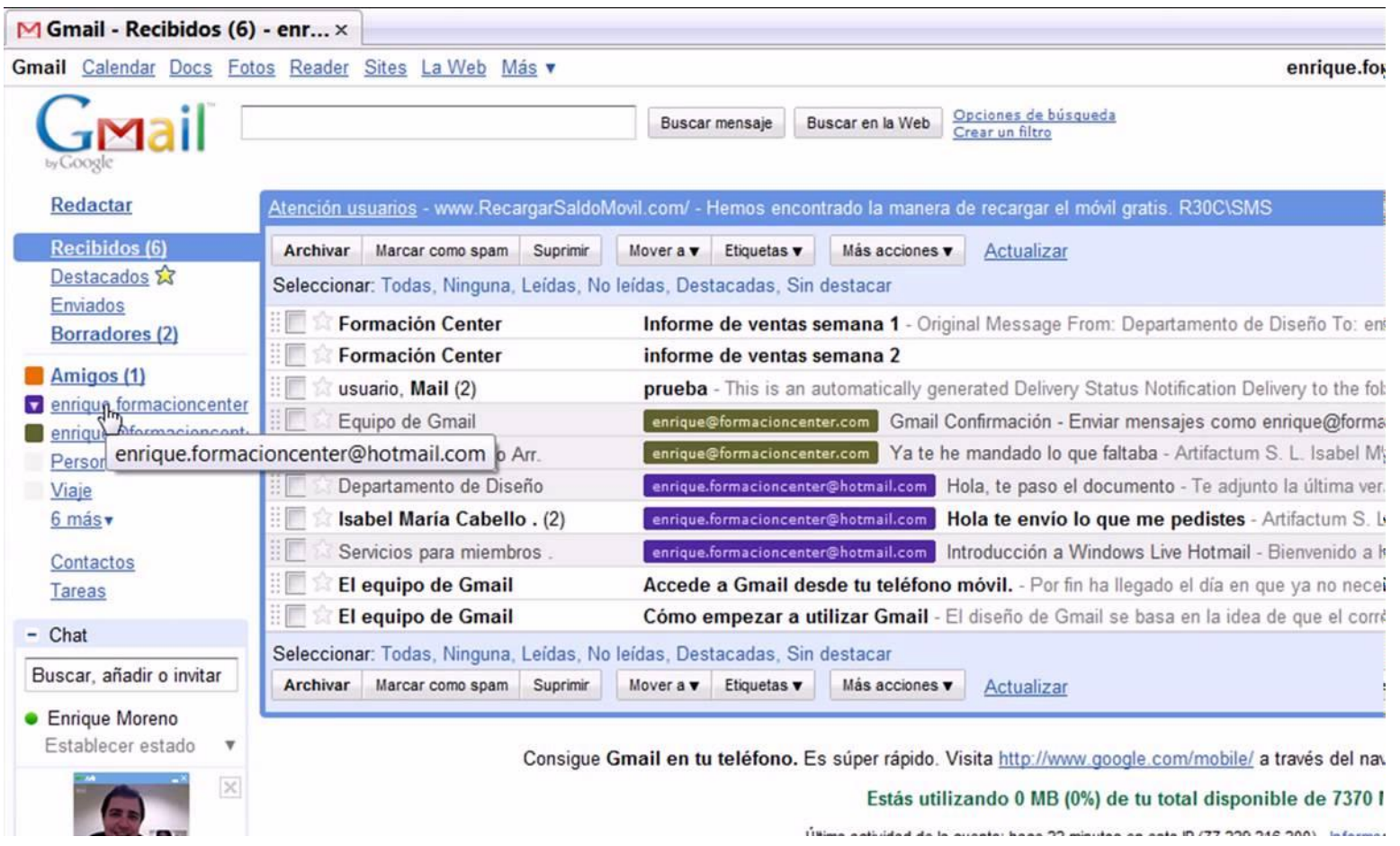

Imagen tomada de internet

El correo electrónico puede clasificarse con etiquetas/carpetas de colores para que los usuarios puedan organizarse según la temática o área del proyecto. Así mismo, se pueden crear grupos de contactos y listas de correos con los mismos u otros criterios de clasificación.

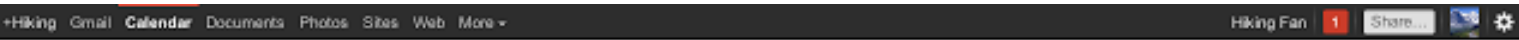

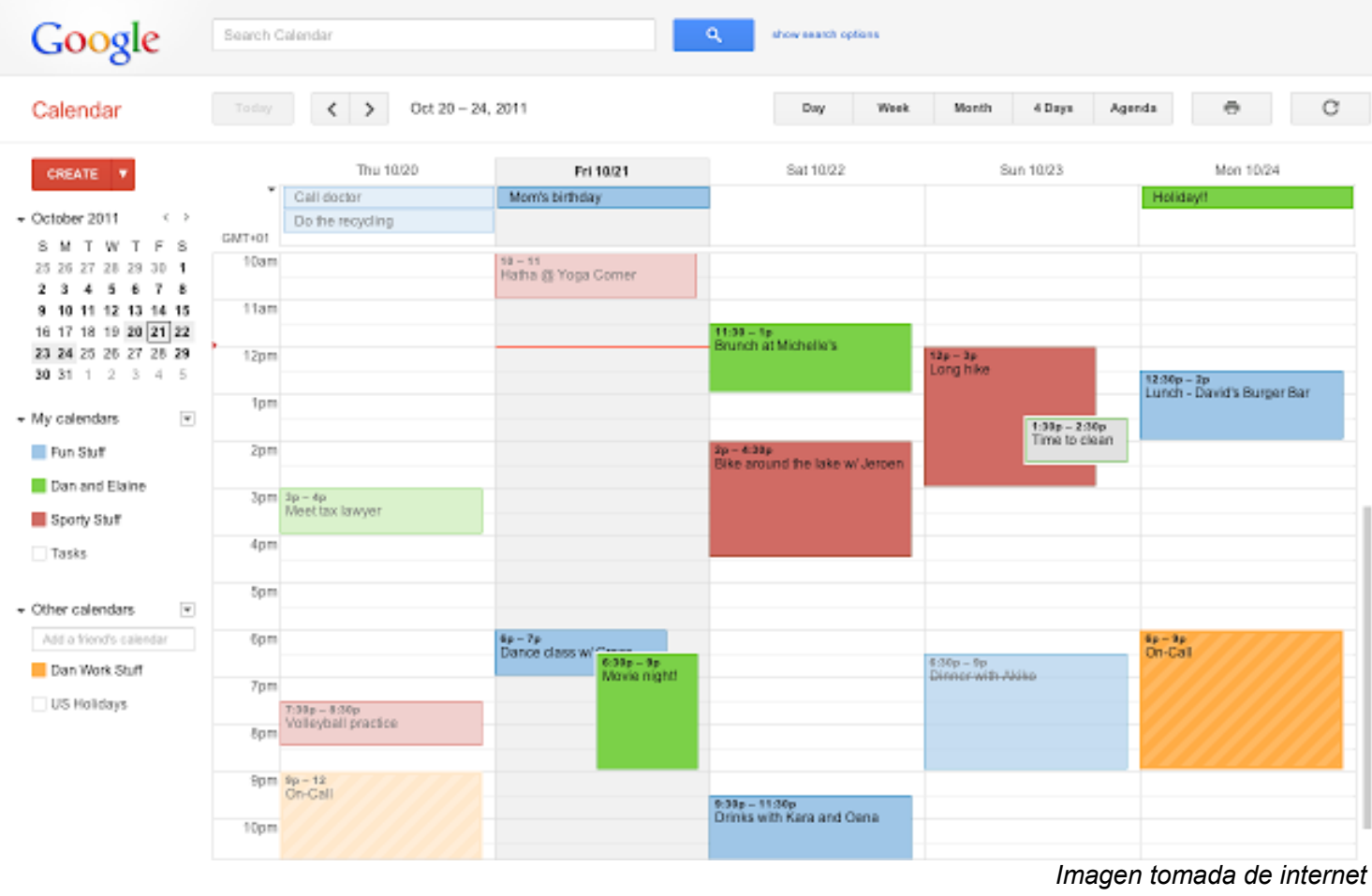


Así mismo, el caso del calendario permite crear eventos clasificados por colores según la actividad, temática, grupo responsable o según el método de organización más conveniente para el proyecto. Cada evento se puede compartir por mail con las personas involucradas, se pueden agregar datos de localización y observaciones y se pueden programar alertas para que, a través de un mensaje, la aplicación nos avise o recuerde que pronto tendremos un evento, reunión o tarea pendiente.

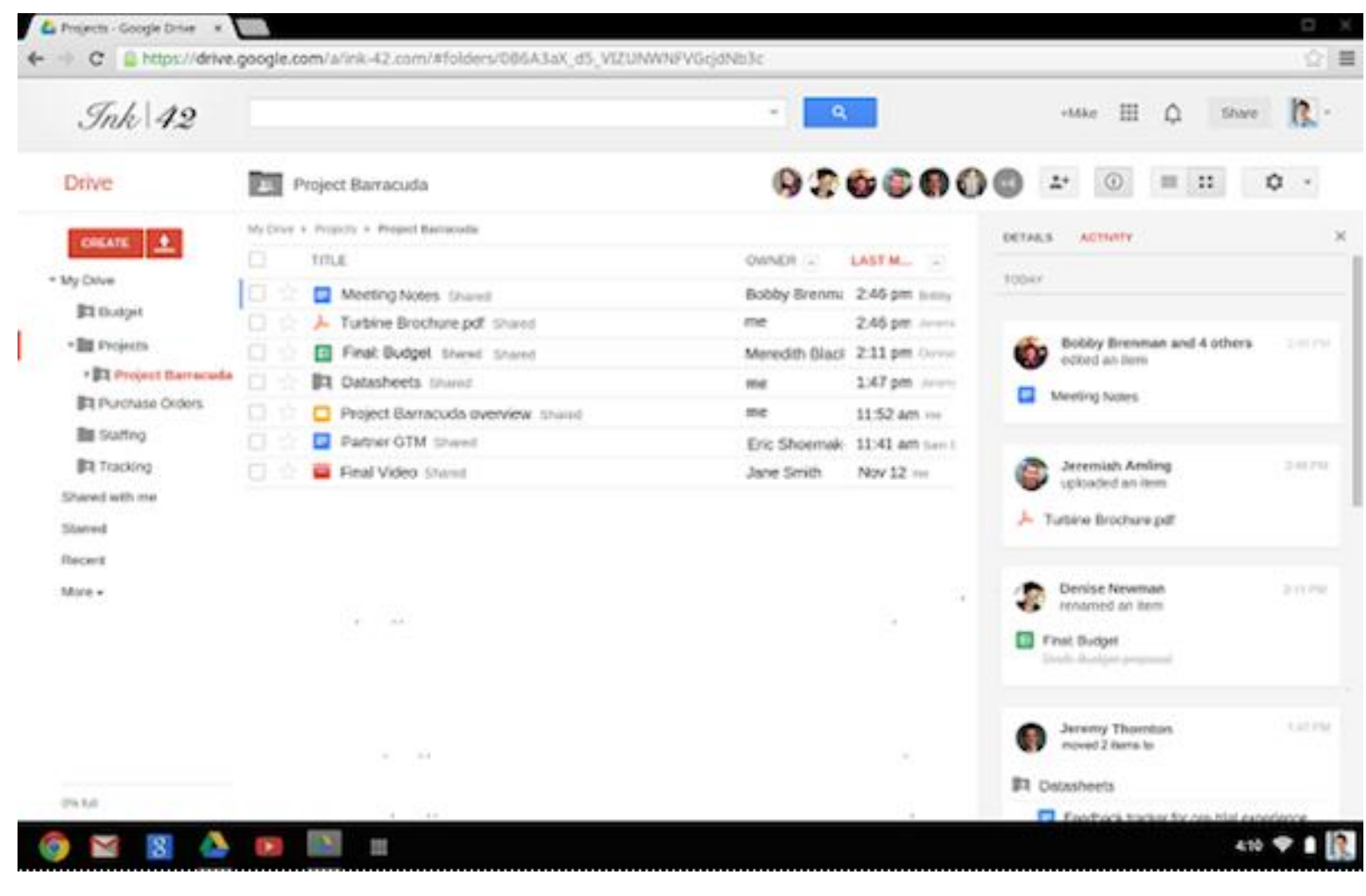

El Drive nos muestra en el costado izquierdo el tipo de archivos que podemos crear dentro de la aplicación o que podemos subir desde nuestra computadora para guardarlos en internet: documentos de texto, presentaciones, hojas de cálculo, pdf, carpetas, entre otros. Separa además los archivos entre los creados por nosotros mismos y los que nos ha compartido otra persona. En el lado derecho nos muestra un historial de la actividad de archivos y personas. En la parte superior nos muestra los usuarios que están conectados actualmente (nuestros contactos) o que tienen acceso al archivo en particular, y en la parte central aparece el listado de los archivos que tenemos. 
En el caso de Facebook, es bien sabido que la gran mayoría de gente e información se mueve a través de este medio por ser más visual, por tener a la vista un resumen de todo en orden cronológico (información que puede ser ampliada con un click) y por ser más instantáneo gracias al chat. Al principio esta red social se veía como un simple espacio de ocio y entretenimiento, pero con el tiempo se fue potenciando al identificarse los alcances a nivel comunicativo, ya que los usuarios pasaron a ser productores de sus propios contenidos (cualquiera que sea la índole, de calidad o no, interesantes o no) y que cada vez son más las mejoras de la herramienta, tales como la posibilidad de enlazar o linkear páginas web, publicar videos y gifs, y ahora la posibilidad de transmitir videos en vivo.

Facebook cuenta con dos interesantes y útiles servicios como son: la fanpage y los eventos. La primera casi que reemplaza las páginas web y permite, al igual que un perfil, crear álbumes de fotos y recibir mensajes, pero de manera más institucional. Los eventos son una estrategia muy útil para convocar público a las actividades y tener un estimado de aceptación y asistencia.

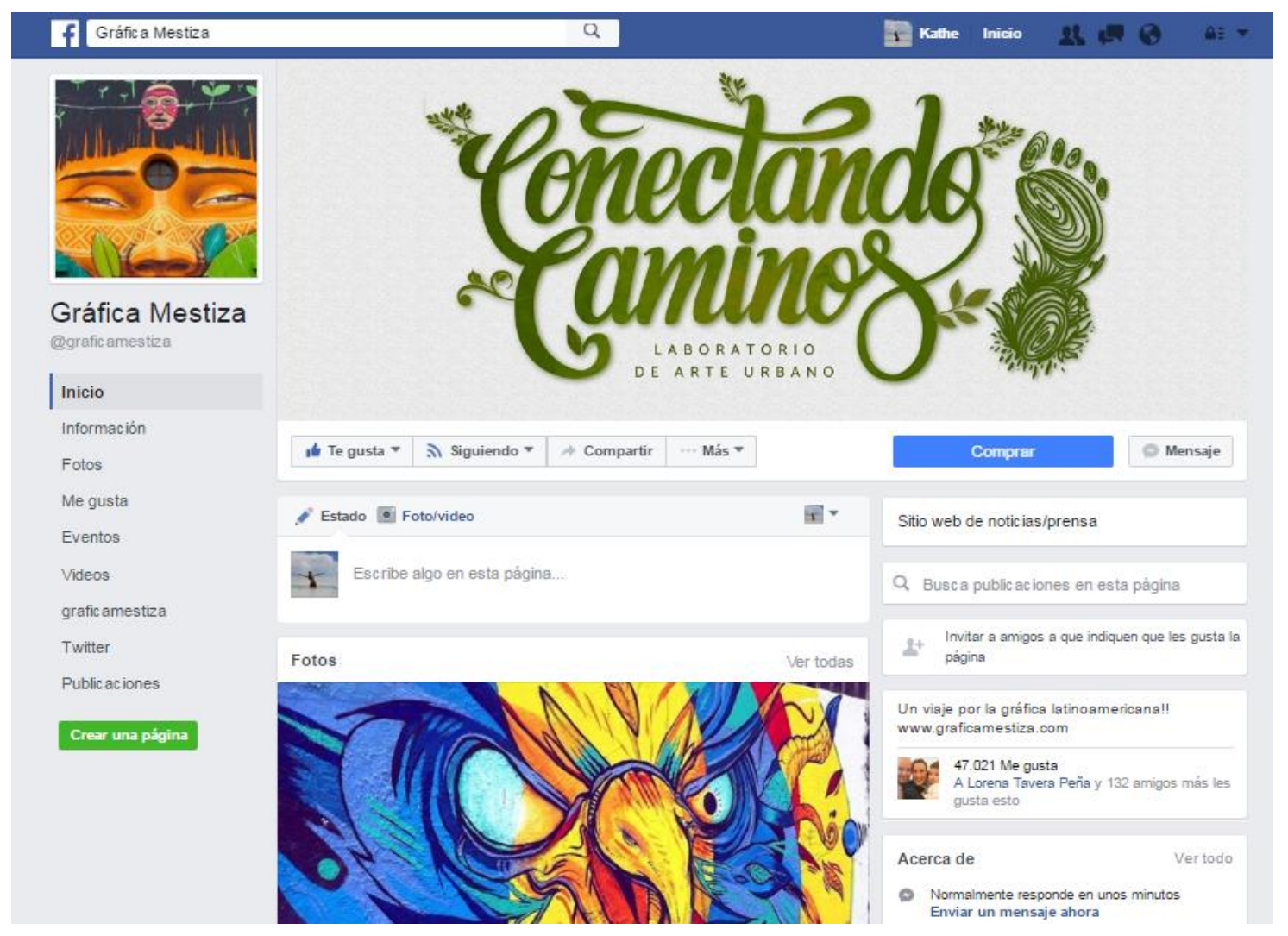




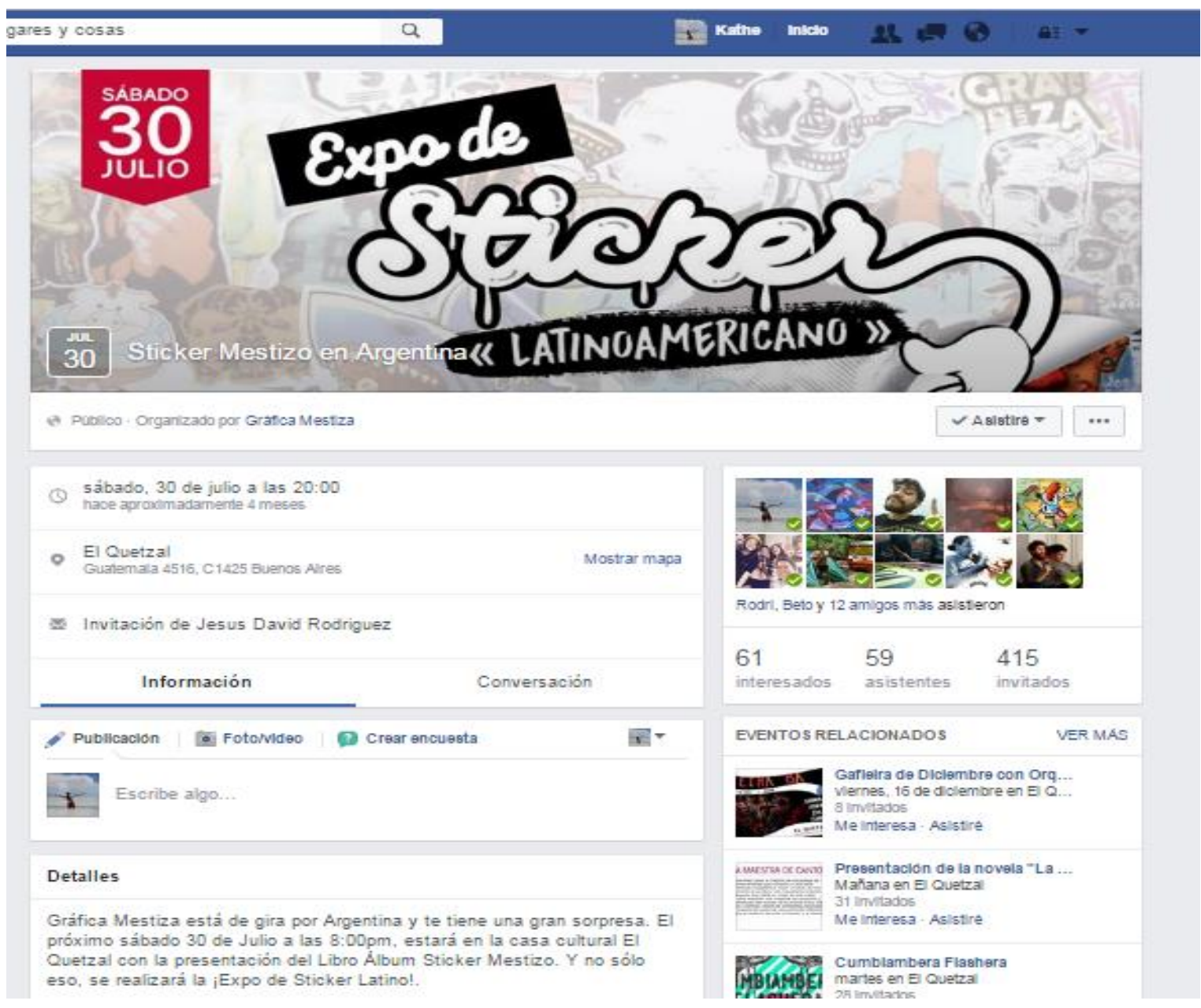

A través de Facebook se puede ir agrandando y nutriendo la red en función de los intereses de nuestra organización o proyecto, podemos contactar y seguir proyectos similares a nuestro campo de trabajo, podemos contactar agrupaciones en otros territorios y aliados estratégicos para seguir nutriendo los procesos.

Existen además otras herramientas y aplicaciones que cumplen funciones más específicas como pueden ser planificar y asignar tareas; diseñar un afiche, tarjeta o volante; crear la infografía u organigrama de algún proceso; hacer una presentación interactiva y multimedial o crear una página web.

Para estas tareas existen las siguientes aplicaciones:

- Trello: Esta herramienta tiene como fin ayudarnos a planificar. Funciona con tarjetas de tareas que se clasifican en: por hacer, en proceso y 
realizado. Cada tarjeta o tarea puede incluir fechas, observaciones, enlaces y por supuesto, las personas encargadas de llevarlas a cabo. Las tarjetas se van moviendo de una categoría a otra en la medida en que va avanzando el proceso.

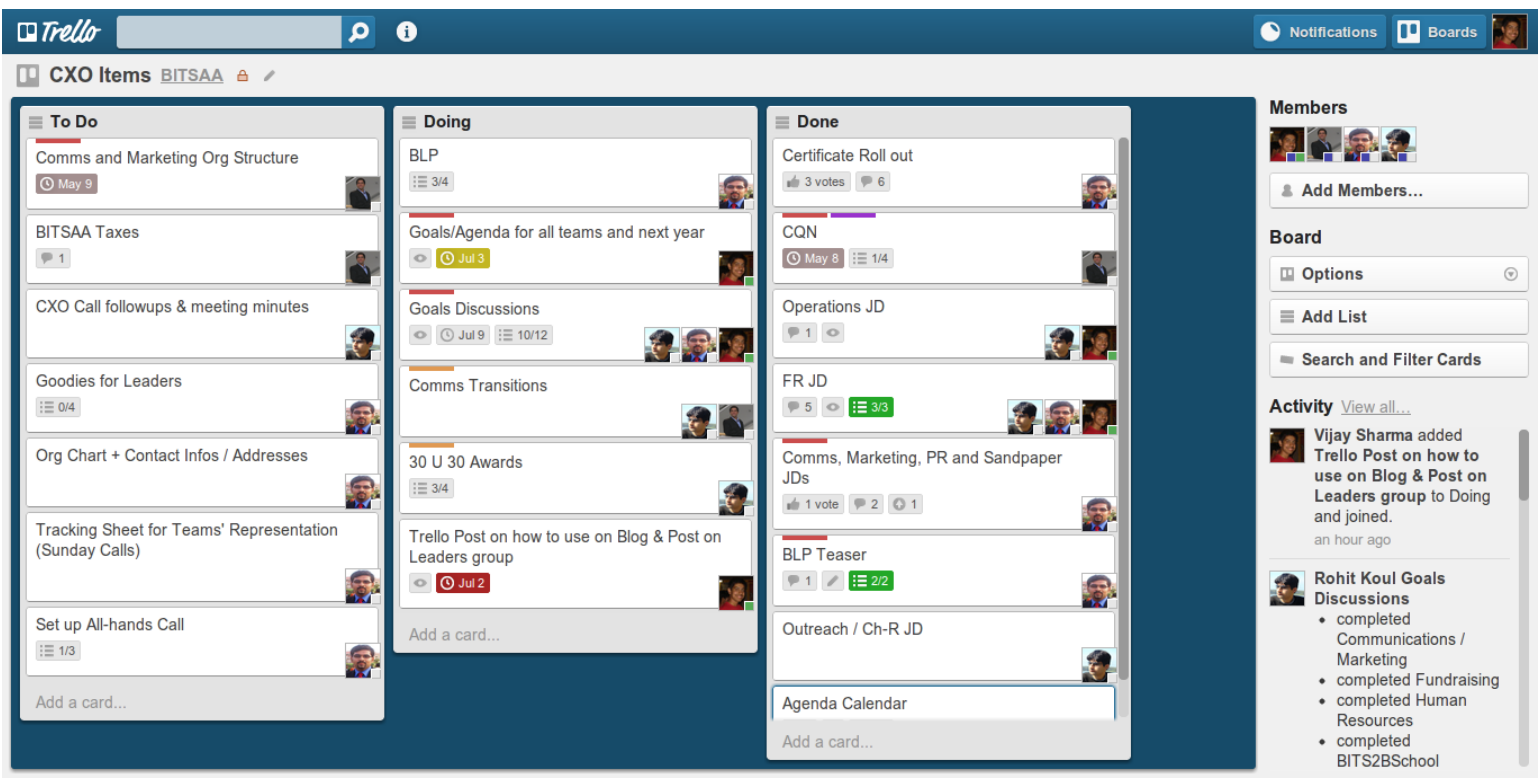

Imagen tomada de internet

- Canva: Esta completa herramienta cuenta con plantillas de medidas predeterminadas para la creación de afiches, tarjetas, diplomas, entre otros, que se pueden enviar por internet o descargar para imprimir. Tiene un gran banco de imágenes, diseños y tipografías que se pueden modificar y combinar para crear diseños según nuestras necesidades.

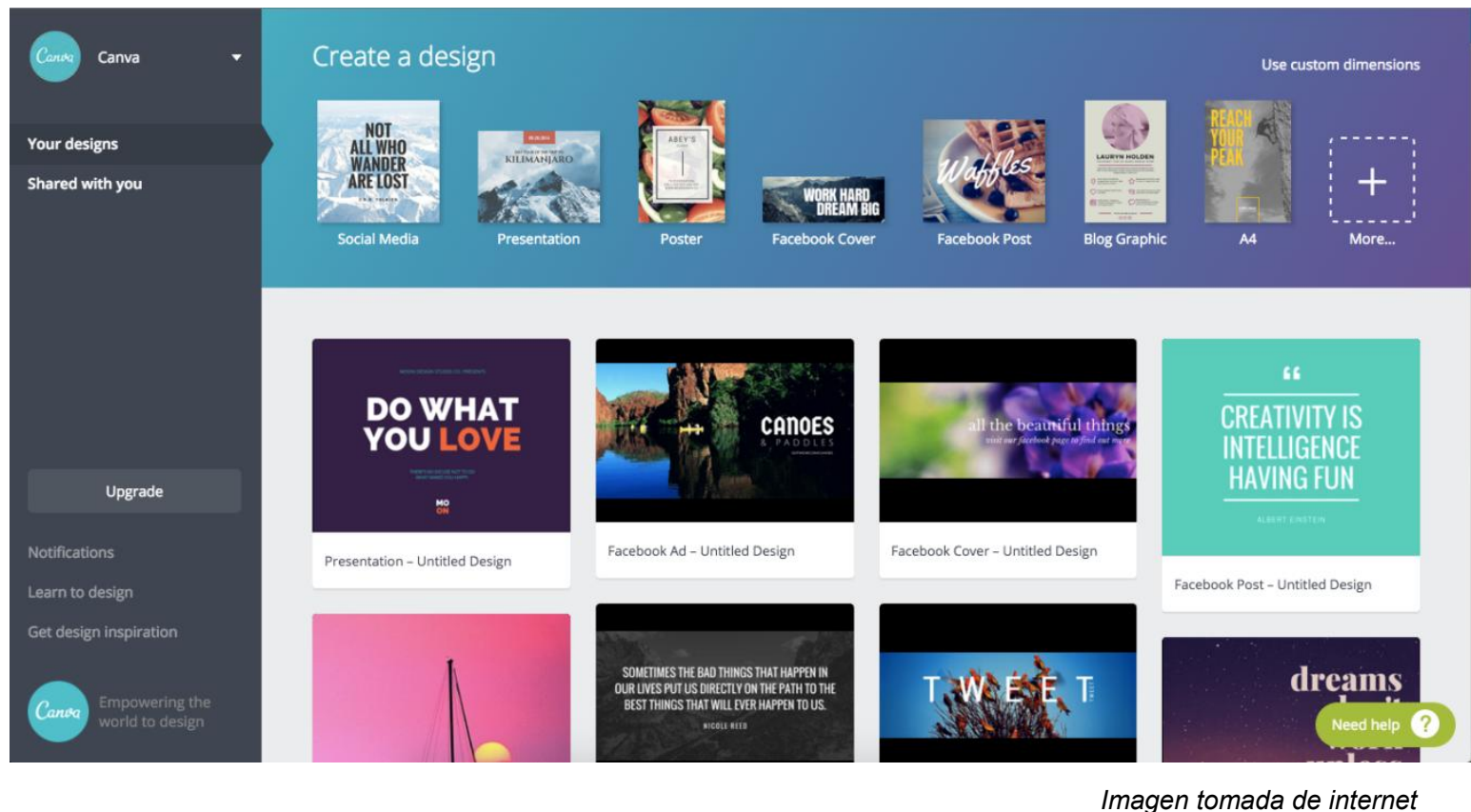



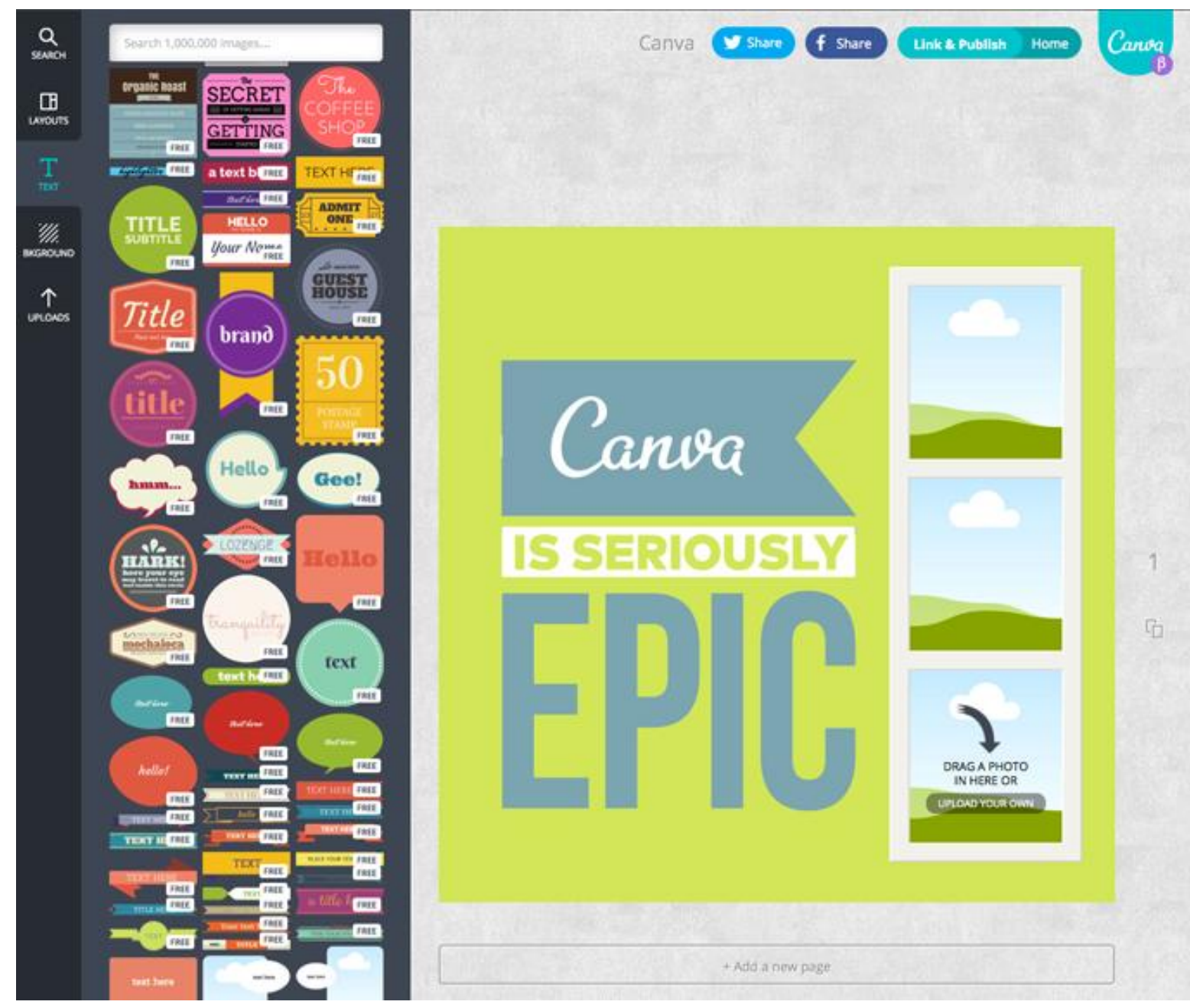

Imagen tomada de internet

- Prezi: Esta aplicación lleva las presentaciones a otro nivel, ya que las hace más interactivas. Parte de una diapositiva general que nos muestra el mapa de la presentación y nos lleva adentrándose a cada tema inserto en marcos. Cada marco puede incluir fotos, videos o enlaces. La presentación puede visualizarse de manera online o se puede descargar. 


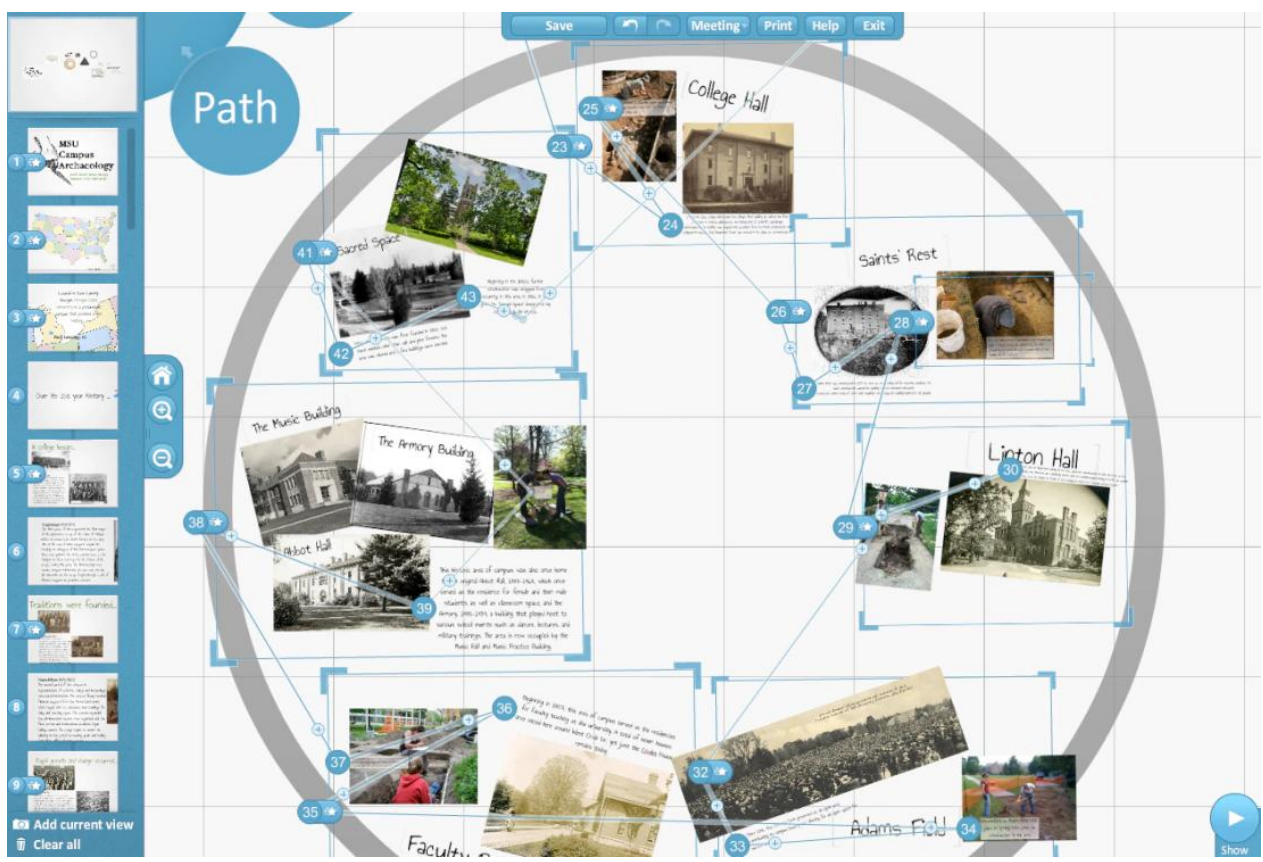

Imagen tomada de internet

- Wix: Al igual que un blog, Wix tiene un sinnúmero de plantillas y de forma gratuita se pueden crear páginas web para publicar información más completa sobre los proyectos.

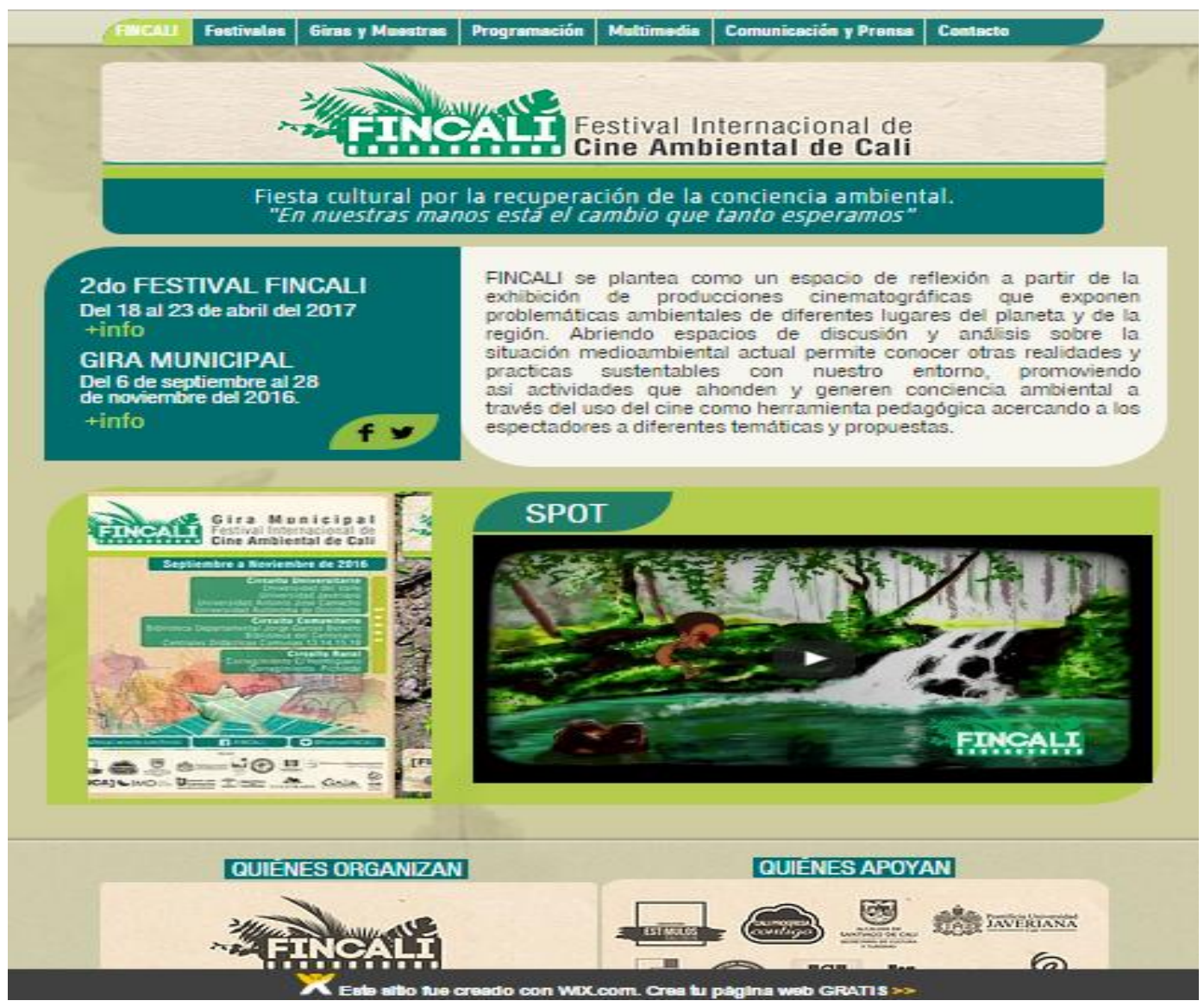

Proyecto cultural 
Algunas de estas aplicaciones están en inglés, pero los íconos y el menú es prácticamente el mismo en todos los casos, ya que con el tiempo se han ido estandarizando, tanto dentro de los programas como en los dispositivos. Todas están disponibles en internet, requieren que nos registremos con una cuenta de mail y en algunos casos cuentan con aplicación para el celular o tablet. La mayoría de elementos son gratuitos, pero si queremos un uso más profesional o servicios más completos, se deben pagar.

Para las redes sociales también hay otras alternativas o complementos como Twitter, Instagram... y suele pensarse que es necesario tener presencia en todas las redes por el simple hecho de estar a la moda. Sin embargo, si se elige la herramienta adecuada para nuestra gestión y se optimiza su alcance comunicativo, bastará, ya que para sostener una red social en necesario tener contenido constantemente, publicar con periodicidad para que nuestras notificaciones lleguen a más gente y para mantener actualizadas nuestras páginas y a nuestros seguidores. Si bien es muy importante la comunicación en nuestros proyectos, también es cierto que es una tarea que requiere tiempo de dedicación y en este caso es preferible tener pocos posteos, pero periódicos y de calidad.

Cabe mencionar que las aplicaciones expuestas son gratuitas, pero son creadas por empresas privadas con fines comerciales, es por esto que aparece publicidad constantemente y recomendaciones de otras páginas que pueden ser de nuestro interés, basados en las búsquedas que hemos hecho en internet, las páginas que hemos visitado o los likes que hemos dado en Facebook. Por otra parte, existe lo que se conoce como software libre, que se refiere a programas gratuitos y de código abierto (que se puede compartir y modificar en su programación con fines de mejoramiento) y que ofrece otras soluciones para el desarrollo de nuestros proyectos. El navegador Mozilla es un ejemplo o el paquete Libre Office para crear documentos de texto, presentaciones y hojas de cálculo, que es el equivalente al paquete comercial de Microsoft. 
Todas estas herramientas son fáciles de manejar, si se les dedica tiempo y atención y no requieren de conocimientos técnicos expertos más allá del uso del dispositivo (computadora, celular, tablet), leer con atención las instrucciones paso a paso, ser creativos y ser conscientes de lo que queremos comunicar (actualmente existen tutoriales en Youtube que nos ayudan a entender $y$ resolver dudas).

\subsubsection{Herramientas Digitales}

No sólo existen programas o aplicaciones digitales que nos sirven para el desarrollo de nuestros proyectos, sino que además hay organizaciones que brindan apoyo y asesorías de manera virtual para fortalecer a otros proyectos y organizaciones sociales, brindando estrategias y herramientas de gestión.

Un buen ejemplo de esto es la plataforma Wingu - Tecnología sin fines de Lucro $\mathrm{AC}^{81}$, cuyos ejes de trabajo son: 1.- capacitación e impacto: talleres presenciales y en línea gratuitos sobre herramientas tecnológicas relacionadas con potenciar el trabajo de las ONGs. 2.- implementación y acompañamiento: a través de servicios personalizados se implementan herramientas y sistemas dentro de las organizaciones para mejorar su gestión. 3.- datos abiertos y tecnología cívica: se promueve la apertura de datos por parte de las organizaciones para la generación de conocimiento, y desarrollo de herramientas web colaborativas que promuevan cuestiones cívicas como transparencia, rendición de cuentas, entre otras.

Desde el 2014 esta plataforma ha logrado fortalecer el trabajo de más de 2.500 organizaciones en México, a través de sus herramientas digitales, talleres y festivales, expandiendo su alcance con subsedes en otros lugares de Latinoamérica, demostrando, como lo dice su coordinadora Ximena Arrieta, que "la tecnología es un habilitador de procesos, nunca debe ser vista como la panacea o la solución a los problemas de las organizaciones. Es muy

\footnotetext{
${ }^{81}$ http://www.winguweb.org/
} 
importante tener muy claros los procesos de una organización para entender cómo la tecnología puede ayudar simplemente a hacerlos más eficientes" ${ }^{\prime 2}$.

Existen otras plataformas que no están enfocadas precisamente en organizaciones sociales, pero que ofrecen cursos virtuales gratuitos de universidades prestigiosas para aquellos con poco tiempo. Para quienes prefieren asistir a clases presenciales, cada vez más aparecen ofertas de formación en oficios y actividades específicas en bibliotecas o centros culturales, que pueden ayudar a fortalecer nuestras habilidades y por ende, nuestros proyectos.

En el caso del audiovisual, documental y periodismo, existe un equivalente a Wingu que se llama Witness ${ }^{83}$, que ofrece guías prácticas descargables con consejos para el registro, la elaboración de entrevistas y demás, bastante útiles para medios auto gestionados, comunitarios y alternativos. $Y$ en un panorama más general, y para los que pasan horas recorriendo las redes sociales, existe una cuenta de Instagram llamada APB digital ${ }^{84}$, en la que pueden encontrar tips de marketing digital en sencillos y divertidos videos que te ayudarán a optimizar las redes sociales en función de tu emprendimiento o proyecto, haciendo uso de la terminología correcta del rubro y abarcando temas como las bases de datos, el tráfico de visitas, los formatos y las aplicaciones de cada red.

\subsubsection{Plataformas de recaudación de recursos}

En Latinoamérica la web más conocida para la recaudación de fondos es Ideame $^{85}$, donde se pone en práctica el concepto de "financiamiento colectivo". En esta plataforma se suben los proyectos en video, acompañados de un pequeño texto explicativo y que invita a los visitantes a aportar dinero. Cada

\footnotetext{
${ }^{82}$ Entrevista realizada vía Skype con Ximena Arrieta, estudiante de PLANGESCO y coordinadora de Wingu México.

83 https://es.witness.org/recursos/

${ }^{84}$ APB Digital, creado por Claudia Galeán (estudiante de PLANGESCO) e Ivette Rodríguez https://www.instagram.com/apbdigital/?hl=es

${ }^{85}$ https://www.idea.me/
} 
aportante recibe una recompensa dependiendo del valor de su aporte y ayuda a cumplir los sueños y materializar las ideas de un emprendedor.

Los proyectos financiados pertenecen a distintas artes y rubros del sector social y aunque en la plataforma existen apoyos y alianzas institucionales, los aportes monetarios provienen de personas comunes y corrientes que apoyan la cultura.

Algunos proyectos logran financiar la totalidad (o más) gracias a la difusión en la plataforma y otras redes sociales, en cambio otros no lo logran, pero a pesar de esto, todos obtienen beneficios (el dinero recaudado o el apoyo de Ideame en cuanto a asesorías se refiere).

Volver a Habitar recaudó el $113 \%$ gracias a 74 colaboradores, para un total de $\$ 9.050$ pesos argentinos ${ }^{86}$. En cambio, Gráfica Mestiza ${ }^{87}$ sólo pudo alcanzar el $24 \%$ en esta plataforma con 41 colaboradores, para un total de $\$ 13.584$ pesos argentinos.

Ideame es tal vez, la plataforma de financiamiento más conocida y eficiente en Latinoamérica, pero basta con googlear crowdfunding para encontrar un sinnúmero de opciones acordes a nuestras necesidades.

\subsubsection{Estrategias de comunicación (redes sociales)}

En este mundo cada vez más tecnologizado y conectado por las redes sociales, me atrevería a afirmar que la gran mayoría somos usuarios de Facebook, lo usamos como medio de comunicación, canal de información, como diario personal... y podría decirse que esa misma mayoría no entiende cómo funciona realmente ni cómo sacarle el mayor provecho, solamente lo usan desprevenida e intuitivamente.

\footnotetext{
${ }^{86}$ https://www.idea.me/proyectos/5523/volver-a-habitar

${ }^{87}$ https://www.idea.me/proyectos/34688/sticker-mestizo
} 
Existen muchos manuales y páginas web que ofrecen consejos y estrategias para ser un buen community manager ${ }^{88}$, pero lo que debemos tener claro es nuestro objetivo como organización y qué queremos que el mundo sepa de nosotros.

El primer paso es crear un perfil o cuenta de la organización, donde se describa y vea, mediante un logo o foto, quiénes somos y qué hacemos. Es muy importante que la persona que vaya a encargarse de esta área, separe su vida personal de las actividades del proyecto, puesto que la idea es compartir libremente y brindar acceso ilimitado a las publicaciones en las redes sociales y de la calidad de nuestras publicaciones depende muchas veces el impacto y efectividad que tengamos con los espectadores y seguidores.

No es necesario ser un experto, pero sí se requiere de constancia y creatividad. Cuando ya tenemos creado el perfil o página en las redes sociales, debemos publicar o postear un contenido (imagen o texto) con una frecuencia determinada por el alcance que queremos tener. En la mayoría de los casos, en las organizaciones se trabaja voluntariamente y no se puede tener una dedicación de tiempo completo, pero con una publicación diaria puede bastar para que nuestros seguidores estén pendientes de nuestro proyecto.

¿Qué podemos publicar? una foto de alguna de nuestras actividades, un evento que vayamos a realizar, información sobre los servicios que prestamos, una convocatoria, y si nosotros mismos no producimos información, podemos compartir un artículo escrito por otros, la actividad de otro proyecto amigo algún otro contenido que sea coherente con nuestros objetivos. En este punto debemos tener cuidado porque lo que compartimos o a lo que le damos un me gusta (like) dice mucho de quiénes somos y qué pensamos, y a su vez nos relaciona con informaciones que a lo mejor son irrelevantes para nuestro trabajo (publicidades por ejemplo), debido a que las redes sociales funcionan

\footnotetext{
${ }^{88}$ El community Manager es el profesional responsable de construir, gestionar y administrar la comunidad online alrededor de una marca en Internet, creando y manteniendo relaciones estables y duraderas con sus clientes, sus fans y, en general, cualquier usuario interesado en la marca. Cada vez, este rol dentro de una organización ha tomado mayor importancia, junto con la comunicación, el diseño y la publicidad.
} 
por tendencias o grupos, es decir que si le damos un me gusta a una publicación de zapatos (por ejemplo), entramos a formar parte de una comunidad interesada en los zapatos y las redes sociales nos enviarán continuamente información sobre este tema. Así que es mejor aprovechar esto y dar like a proyectos amigos, a páginas de recursos, de información y demás, relacionados con nuestros intereses, para agrandar nuestra red y para que nos vea más gente.

¿Cuándo publicar? al parecer existen horarios ideales para publicar, en los que gran cantidad de personas están conectadas y éstos a simple vista coinciden con el desayuno, almuerzo y cena. Horarios en los que la mayoría de la gente se toma unos minutos fuera de sus labores para dar un recorrido por las redes sociales. Obviamente, estos horarios dependen del lugar en el que estamos ubicados y del público al que queremos llegar, pero nos iremos dando cuenta de la popularidad y el alcance de nuestras publicaciones según los likes que reciban. No obstante, no debemos olvidar que si bien la comunicación es un área muy importante de nuestro proyecto, lo fundamental es el desarrollo del mismo y este trabajo se realiza cara a cara con nuestros compañeros e interlocutores. Es por esto, que tampoco es indispensable que estemos presentes en todas las redes o aplicaciones que existen. Si no tenemos muchos contenidos o informaciones constantes para publicar es innecesario tener cuentas de Twitter, Snapchat, Instagram y demás. Debemos saber elegir la más útil para nuestras actividades y sacarle el mayor provecho, usando las herramientas disponibles (creación de eventos, programación de publicaciones semanales, notificaciones, etc.) y siendo constantes (una publicación diaria, una semanal...) para que nuestros seguidores no nos dejen en el olvido. Debemos ser creativos y claros en nuestro mensaje ${ }^{89}$.

\footnotetext{
${ }^{89}$ Curso de iniciación de community manager - PDF: https://drive.google.com/file/d/0BYjv80hH3jXNUw4Tm5Ka2cyWU0/view? usp=sharing
} 


\subsection{Trabajo en Red (intercambios)}

Otro tipo de intercambio que puede fortalecer un proyecto es el trabajo y alianza con organizaciones de otros rubros, quienes pueden proporcionar sus habilidades y un punto de vista diferente. En el caso de proyectos como Gráfica Mestiza y Volver a Habitar, se vincularon personas de distintas áreas a la parte más orgánica (periodistas, fotógrafos, músicos, diseñadores) y también comercios, tiendas de pintura, espacios culturales, impresores, fabricantes de camisetas, quienes apoyaron las actividades ofreciendo sus productos a cambio de publicidad o a un muy bajo costo.

Lograr estos intercambios no monetarios también es una buena estrategia cuando iniciamos un proyecto social o cultural con pocos recursos. Además, es una forma de vincular a otros actores sociales de la comunidad, creando una red de colaboración en la que todos se pueden ver beneficiados, fortalecer sus actividades, hacerlas sostenibles en el tiempo y en una siguiente instancia, rentables.

\subsection{Convocatorias}

Como ya se mencionó en un apartado anterior, los distintos gobiernos han venido aportando al fortalecimiento de las industrias culturales y gracias a esto, las iniciativas cuentan con distintas líneas de apoyo a través de: programas gubernamentales, instituciones culturales y empresas privadas (responsabilidad social empresaria).

El mecenazgo existe para las instituciones culturales y de parte de ellas y consiste en apadrinar proyectos, ofreciendo recursos económicos e infraestructura para su desarrollo.

En el caso de la empresa privada, desde hace una década se está implementando lo que se conoce como responsabilidad social empresaria y que consiste básicamente en retribuir de manera positiva a la sociedad. Es 
decir, las empresas, sin importar su actividad, destinan cierto porcentaje de sus ganancias para implementar o patrocinar programas sociales. En el caso de Colombia, el Fondo de Desarrollo Cinematográfico recibe recursos de la empresa privada para financiar la realización de diversas producciones audiovisuales al año. También lo hacen las multinacionales petroleras, quienes dicen retribuir a las comunidades con programas sociales, educativos y ambientales.

A esta línea de financiación se suman cada vez más empresas ya que esto les beneficia en la exención de impuestos y por esto es de suma importancia que los proyectos conozcan las opciones disponibles para acceder a recursos económicos para materializar sus objetivos.

En el ámbito más cultural y artístico no dejan de surgir convocatorias para exposiciones, premios y residencias como una plataforma para mostrar el trabajo creativo, una experiencia de aprendizaje y de vida y una gran motivación para llevar distintas expresiones a nuevos espacios.

Para estar enterados de fechas de convocatorias y otras actualizaciones, existe una herramienta en Google (y en otras plataformas) que genera una alerta que llega al correo electrónico ${ }^{90}$ y nos mantiene informados sobre todo lo que se publique acerca de nuestros temas de interés.

\subsection{Modelo de proyectos}

La mayoría de convocatorias tienen sus propios formatos para completar con los puntos de nuestros proyectos, no obstante, puede ser de gran utilidad conocer los items a tener en cuenta y saber a qué se refiere cada uno.

Primero debemos identificar una problemática que nos genera inquietud y por la cual formulamos el proyecto como una posible solución, con uno o varios

\footnotetext{
${ }^{90}$ Cómo usar Google Alerts: http://computerhoy.com/paso-a-paso/internet/como-usar-google-alertsrecibir-alertas-tus-busquedas-17395
} 
objetivos claros y una estrategia de trabajo para cumplir nuestra meta en determinado tiempo y con determinados recursos humanos, técnicos y económicos.

1. Nombre del proyecto: Indicar de modo sintético y mediante un título lo que se quiere hacer. Debe contestar a las siguientes preguntas: ¿Qué se va hacer? ¿Sobre qué? ¿Dónde?

2. Fundamentación (antecedentes y justificación): Detallar el problema identificado que ocasiona inconvenientes y se transforma en un obstáculo para el desarrollo de la comunidad destinataria del proyecto. Explicar cómo y por qué el proyecto es la alternativa de solución más pertinente y viable -técnica, social, ambiental y económicamente- para solucionar el problema. Describir la situación actual y cómo se pretende que esta se transforme una vez ejecutado el proyecto.

3. Objetivos:

Objetivo General: Describe el objetivo global al que el proyecto pretende contribuir en el largo plazo. Si el problema es la carencia, el objetivo a alcanzar la suficiencia. Redactar el objetivo general es poner el problema en términos de acción positiva.

Objetivo específico: Es el propósito concreto del proyecto, lo que se espera alcanzar para los beneficiarios directos al finalizar la ejecución del mismo. Pueden ser uno o más objetivos específicos.

4. Descripción del proyecto: Hacer un resumen del proyecto, es decir explicar en qué consistirá el proyecto. Una pregunta para responder podría ser: ¿Qué se quiere hacer?

5. Estrategia de implementación del proyecto: Describir las principales actividades que se desarrollarán en el marco del proyecto. Las actividades son las tareas que se realizan en un proyecto con el fin de 
obtener los productos previstos para el mismo. Una pregunta que puede ayudar es: ¿De qué manera lo haremos?

6. Beneficiarios del proyecto: Es el grupo de personas a quienes está dirigido el proyecto (personas, familias, grupos sociales). Describir, en su caso, la localización geográfica de la población beneficiaria, actividad que desarrolla, condiciones socio-económicas, etc.

7. Plan de trabajo con actividades (cronograma): Señalar las actividades en orden cronológico (hasta 12 meses) según los objetivos y establecer fechas a cada una de ellas. El plan de trabajo debe presentar las etapas de realización y el encadenamiento de dichas etapas, es decir, la forma como éstas se suceden y coordinan. Por lo general se presenta en un cuadro que incluye los objetivos, actividades y fechas (meses del año).

8. Resultados esperados: Son los productos terminados que se obtienen al realizar el proyecto y conducen al cumplimiento de los objetivos específicos del mismo. Indicar el impacto sobre la población objeto que se espera obtener a partir de la implementación del proyecto. Una pregunta que puede servir es: ¿Qué debe producir el proyecto para que se cumpla con los objetivos?

9. Presupuesto: El presupuesto son los recursos económicos necesarios para la ejecución del proyecto. Deben figurar en forma detallada y por etapas indicando su procedencia. Este ítem también debe ser presentado en una tabla que incluya las actividades relacionadas con su valor monetario y su tiempo de ejecución.

En algunos casos se debe considerar también un apartado donde se presentan los integrantes del proyecto o equipo de trabajo, pero esto varía dependiendo de los requisitos de la entidad a la que le vayamos a presentar el proyecto. 
En internet se encuentran disponibles algunos modelos que pueden guiarnos en la elaboración de proyectos. ${ }^{91}$

\section{Otros relatos (continuidad y otros proyectos similares)}

Los tres proyectos mencionados en el presente trabajo han logrado tener continuidad gracias a la implementación de las estrategias de gestión descritas, a la perseverancia, al trabajo en equipo y a la creatividad que los han llevado a generar nuevas iniciativas.

- $a$. Crafiteria ARTE URBano a C CAFE

En el caso de Gráfica Mestiza, actualmente cuenta con una tienda virtual que funciona en su página web y donde se promocionan artículos de diseño (bolsos, libros, camisetas) que los mismos artistas producen de manera paralela a los murales, como una fuente de ingreso adicional. También logró abrir un espacio físico con el mismo fin: La Grafitería ${ }^{92}$, que también es aprovechado para realizar reuniones, talleres, exposiciones y pequeños eventos que la posicionan como un lugar de referencia de la gráfica urbana en la ciudad (Cali) y garantiza el financiamiento de los integrantes del colectivo y sus producciones, como es el caso de la segunda edición del libro álbum de stickers mestizos, que en su convocatoria recibió más de 500 diseños de distintos artistas latinoamericanos ${ }^{93}$.

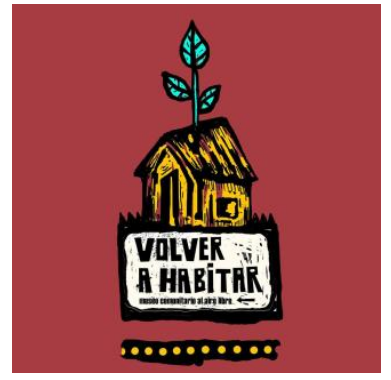

Volver a Habitar, después de varios años de trabajo continuo con la comunidad de vecinos de La Plata, invita a artistas de distintos lugares con el nuevo objetivo de hacer

\footnotetext{
${ }^{91}$ Revista Iberoamericana de Educación OEl: http://rieoei.org/experiencias143.htm ${ }_{93}$ https://www.facebook.com/lagrafiteriacali/?fref=ts
}

https://www.facebook.com/graficamestiza/photos/a.360498467322824.77984.179618878744118/1388957447810 249/?type=1\&theater 
de la ciudad un museo a cielo abierto y seguir democratizando el arte y la cultura $^{94}$.

La tragedia que los convocó en sus inicios, ahora los motiva para dar vida a un nuevo proyecto que sirve como plataforma para artistas de distintos niveles y que ofrece acceso a toda la sociedad a un sinnúmero de murales que harán parte del paisaje y el embellecimiento platense ${ }^{95}$.

En esta misma línea surgió el proyecto Pintó la Isla, a partir de unos talleres de derechos humanos en la escuela 24 de Isla Maciel donde los alumnos terminaron haciendo graffiti para expresar sus inquietudes y que ahora tiene gran impacto en toda

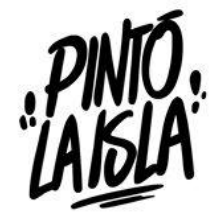
la comunidad, con la idea de ser también un museo a cielo abierto y embellecer el barrio como atractivo turístico, quizás respondiendo un poco al principio de gentrificación que busca mejorar la calidad de vida de sus habitantes y que otros sectores de la sociedad pongan el foco en el barrio (como sucede con el barrio La Boca) ${ }^{96}$.

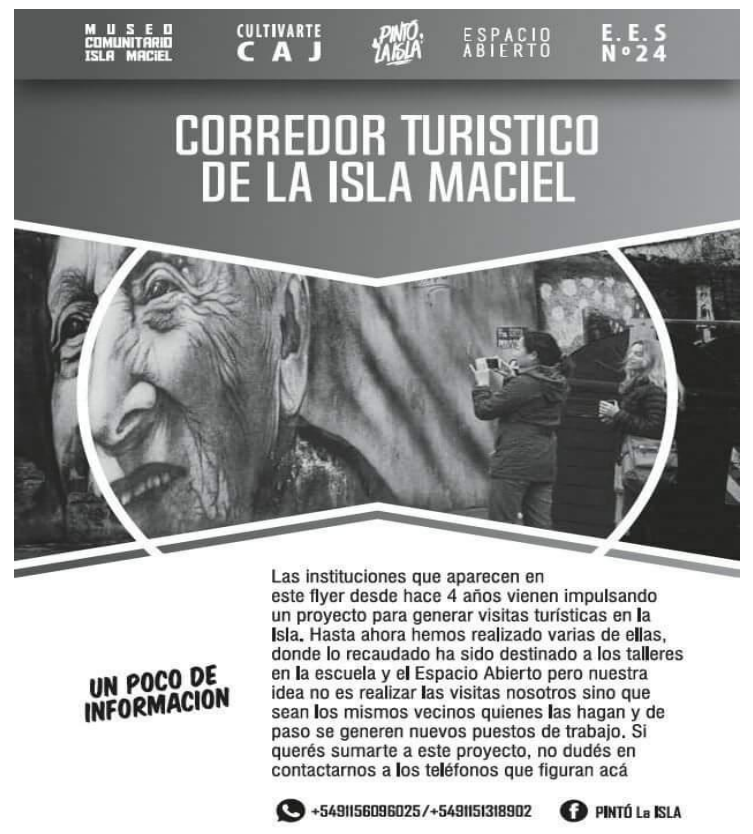

\footnotetext{
${ }^{94}$ MATU de Chile, primer artista invitado: https://www.facebook.com/volverahabitar/posts/1000763256720366:0

95 https://www.facebook.com/volverahabitar/videos/1005741179555907/

96 Documental: El papel de los murales en la gentrificación de Bushwick: https://www.youtube.com/watch?v=RsaFeiWFA3w
} 


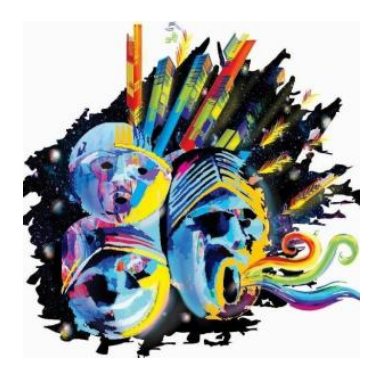

Por su parte, la Minga de Muralistas de los Pueblos, logró una réplica de su proyecto en otro departamento (provincia) y se denomina Pinto Putumayo. En esencia persigue el mismo objetivo de acercar el arte a zonas rurales y darle voz a través de los murales a comunidades que sufren el flagelo de la guerra.

En este caso, Pinto Putumayo encaró una importante movida en la pasada inundación de Mocoa, donde el desbordamiento de 3 ríos dejó 358 hectáreas afectadas y más de 300 personas muertas ${ }^{97}$. El proyecto convocó a artistas de distintas áreas para realizar brigadas en 4 albergues y acompañar a niños y mujeres, intentando contenerlos y devolverles una sonrisa en medio de la tragedia ${ }^{98}$.

Como estos casos, también encontramos iniciativas de carácter gubernamental que convocan a muralistas para crear un diálogo más fluido con la ciudad, como es el caso de Embellecimiento Urbano ${ }^{99}$, a través del cual se han pintado y recuperado varios puentes de las autopistas de Buenos Aires.

\section{CONCLUSIONES}

Luego de todo este recorrido y sin la intención de ser reiterativa, pero sí con la idea de destacar los logros de las experiencias sistematizadas y fortalecer el surgimiento de nuevas iniciativas, considero fundamental resaltar algunos aprendizajes.

La comunicación fue uno de los objetivos fundamentales de todos los proyectos mencionados y para lograrlo, todos tuvieron en cuenta a sus destinatarios y los recursos con los que contaban. En esta tesis he impulsado el uso de las herramientas digitales debido al contexto en el que nos encontramos

\footnotetext{
${ }^{97}$ http://www.elpais.com.co/colombia/cifra-de-muertos-por-avalancha-en-mocoa-asciende-a-314.html

98 https://www.facebook.com/permalink.php?story fbid=279936305766610\&id=100012507278777

${ }^{99}$ https://www.facebook.com/EmbellecimientoUrbano/?fref=ts
} 
actualmente y a las potencialidades que ofrecen. No obstante, fue la gráfica urbana el principal producto comunicacional que logró empoderar a las comunidades, quienes a su vez, la legitimaron como expresión cultural y artística. En este caso, las redes sociales y demás plataformas fueron mecanismos que ayudaron a los proyectos a trascender fronteras y barreras territoriales y económicas.

La gráfica urbana es el objeto de estudio que llamó mi atención para el desarrollo de esta tesis y queda comprobado a lo largo del relato de experiencias que a través de ella, los distintos proyectos lograron crear un público más consciente de sus propias realidades e inquietudes, lograron darle voz a diversas comunidades y situaciones y lograron posicionar al graffiti como una herramienta poderosa de comunicación, que poco tienen que ver con el estigma vandálico que ha cargado durante años.

Pero además de un producto comunicacional, las tres experiencias desarrollaron un proceso de comunicación valioso de destacar y posible gracias a la vinculación con la comunidad. La gráfica urbana tiene la ventaja de convertirse en un lenguaje universal, que puede transmitir un mensaje a personas de distintas edades y condiciones sociales y en este proceso, cada uno de los proyectos ha dialogado con los distintos actores vinculados. En el caso de Gráfica Mestiza, siempre ha sostenido una comunicación horizontal con los artistas para generar productos colectivamente y en función de educar públicos interesados en la gráfica urbana. Por su parte, Volver a Habitar trabajó según las necesidades de su comunidad y logró vincularla fortaleciendo los lazos entre vecinos. Finalmente, La Minga hizo partícipes a los campesinos de los contenidos y la producción de murales con los que hicieron visibles sus problemáticas. Aplicando los conceptos de Susan Sontang ${ }^{100}$ sobre la imagen, aquí la gráfica urbana se convierte en un recurso para la memoria, los murales pasan a formar parte de la memoria colectiva (a pesar de su fugacidad) y a relatar la historia de nuestras comunidades.

\footnotetext{
${ }^{100}$ SONTANG. S., Sobre la Fotografía. Ed. Alfaguara. México. 2006.
} 
Los logros de estos proyectos, como es evidente, sólo fueron posibles gracias al trabajo en red y con la comunidad, lo cual además es fundamental para garantizar la continuidad en el tiempo, el mejoramiento de los procesos y la sostenibilidad.

Es aquí donde las herramientas digitales cobran importancia para la consecución de recursos económicos y a su vez, para la optimización de los mismos, debido a las potencialidades que tienen a la hora de comunicar, hacer publicidad, generar nuevos contactos, trabajar a distancia, gestionar, producir, y todo esto de manera gratuita, facilitando que los procesos tengan mayor alcance, no se desgasten, tengan continuidad y más importante aún, que los artistas puedan vivir y subsistir de lo que les gusta y saben hacer, que puedan sacarle el mayor provecho a su trabajo y que sus obras sean valoradas.

En el mejor de los casos, los proyectos pueden llegar a convertirse en modelos sustentables y sostenibles en términos de emprendimiento, que puedan dejar de depender de fondos económicos y subsidios. Es por esto, que en mi rol como facilitadora pongo a disposición un acercamiento a manual de gestión para todas aquellas iniciativas que surgen desde la base social con la intención de aportar y mejorar su realidad. No se trata de un manual para expertos ni tiene la última palabra, pero recoge una buena cantidad de herramientas accesibles, gratuitas y fáciles de usar desde cualquier dispositivo, y a las que se pueden seguir sumando nuevas estrategias que vayamos recogiendo en nuestro camino de gestión. Espero que sea de gran utilidad y un punto de partida para que nuevas ideas florezcan. 


\section{BIBLIOGRAFÍA:}

- ARRUETA, BRUNET y GUZMÁN (Comp.). La Comunicación como Objeto de Estudio. Fadeccos. 2010.

- BELTRÁN, L.R. Comunicación para el Desarrollo en Latinoamérica. Una evaluación sucinta al cabo de cuarenta años. Discurso inaugural de la IV Mesa Redonda sobre Comunicación y Desarrollo. IPAL. Lima. 1993.

- BOURDIEU, P. Capital Cultural, Escuela y Espacio Social. Siglo XXI Editores. 1997.

- CASTORIADIS, C. Sujeto y Verdad en el Mundo Histórico - Social. Fondo de Cultura Económica. México. 2004

- CERASO, C. (Directora) Sembrando mi Tierra de Futuro. Comunicación, planificación y gestión para el desarrollo local. Unidad de Prácticas y Producción de Conocimiento. Facultad de Periodismo y Comunicación social. Universidad Nacional de La Plata.

- DAlLERA, O. La Sociedad como Sistema de Comunicación. Editorial Biblos.

- FOCAULT, M. Vigilar y Castigar. Siglo XXI Editores. Buenos Aires. 2003

- HOPENHAYN, M. Educación, Comunicación y Cultura en la Sociedad de la Información: perspectiva latinoamericana. En Revista de la CEPAL 81. 2003

- MORIN, E. Tierra Patria. Nueva Visión. Buenos Aires. 2006.

- MACCARI y MONTIEL. Gestión Cultural para el Desarrollo. Ariel. Buenos Aires. 2012.

- SACHS, W. (Ed.) Diccionario del desarrollo: Una guía del conocimiento como poder. PRATEC. 1996.

- SONTANG, S. Sobre la Fotografía. Ed. Alfaguara. México. 2006.

- STAHL, J. Street Art. HFullmann. China. 2009. 
- WILLIAMS, R. Sociología de la cultura. Paidós Comunicación. 1981.

\section{Documentos:}

- Política Nacional para la Promoción de Industrias Culturales en Colombia (2010)

https://www.dnp.gov.co/LinkClick.aspx?fileticket=7HO7fAcbwCg\%3D\&tabid=285

- Compendio de Políticas Culturales, Política para el emprendimiento y las industrias culturales. Colombia. 2010

http://culturaparaeldesarrollo.files.wordpress.com/2011/06/mincultura-colombiacompendio-polc3adticas-culturales.pdf

- Ley de Servicios de comunicación Audiovisual. Argentina. Texto actualizado al 2010.

http://www1.hcdn.gov.ar/dependencias/dip/L\%2026522.pdf

\section{Tesis de grado:}

- $\quad$ ARRÚA, V. Modalidades de conocimiento en Prácticas de Planificación y Gestión de la Comunicación: Análisis de experiencias del Programa de Unidad de Prácticas y Producción de Conocimiento. Maestría en Planificación y Gestión de la Comunicación. PLANGESCO. Facultad de Periodismo y Comunicación Social. Universidad Nacional de La Plata. 2009.

- BARRAgÁN, R. Pegame: Un estudio sobre el sticker artístico. Maestría en Estética y Teoría del Arte. Facultad de Bellas Artes. Universidad Nacional de La Plata. 2015. 
- RODRIGUEZ, J. Análisis Gráfico del Post-graffiti en Cali. Tesis de Grado. Diseño Gráfico. Universidad del Valle.

http://www.graficamestiza.com/index.php/actualidad/investigacion/105-analisisgrafico-del-post-graffiti

- VILLEGAS, M. Aproximación del Espacio Público a través del Graffiti Costa Rica. Tesis de Grado. Licenciatura en Antropología Social. Universidad de Costa Rica.

http://www.graficamestiza.com/index.php/actualidad/investigacion/200apropiacion-del-espacio-publico-a-traves-del-graffiti-costa-rica

\section{Videos y documentales:}

- Documental: Historia del Graffiti en Bogotá: https://www.youtube.com/watch?v=1REZmPKrINA

- $\quad$ Calle Libre - Graffiti + Street Art en Latinoamérica: http://www.youtube.com/watch?v=8NaHKw8bcrc\&fb source=message

- Gráfica Mestiza: Gira Argentina: https://www.youtube.com/watch?v=NmshbkgsLOY\&t=4s

- Luxor - Charla TED "Democratizando el Arte": https://www.youtube.com/watch?v=R8TdfaXA7zc\&t=12s

- Volver a Habitar: Caso Los Hornos: https://www.youtube.com/watch?v=KlaT4nGDI84\&t=134s 
- Minga Muralistas de los pueblos: Muralismo en el territorio Nasa: https://www.youtube.com/watch?v=GpwlFEbPtFE

10. Anexos:

Manual:

- Guía de Gestión: Paquete de herramientas para desarrollar proyectos

Esta guía o manual pretende compartir herramientas útiles, accesibles y gratuitas que pueden ser aplicadas en el desarrollo de iniciativas culturales y populares o de diversa índole, para fortalecer sus procesos y propiciar su sostenibilidad. 
